\title{
WestVirginiaUniversity
}

THE RESEARCH REPOSITORY @ WVU

Graduate Theses, Dissertations, and Problem Reports

2006

\section{A new reduced order model for solid oxide fuel cells}

\author{
Suryanarayana Raju Pakalapati \\ West Virginia University
}

Follow this and additional works at: https://researchrepository.wvu.edu/etd

\section{Recommended Citation}

Pakalapati, Suryanarayana Raju, "A new reduced order model for solid oxide fuel cells" (2006). Graduate Theses, Dissertations, and Problem Reports. 3458.

https://researchrepository.wvu.edu/etd/3458

This Dissertation is protected by copyright and/or related rights. It has been brought to you by the The Research Repository @ WVU with permission from the rights-holder(s). You are free to use this Dissertation in any way that is permitted by the copyright and related rights legislation that applies to your use. For other uses you must obtain permission from the rights-holder(s) directly, unless additional rights are indicated by a Creative Commons license in the record and/ or on the work itself. This Dissertation has been accepted for inclusion in WVU Graduate Theses, Dissertations, and Problem Reports collection by an authorized administrator of The Research Repository @ WVU.

For more information, please contact researchrepository@mail.wvu.edu. 


\title{
A NEW REDUCED ORDER MODEL FOR SOLI D
}

\section{OXI DE FUEL CELLS}

\author{
Suryanarayana Raju Pakalapati
}

Dissertation submitted to the

College of Engineering and Mineral Resources

at West Virginia University

in partial fulfillment of the requirements

for the degree of

Doctor of Philosophy

in

Mechanical Engineering

I smail Celik, Ph.D., Chair

Richard Bajura, Ph.D.

Harry Finklea, Ph.D.

Bruce Kang, Ph.D.

Randall Gemmen, Ph.D.

Andrei Smirnov, Ph.D.

Department Mechanical and Aerospace Engineering

West Virginia University

Morgantown, West Virginia

2006

Keywords: Fuel Cell Modeling, SOFC, Reduced Order Modeling, Electrochemistry

Copyright 2006 Suryanarayana Pakalapati 


\section{ABSTRACT}

\section{A New Reduced Order Model For Solid Oxide Fuel Cells}

\section{Suryanarayana Pakalapati}

Fuel cells are one of the promising eco-friendly and efficient electricity generators for future energy infrastructure. Rigorous research has been underway for over a decade to develop fuel cell technology as a viable alternative to the conventional energy sources. Numerical modeling has played a prominent role in such research endeavors. Detailed multidimensional models reveal important information regarding the performance of a fuel cell but they are computationally intensive. Relatively simple zeroand one-dimensional models on the other hand average out the details that could be critical. The topic of this dissertation is a new strategy for modeling fuel cells which is not as complex as the multi-dimensional models but at the same time retains important details of three dimensional distributions inside the important components of a Solid Oxide Fuel Cell (SOFC). The objective is to develop a new reduced order model for transient three dimensional modeling of SOFCs. The reduction in complexity is achieved by using onedimensional models for the gas channels and three dimensional modeling for solid and porous regions. This approach circumvents the problem of solving three-dimensional Navier Stokes equations inside the channels but still resolves the details inside the more important components, electrodes and electrolyte. Another unique feature of the new approach is the electrochemistry model which calculates the electric potential jump across 
the anode/electrolyte and cathode/electrolyte interfaces separately. The electrochemistry model is tested separately, validated and then incorporated into the SOFC model. The computer code for the model is developed on the foundation of the Navier Stokes solver, DREAM, developed by Dr. Ismail Celik and his co-workers and hence it is named DREAM SOFC. The new model has the advantage of faster run time for transient simulations compared to a complex three dimensional model while resolving almost as many details. This makes the new model more suitable for modeling multi-cell SOFC stacks consisting of as many as 50 cells. The computer code is first verified using the numerical results from literature and also a multi-dimensional fuel cell model FLUENT SOFC. Following the validation, parametric studies were performed to study the effect of parameters such as electrolyte thickness, convective heat transfer coefficient etc. which yielded interesting results. Numerical uncertainty in the results was found out to be small by means of Richardson extrapolation using computations on two grids. The temperature dependence of electrical conductivity of the SOFC materials was found to be making the current distribution more uniform in the co-flow configuration and more non-uniform in counter-flow configuration. It was shown that while thinner electrolytes give better power output, they produce highly nonuniform current distribution inside the SOFC. The start-up transients of a coflow SOFC were simulated and it was observed that it takes about 30 min for the cell to reach steady state. 


\section{Acknowledgements}

A doctoral degree for me would not have been possible without Dr. Ismail Celik. He encouraged me into it and guided me through every step. He led me by example. His knowledge and wisdom were my resources, his hard work my inspiration and his persistence my motivation during these years. I would like to express my heartfelt deep appreciation to my advisor, Dr. Celik, for his mentoring, encouragement and financial support throughout my graduate studies. Special thanks are due to the other members in my graduate committee- Dr. Richard Bajura, Dr. Harry Finklea, Dr. Bruce Kang, Dr. Randall Gemmen and Dr. Andrei Smirnov for taking time from their busy schedules to review my work. Their comments and suggestions made this dissertation more valuable to me. I am grateful to United States Department of Energy (USDOE) National Energy Technology Laboratory (NETL) for funding this work. I would also like to thank Dr. Maria Salazar-Villalpando for her help with the electrochemistry model. I am grateful to all my teachers from whom I learned the concepts needed to finish this work.

It has been a tough time thousands of miles away from home but the group of friends I found in our Computational Fluid Dynamics and Applied Multi-Physics (CFD\&AMP) Center have made me forget all about it and for that I would like to thank them all. I would like to specially thank Ibrahim Yavuz, Andrew Burt, Zeynep Cehreli, Cem Ersahin, Egemen Ogretim, Christian Shaffer, Raven Honsaker and Richard Snoderly for innumerable good times we had together. I also would like to express my appreciation for the camaraderie extended to me by my good friends Aditya Vuchi, Neelima Marupuru, Deepak Mehra, Raja Saripalli, Srinivas Addepalli, Srinivas Muvvala and Balaji Datti. Finally, I would like to express my gratitude to my parents, my brother and all my family for their love, affection and continuous support. 


\section{TABLE OF CONTENTS}

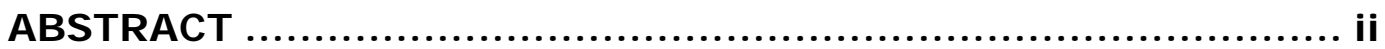

TABLE OF CONTENTS.$\ldots \ldots \ldots \ldots \ldots \ldots \ldots \ldots \ldots \ldots \ldots \ldots \ldots \ldots \ldots \ldots \ldots \ldots \ldots \ldots \ldots$

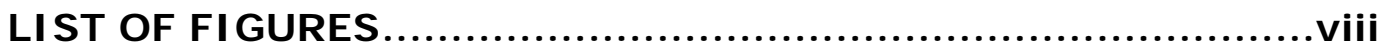

LI ST OF TABLES.$\ldots \ldots \ldots \ldots \ldots \ldots \ldots \ldots \ldots \ldots \ldots \ldots \ldots \ldots \ldots \ldots \ldots \ldots \ldots \ldots \ldots \ldots \ldots \ldots$

Nomenclature.............................................................. xii

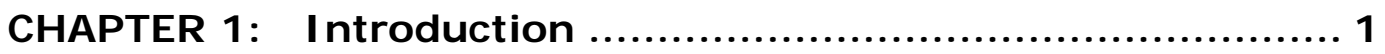

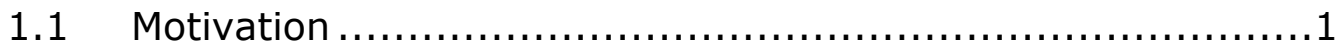

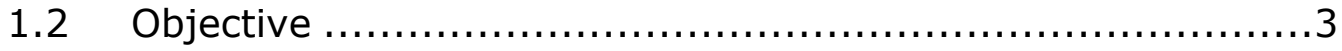

1.3 Organization of Thesis........................................

CHAPTER 2: Literature Review .................................... 6

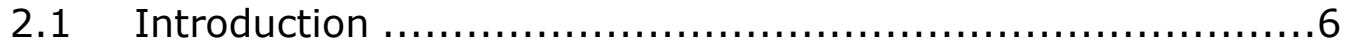

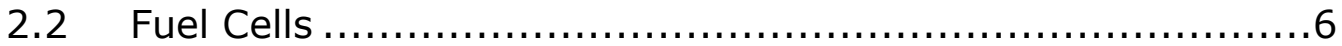

2.2.1 Types of Fuel Cells ............................................

2.2.2 Working of a YSZ based Solid Oxide Fuel Cell ................8

2.2.3 Thermodynamics of Fuel cells .............................. 10

2.2.4 Fuel Cell Stacking and Layouts .............................. 13

2.2.5 Solid Oxide Fuel Cell Materials ............................. 15

$2.3 \quad$ Fuel Cell Modeling . .............................................. 17

2.3.1 Electrode Level Modeling ................................... 19

2.3.2 Cell level modeling ............................................. 20

2.3.3 Stack Level Modeling ......................................... 22

2.3.4 System Level Modeling ................................... 23

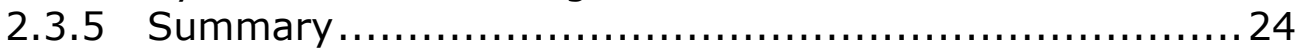

CHAPTER 3: mathematical Model................................... 25

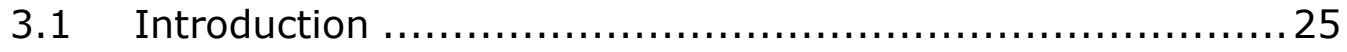

3.2 Three-Dimensional Model ................................... 26

3.2.1 Species Concentration Field ................................ 27 


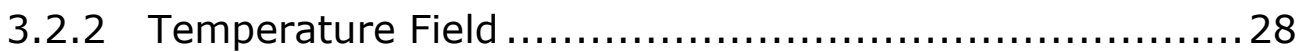

3.2.3 Electric Potential (Current) Field .......................... 29

3.3 One Dimensional Model for Gas Channels ......................29

3.3.1 Mass conservation .......................................... 31

3.3.2 Specie conservation........................................ 31

3.3.3 Momentum conservation .................................. 32

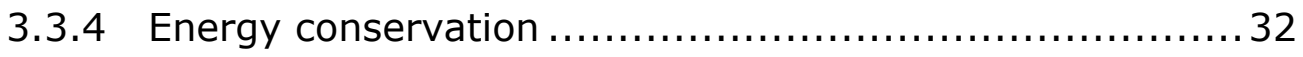

CHAPTER 4: Numerical I mplementation .............................. 34

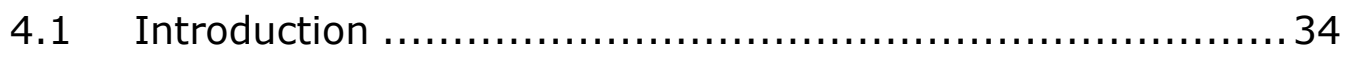

4.2 Discretization of Three Dimensional Equations ................. 35

4.3 Boundary Conditions......................................... 38

4.3.1 Drichlet boundary condition for electric potential ............ 39

4.3.2 Neumann boundary for Electric Potential .................. 41

4.4 Discretization of One-Dimensional Equations .................. 42

4.5 Modeling Issues .............................................. 45

4.5.1 Source Term for Electric Potential Field..................... 45

4.5.2 Convective Heat and Mass Transfer in Gas Channels ......46

4.5.3 Heat Sources Due to Specie Fluxes ......................... 49

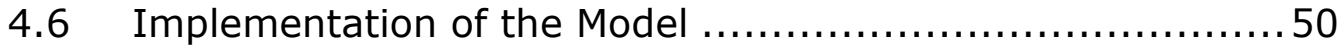

CHAPTER 5: electrochemistry model ............................... 52

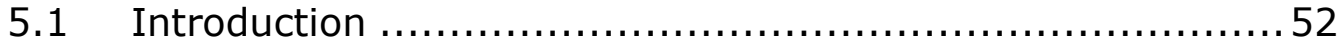

5.2 Theory And Analysis .......................................... 55

5.2.1 Gibbs Free Energy Change for Half Reactions ............. 57

5.2 .2 Overpotentials ............................................ 58

5.2.3 Transfer Coefficients ....................................... 59

5.2.4 Exchange Current Density ................................ 61

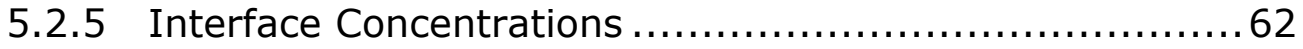

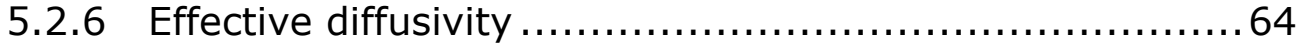

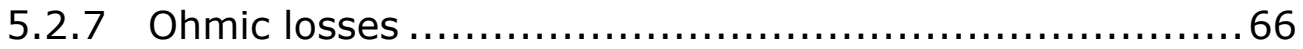

5.2.8 Bulk Concentrations ......................................66 66

5.2.9 Oxygen Ion Concentration ............................... 67

5.3 Results and Discussion ........................................ 68

CHAPTER 6: verification and validation of the Code.............. 77

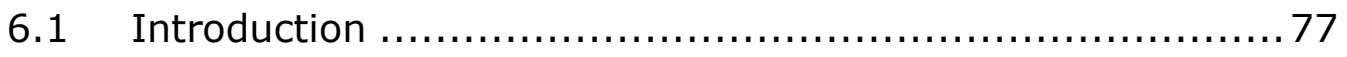

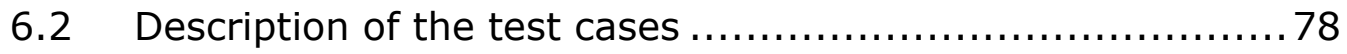

6.3 RESULTS .................................................... 81

6.3.1 Comparison with Results from Literature .................. 81

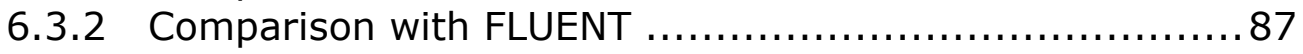


CHAPTER 7: Parametric Study ......................................... 97

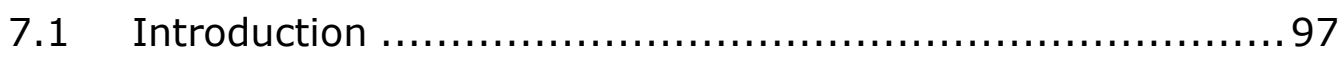

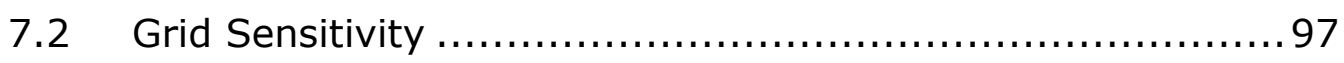

7.3 Effect of variable electrical conductivity ..................... 103

7.4 Effect of Thickness of Electrolyte ........................... 110

7.5 Effect of convection heat transfer coefficient ................. 113

7.6 Start-up Transients .......................................... 115

CHAPTER 8: Conclusions and Future Work ......................... 119

8.1 Conclusions ................................................. 119

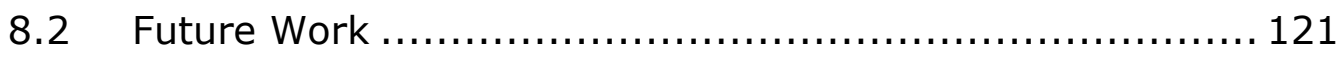

REFERENCES ................................................................... 123

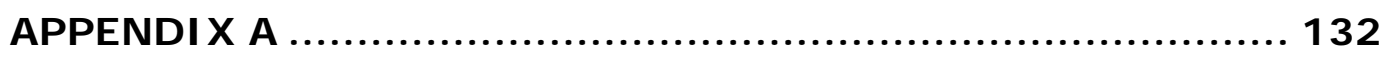

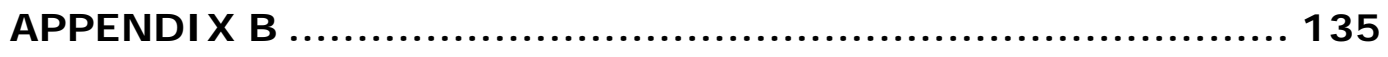

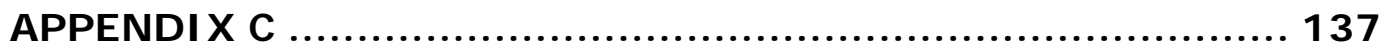




\section{LIST OF FI GURES}

Figure 2.1: Basic components and working of a Solid Oxide Fuel Cell..........9

Figure 2.2: Typical Voltage-Current Curve for a Fuel Cell. .................... 11

Figure 2.3: Various designs of Solid Oxide Fuel Cells. (after Minh, [5])...... 14

Figure 2.4: Various configurations of Solid Oxide Fuel Cells. (after Burt [6])15

Figure 3.1: Control volume used for one dimensional gas channel model.... 30

Figure 4.1: Geometry of the system used in the simulations................ 35

Figure 4.2: Schematic of the boundaries of the test domain $\ldots \ldots \ldots \ldots \ldots \ldots \ldots \ldots$

Figure 4.3: Schematic of gas channel solid region interface $\ldots \ldots \ldots \ldots \ldots \ldots \ldots 46$

Figure 5.1: Schematic of variation of electric potential across a SOFC .......54

Figure 5.2: Variation of transfer coefficient with temperature $\ldots \ldots \ldots \ldots \ldots \ldots 60$

Figure 5.3: Variation of anode limiting current with pore size................65

Figure 5.4: Comparison of experimental [54] and calculated cathode overpotentials: transfer coefficients from Eq. (5-20) with $\beta_{\text {min }}=0.116, \gamma=0.06, T_{s}=1035:$ pore size $=0.45$ micron $\ldots \ldots \ldots . .70$

Figure 5.5: Comparison of experimental [54] and calculated anode overpotentials: transfer coefficients from Eq. (5-20) with $\beta_{\min }=0.2, \gamma=0.02, T_{s}=975:$ pore size $=.25$ micron. 70

Figure 5.6: V-I plots at different temperatures using constant oxygen ion concentration in electrolyte at all temperatures $\left(Y_{O^{=}}=0.1\right) \ldots \ldots .73$

Figure 5.7: Influence of oxide ion concentration on V-I plots at $\mathrm{T}=973 \mathrm{~K} . .74$

Figure 5.8: Comparision between the experimental (Jiang and Virkar [61]) results and model predictions of $\mathrm{V}$-I plots for different fuel gas compositions.

Figure 6.1: Cross-section of the parallel channel SOFC used for simulations 80

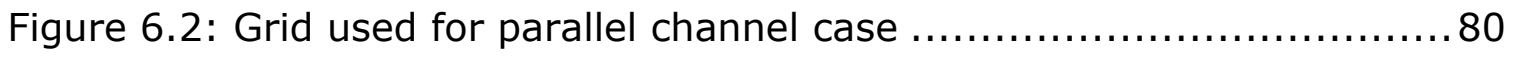

Figure 6.3: Current contours for co flow configuration; (a) DREAM, and (b) KFA (Achenbach [63]) 
Figure 6.4: Temperature contours for co flow configuration; (a) DREAM, and (b) Risø (Achenbach [63]).

Figure 6.5: Current contours for counter flow configuration; (a) DREAM, and (b)KFA (Achenbach [63])

Figure 6.6: Temperature contours for counter flow configuration; (a) DREAM, and (b) Ris $\varnothing$ (Achenbach [63]) ................................. 84

Figure 6.7: Current contours for cross flow configuration; (a) DREAM, and (b)KFA (Achenbach [63])

Figure 6.8: Temperature contours for cross flow configuration; (a) DREAM, and (b) Ris $\varnothing$ (Achenbach [63]) .................................. 85

Figure 6.9: $y$-current density at the anode/electrolyte interface for co-flow case; (a) DREAM (b) FLUENT, and (c) Profiles along the channel direction near the middle of the cell ............................... 88

Figure 6.10: Temperature at the anode/electrolyte interface for co-flow case; (a) DREAM (b) FLUENT, and (c) Profiles along the channel direction near the middle of the cell ....

Figure 6.11: Hydrogen mass fraction at the anode/electrolyte interface for co-flow case; (a) DREAM (b) FLUENT, and (c) Profiles along the channel direction near the middle of the cell

Figure 6.12: $y$-current density at the anode electrolyte interface for counterflow case; (a) DREAM (b) FLUENT (c) Profiles along the channel direction near the middle of the cell.

Figure 6.13: Temperature at the anode electrolyte interface for counter-flow case; (a) DREAM (b) FLUENT, and (c) Profiles along the channel direction near the middle of the cell....

Figure 6.14: Hydrogen mass fraction at the anode/electrolyte interface for counter-flow case; (a) DREAM (b) FLUENT, and (c) Profiles along the channel direction near the middle of the cell ................... 95

Figure 7.1: Effect of grid density on the current distribution ................. 98

Figure 7.2: Effect of grid density on the hydrogen mass fraction distribution

Figure 7.3: Effect of grid density on the temperature distribution ............. 99

Figure 7.4: Effect of inactive entrance region on the current distribution .. 102

Figure 7.5: Effect of inactive entrance region on the hydrogen mass fraction distribution 102

Figure 7.6: Effect of inactive entrance region on the temperature distribution 103

Figure 7.7: Effect of temperature dependence of conductivity on the current density distribution at the anode/electrolyte interface for the co-

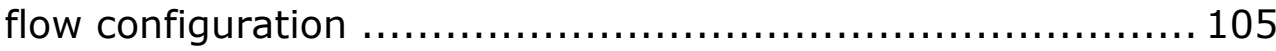


Figure 7.8: Effect of temperature dependence of conductivity on the hydrogen mass fraction distribution inside the fuel channel for co

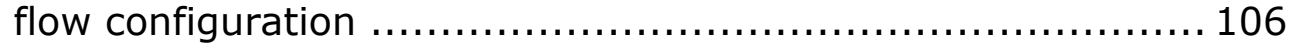

Figure 7.9: Effect of temperature dependence of conductivity on the temperature distribution inside the air channel for the co-flow configuration

Figure 7.10: Effect of temperature dependence of conductivity on the current density distribution at anode/electrolyte interface for the counter-

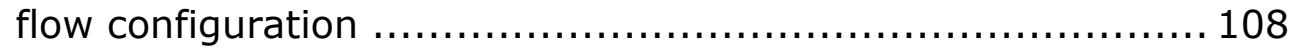

Figure 7.11: Effect of temperature dependence of conductivity on the hydrogen mass fraction distribution inside a fuel channel for the counter-flow configuration 109

Figure 7.12: Effect of temperature dependence of conductivity on the temperature distribution inside an air channel for the counter-

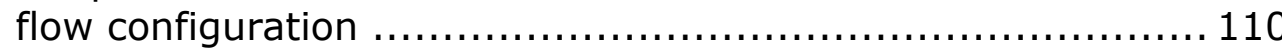

Figure 7.13: Effect of electrolyte thickness on the current density distribution

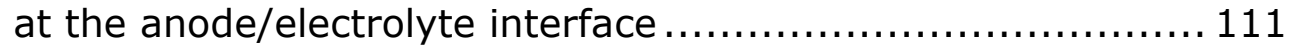

Figure 7.14: Effect of electrolyte thickness on the hydrogen mass fraction distribution inside a fuel channel ....

Figure 7.15: Effect of electrolyte thickness on the temperature distribution inside the air channel

Figure 7.16: Effect of convective heat transfer coefficient on the temperature distribution inside an air channel .... 114

Figure 7.17: Effect of convective heat transfer coefficient on the current density distribution at the anode/electrolyte interface....

Figure 7.18: Effect convective heat transfer coefficient on the hdrogen mass fraction distribution inside a fuel channel

Figure 7.19: Time variation of temperature at a monitor point near the center of the SOFC. 116

Figure 7.20: Y-current density $\left(\mathrm{A} / \mathrm{m}^{2}\right)$ contours near anode/electrolyte interface at various instances.

Figure 7.21: Temperature (K) contours near anode/electrolyte interface at various instances

Figure a.1: Variation of electric potential along the thickness of the SOFC 133

Figure a.2: Current lines inside the SOFC at the mid-section ............... 133

Figure a.3: Variation of $\mathrm{H}_{2}$ mass fraction along the thickness of the SOFC 134

Figure a.4: Variation of $\mathrm{O}_{2}$ mass fraction along the thickness of the SOFC 134 


\section{ST OF TABLES}

Table 5.1. Model constants for exchange current equation (Eq. 5-22) .......6 62

Table 5.2: Validation with the experimental data from Godickemeier et. al. 66

Table 5.3: Parameters of Experiments by Godickemeier and Gauckler [54]. 68

Table 5.4: Parameters of Experiments by Jiang and Virkar [61] .............. 75

Table 6.1: Details of the geometry of SOFC used for simulation (Achenbach

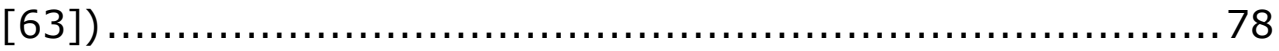

Table 6.2: Details of the geometry of SOFC used for simulation (Achenbach

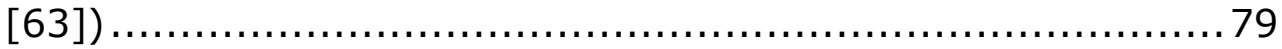

Table 6.3: Details of the SOFC geometry used (Achenbach [63]) ............ 81

Table 6.4: Predictions for key parameters for co flow configuration .......... 85

Table 6.5: Predictions for key parameters for counter flow configuration ....86

Table 6.6: Predictions for key parameters for cross flow configuration .......86

Table 6.7: Predictions for key parameters for co-flow configuration ...........96 96

Table 6.8: Predictions of key parameters for counter flow configuration .....96 


\section{Nomenclature}

A

$A_{\text {layer }}$

$a_{f}$

$a_{s}$

C

$C^{*}$

$C_{p}$

C

D

$d_{p}$

$\Delta E$

F

$f=\frac{n F}{R T}$

$\vec{f}$

$\Delta G^{0}$

h

$h_{\text {con }}$

I

i

$i_{L}$

$i_{0}^{A}$

$i_{0}^{C}$

model parameter $(1 / K)$

Cross-sectional area of a component layer $\left(\mathrm{m}^{2}\right)$

Area factor (nounits)

Surface area of solid matrix for unit volume of mixed media $\left(\mathrm{m}^{-1}\right)$

Concentration at the reaction site $\left(\mathrm{mol} / \mathrm{m}^{3}\right)$

Bulk concentration $\left(\mathrm{mol} / \mathrm{m}^{3}\right)$

specific heat at constant pressure $(\mathrm{J} / \mathrm{kg})$

molar concentration $\left(\mathrm{mol} / \mathrm{m}^{3}\right)$

Diffusion coefficient $\left(\mathrm{m}^{2} / \mathrm{s}\right)$

pore diameter $(m)$

Electric potential difference across an interface or a cell $(V)$

Faraday's constant (columb/mole)

factor $(1 / v)$

flux of a conserved scalar

standard Gibbs free energy change $(\mathrm{J} / \mathrm{mol})$

enthalpy $(\mathrm{J} / \mathrm{kg})$

heat transfer coefficient $\left(\right.$ watt $\left./ \mathrm{m}^{2} K\right)$

total current $(A)$

current density $\left(\mathrm{A} / \mathrm{m}^{2}\right)$

Limiting current density $\left(\mathrm{A} / \mathrm{m}^{2}\right)$

Exchange current at electrolyte/anode interface $\left(\mathrm{A} / \mathrm{m}^{2}\right)$

Exchange current at cathode/electrolyte interface $\left(\mathrm{A} / \mathrm{m}^{2}\right)$ 


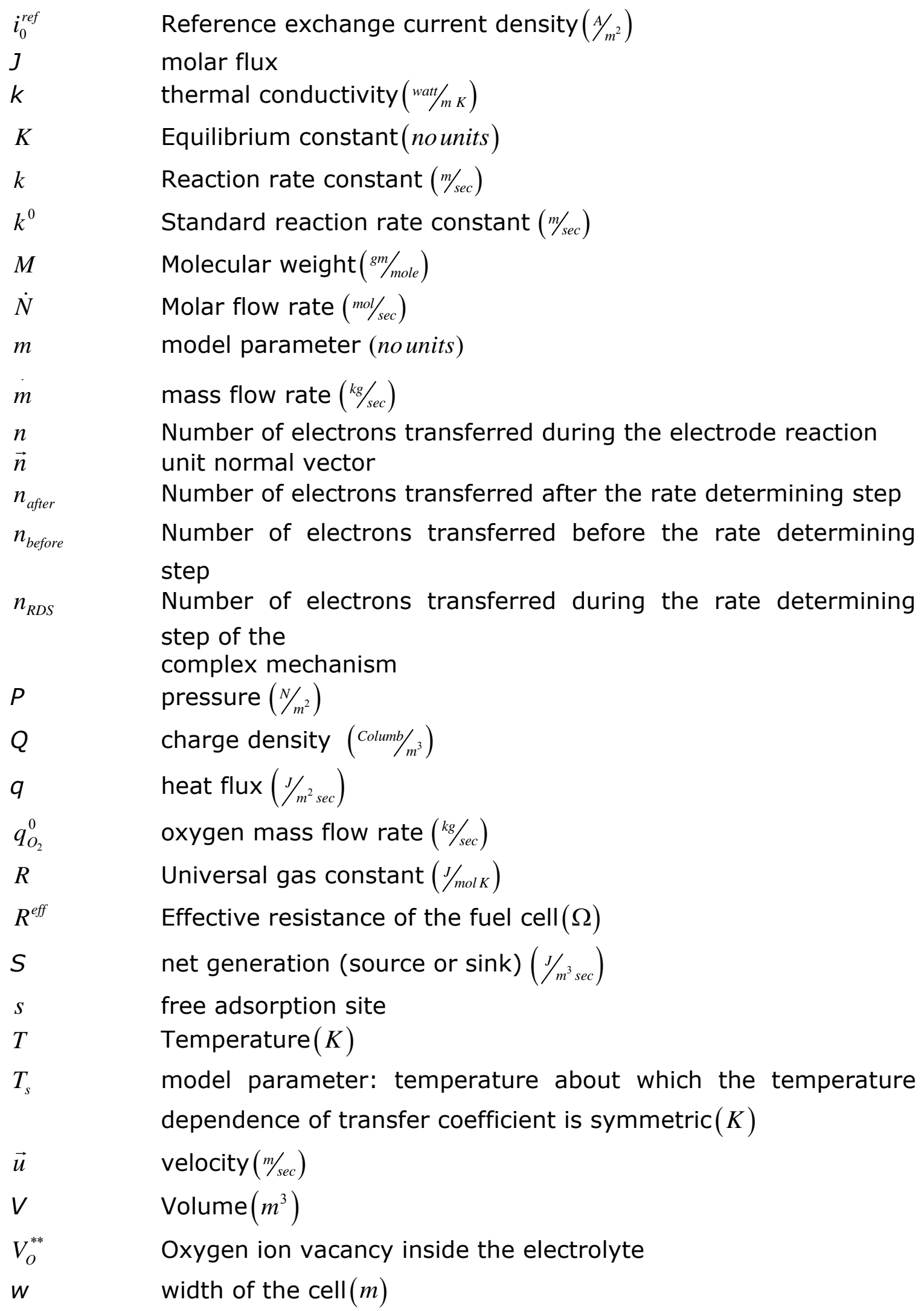




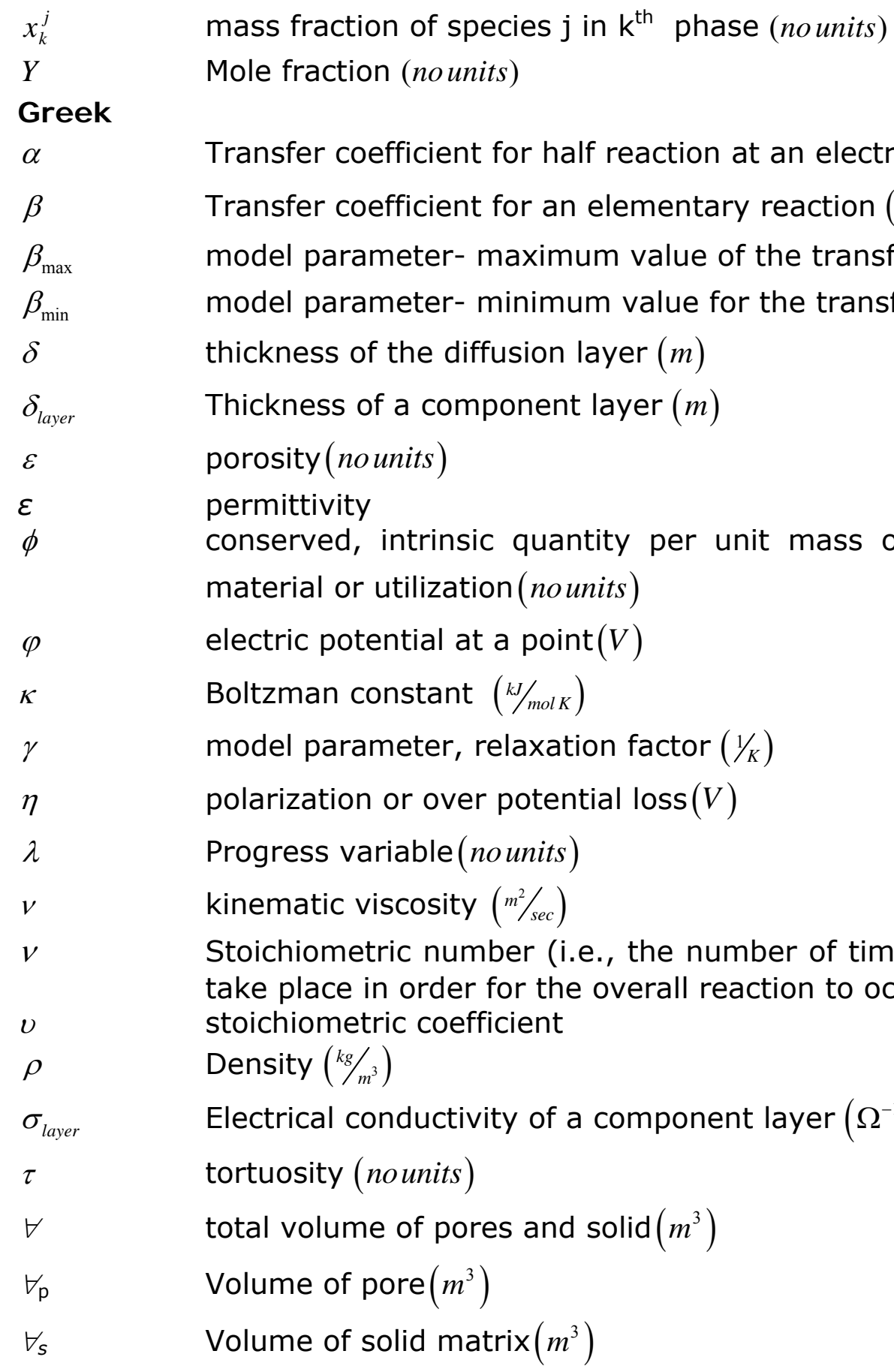

\section{Subscripts}

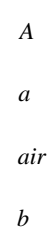

Anode

adsorbed phase

Air channel

$b$

Backward reaction 


\begin{tabular}{|c|c|}
\hline C & Cathode \\
\hline$C / E$ & Cathode/Electrolyte interface \\
\hline cell & Across the whole cell \\
\hline con & $\begin{array}{l}\text { convection } \\
\text { Electrolyte }\end{array}$ \\
\hline$E q$ & Equilibrium state \\
\hline$E / A$ & Electrolyte/Anode interface \\
\hline$E / E$ & Electrode/Electrolyte interface \\
\hline$E / G$ & Electrode/Gas channel \\
\hline $\begin{array}{l}\text { e } \\
\text { echem. } \\
\text { elec } \\
\text { eq }\end{array}$ & $\begin{array}{l}\text { east } \\
\text { Electrochemical } \\
\text { electrical } \\
\text { equilibrium } \\
\text { Forward reaction or fluid }\end{array}$ \\
\hline $\begin{array}{l}g \\
\text { fuel }\end{array}$ & $\begin{array}{l}\text { gas } \\
\text { Fuel channel }\end{array}$ \\
\hline $\begin{array}{l}I \\
k, 1 \\
L\end{array}$ & $\begin{array}{l}\text { interface } \\
\text { different phases } \\
\text { Leakage }\end{array}$ \\
\hline$m$ & $\begin{array}{l}\text { mean } \\
\text { Negative electrode }\end{array}$ \\
\hline $\begin{array}{l}n b \\
P E\end{array}$ & $\begin{array}{l}\text { north boundary } \\
\text { Positive electrode }\end{array}$ \\
\hline$P$ & $\begin{array}{l}\text { pressure } \\
\text { Product species or product species }\end{array}$ \\
\hline$R$ & Resistance \\
\hline$r$ & Reactant species \\
\hline ref & $\begin{array}{l}\text { radiation } \\
\text { reference } \\
\text { solid }\end{array}$ \\
\hline$s b$ & south boundary \\
\hline$T$ & $\begin{array}{l}\text { Temperature } \\
\text { west }\end{array}$ \\
\hline $\begin{array}{l}w \\
\text { YSZ }\end{array}$ & Yittria Stabilized Zirconia electrolyte \\
\hline
\end{tabular}

\section{Superscripts}

$\begin{array}{ll}c & \text { convection } \\ d & \text { diffusion } \\ \text { eff } & \text { effective } \\ n & \text { north } \\ O C & \text { Open circuit }\end{array}$


reference

south 


\section{CHAPTER 1: \\ I NTRODUCTI ON}

\subsection{Motivation}

Harnessing of energy in natural fuels and using it in machines, which eventually replaced men and animals in doing menial jobs, was one of the major factors that helped improve the quality of human life and accelerated the advancement of technology over the last two centuries. Starting with the industrial revolution in late eighteenth century, machines have infiltrated into almost all aspects of our daily lives. Today, our dependence on the machines and the energy or fuels to run them is so thorough that one cannot even imagine our existence without them. After steadily increasing use of natural fuels with conventional conversion techniques for several decades, we arrived at a point where the inevitable exhaustion of the known natural fuel resources on earth cannot be considered a distant future. Also, the conventional methods of energy conversion entail production of harmful byproducts that have been polluting our environment at ever increasing rates. These concerns over the conventional fuels and techniques fueled research in alternative fuels and methods for energy conversion. While only a clean and renewable energy source (such a solar, wind or hydel power) can solve these problems in long term, more efficient and less polluting devices of energy conversion using conventional fuels can be helpful in the meantime. Fuel cells are thought to be an appealing choice for such technology. Seeing this, the United States government announced "Hydrogen Fuel Initiative" in 2003 to further the development of technologies that would enable an energy 
infrastructure based on fuel cells and hydrogen produced from fossil fuel available in United States.

Fuel cells directly convert the chemical energy in the fuel to electrical energy without the intermediate steps of heat and mechanical energy conversions as is the case in conventional methods based on combustion. Thus fuel cells are inherently more efficient and also less polluting. They were demonstrated to be technologically feasible for automobiles, modular power sources, and also centralized power stations. However, much research is still required to make them economically viable in comparison with conventional generators. Research is also needed for economical production and handling of hydrogen which is the exclusive fuel for some fuel cells. Solid oxide fuel cells, however, can directly operate on natural gas or gases derived from coal. Also they operate at elevated temperatures producing good quality waste heat which can be used for heating purposes or to run bottoming cycles based on gas turbines to produce more power.

The Solid state Energy Conversion Alliance (SECA) was formed in 1999 to combine the efforts of government, industry and scientific communities in developing economically viable solid oxide fuel cells. The specific goal of the program is to expedite the development of market ready SOFCs in range of $3 \mathrm{kw}$ and $10 \mathrm{kw}$ for use in stationary, transportation and military applications. Current research in solid oxide fuel cells is mainly aimed at solving material problems caused due to high operating temperatures, problems related to using hydrocarbon fuels, thermal and structural stability of stacks of cells and reforming of hydrocarbon fuels. Numerical modeling is critical for such investigations given the small dimensions of individual cell components and high temperatures which make the instrumentation for detailed experimental investigations very demanding. Depending on the objective, various levels of modeling have been performed by fuel cell researchers. However, there is still need for newer and improved modeling strategies. 
The motivation behind this study is a need for a new level of computational modeling for solid oxide fuel cells that falls between the simplified lumped modeling and complex multi-dimensional modeling found in literature. Simplified zero-dimensional or one-dimensional lumped models for solid oxide fuel cells are mainly used when the overall system performance data is of importance. Also, such modeling can be used at stack level, in which case a zero- or one- dimensional model is used for the stack as a whole. Another approach is to develop a multi-dimensional model for a single cell and run several instances of the model in parallel, one for each cell in a stack, with appropriate communication of data between the cells. Such a set-up will be able to model realistic situations that arise in SOFC stack operation such as non-uniform performance of the individual cells in the stack. Detailed multi-dimensional modeling of a stack, on the other hand, is more difficult to perform given the fact that the smallest scales in a SOFC stack are two to three orders of magnitude smaller than dimensions of the system. Thus the processor and memory requirements for a computer to handle such calculations are extreme making parallel computing almost inevitable. Thus, it is imperative to start with an economical cell level model to be able to effectively model a stack. A fully three dimensional cell level model may not be suitable for stack modeling due to their complexity, especially when simulating transients. In the present study, a reduced order model is pursued which, while retaining most of the details of a three dimensional model, is less computationally intensive and thus more suitable for parallelization to simulate transient operation of stacks.

\subsection{Objective}

The objective of this study is to develop a reduced order multidimensional model for solid oxide fuel cells. The model will resolve most of the important details that are resolved by a three-dimensional model but will be computationally less intensive. The reduction in complexity will be 
achieved through approximations that will smear out less important details. Thus the model is not completely three dimensional and is referred to as a pseudo three-dimensional model. However, the model will use a more detailed electrochemical analysis in the calculations than a usual threedimensional model. DREAM SOFC, a three-dimensional computational fluid dynamics solver developed by $\operatorname{Dr}$. Ismail Celik $[1,2]$ will be used as a foundation for the new model. The specific goals of this work are to:

1. Adopt the DREAM code for transient modeling of fuel cells

2. Identify the potential for reduction of computational costs with minimal possible loss of detail

3. Develop necessary mathematical models for the chosen method of reduced order modeling

4. Develop a detailed electrochemistry model for multi-dimensional fuel cell simulations

5. Implement the reduced order model with the new electrochemistry model

6. Validate the model using results from the literature

7. Perform parametric studies using the new reduced order model

\subsection{Organization of Thesis}

This thesis is divided into 9 chapters including the present introduction. Chapter 2 is on literature review which provides a brief 
introduction to fuel cell technology followed by an assessment of current status of fuel cell modeling. The underlying mathematical relations used in the model are presented in Chapter 3. Chapter 4 is dedicated to the numerical methods employed to solve the mathematical model. Also some novel numerical techniques for modeling of certain fuel cell phenomena are given in Chapter 4. The derivation and independent testing of the new electrochemistry model are provided in Chapter 5. Validation of the complete model against the results from literature and comparison of the model with a different three-dimensional model are done in Chapter 6. Chapter 7 is devoted to a parametric study performed using the new SOFC model. Conclusions and Recommendations of the study are furnished in Chapters 8 and 9 respectively. 


\section{CHAPTER 2: \\ LITERATURE REVI EW}

\subsection{I ntroduction}

Fuel Cells have been attracting the most attention in the search for new efficient and eco friendly energy sources for future. However, much research and development is still needed before they could be commercially viable. Numerical modeling plays a prominent role in the fuel cell research. In this chapter, a brief introduction to fuel cell technology is presented with emphasis on Solid Oxide Fuel Cells (SOFCs) followed by an introduction to numerical modeling. Also, a literature review on the current state of SOFC modeling is included.

\subsection{Fuel Cells}

A fuel cell is an electrochemical device, which converts chemical energy in the fuel directly into electrical energy by means of electrochemical reactions. The working principle is similar to that of a battery. However, there is a difference that in a battery, the components (electrodes and electrolyte) themselves react in the energy conversion process whereas, in a fuel cell, the fuel is supplied in a flow and products of the reactions are removed continuously. This means that the batteries should either be discarded or recharged after their fuel is exhausted, but the fuel cells can operate continuously as long as fuel is supplied and the products and byproducts are removed. The only limit on the period of operation of a fuel cell is that imposed by wear deterioration of the components of the cell, which is 
usually much longer than that of a battery. Since the fuel cells directly convert the chemical energy in fuel to electrical energy, eliminating the intermediate stages of thermal energy (heat from combustion) and mechanical energy (e.g. turbine run on hot gasses or steam) as in conventional electrical power plants, they are known as direct energy conversion devices and are inherently more efficient (Crowe [3]).

\subsubsection{Types of Fuel Cells}

The basic components of a general fuel cell are two porous electrodes, anode and cathode separated by a solid or liquid electrolyte, which is impervious to gases. Fuel is supplied to the anode side and air to the cathode side. The oxidation reaction is made possible by conduction of ions through the electrolyte. Fuel cells are classified according to the electrolyte used. Among many types, the major ones are:

Solid oxide fuel cells (SOFCs): Electrolyte is a ceramic that conducts ions at high temperatures. Operate at $800-1000{ }^{\circ} \mathrm{C}$.

Molten carbonate fuel cells (MCFCs): Electrolyte is a mixture of molten alkali carbonates that conducts carbonate ions. Operate at 600 $700^{\circ} \mathrm{C}$.

Proton exchange membrane fuel cells (PEMFCs): A polymer membrane that conducts protons (or hydrogen ions) is used as an electrolyte. Operate at $80-100{ }^{\circ} \mathrm{C}$.

Phosphoric acid fuel cells (PAFCs): Phosphoric acid is used as electrolyte and it conducts protons. Operate at $180-210^{\circ} \mathrm{C}$. 
Alkaline fuel cells (AFCs): Electrolyte is an aqueous solution of alkaline hydroxide (e.g. $\mathrm{KOH}$ ) which readily conducts hydroxyl ions. Operate at $50-100{ }^{\circ} \mathrm{C}$.

\subsubsection{Working of a YSZ based Solid Oxide Fuel Cell}

Figure 2.1 shows the basic components and working of a solid oxide fuel cell with a YSZ (Yttria Stabilized Zirconia) electrolyte. Fuel (usually hydrogen) is fed to the anode and diffuses through the porous electrode until it comes into contact with the electrolyte. At the interface of fuel, electrolyte and electrode (anode) the fuel molecules ionize releasing electrons (i.e. they get oxidized) which are collected on the anode. In case of a SOFC, hydrogen reacts with oxide ions to form water with release of electrons (Eq.1.1). Similarly, oxidizer is fed to the porous cathode and there at the interface of oxidizer, electrolyte and cathode, oxidizer molecules ionize absorbing electrons (i.e. they get reduced) from the cathode. As a result of the potential difference set up between anode and cathode due to the resultant excess and scarcity of electrons at anode and cathode respectively, an electric current passes through the external circuit through which they are connected. And within the fuel cell, the ions formed at the electrodes migrate through the electrolyte and react to form a by-product, thus completing the circuit and sustaining the process. In a simple hydrogen-oxygen fuel cell, the reactions may be represented by the following equations 


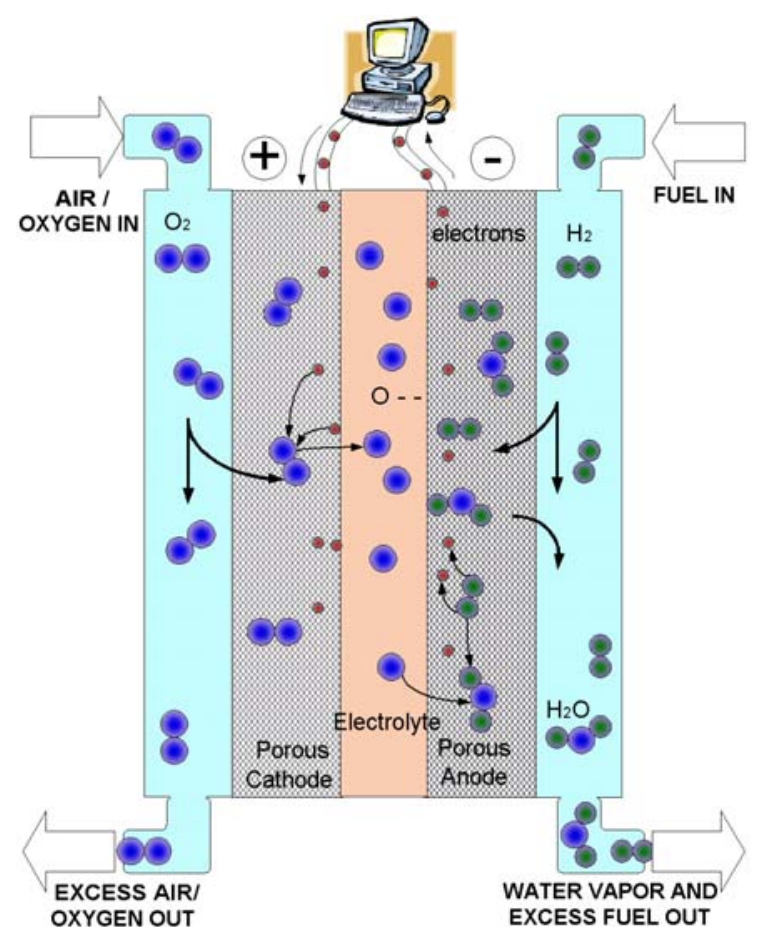

Figure 2.1: Basic components and working of a Solid Oxide Fuel Cell.

Anode:

$$
\mathrm{H}_{2}+\mathrm{O}^{=} \rightarrow \mathrm{H}_{2} \mathrm{O}+2 e^{-}
$$

Cathode:

$$
\frac{1}{2} \mathrm{O}_{2}+2 e^{-} \rightarrow \mathrm{O}^{=}
$$

Overall:

$$
\mathrm{H}_{2}+\frac{1}{2} \mathrm{O}_{2} \rightarrow \mathrm{H}_{2} \mathrm{O}
$$


Here the oxide ions migrate from cathode to the anode and react with hydrogen to form water. Water (steam in case of SOFC) needs to be removed along with any heat produced during the reactions. The working of other types of fuel cells is similar with same overall reaction, but the actual electrode reactions and ion transport vary according to the electrolyte.

\subsubsection{Thermodynamics of Fuel cells}

The current produced and the reactants consumed in a fuel cell are related through stoichiometry. For example, it can be seen that 2 moles of electrons are produced from one mole of hydrogen and 4 moles of electrons are produced from one mole of oxygen from Eqs. (2-1) \& (2-2) respectively. The general expression for current is (Singhal and Kendall [4])

$$
I=Z_{r} \dot{n}_{r} F
$$

Where $I(A)$ is the total current, $z_{r}$ is the stoichiometric numbermoles of electrons per moles of reactant $r, \dot{n}_{r}(\mathrm{~mol} / \mathrm{sec})$ is the molar consumption rate of reactant $r$ and $F($ columbs $/$ mole $)$ is the Faraday's constant that converts moles of electrons to charge in columbs. The electrical power $P$ produced by a fuel cell is given by

$$
P=V I
$$

Where $V(\mathrm{v})$ is the voltage (electrical potential difference) produced by the cell. If the cell were running in ideal conditions converting all the available energy in the reacting fuel into useful electrical power, then

$$
V_{\text {ideal }} I=\dot{n}_{r} \Delta G
$$


Where $V_{\text {ideal }}$ is the ideal or theoretical maximum voltage that can be produced and $\Delta G(\mathrm{~J} / \mathrm{mol})$ is the change in Gibbs function for the reaction. Now substituting Eq. (2-4) in Eq. (2-6), the ideal voltage can be found out to be

$$
V_{\text {ideal }}=\frac{\Delta G}{z F}
$$

Ideal voltage is also referred to as Nernst voltage or open circuit voltage. Equation (2-7) is also known as Nernst's Equation. The change in Gibbs free energy for a reaction is a function of temperature and activities of reactant and product species. Since these parameters vary from point to point inside a fuel cell, ideal voltage is also a local parameter in a fuel cell producing current.

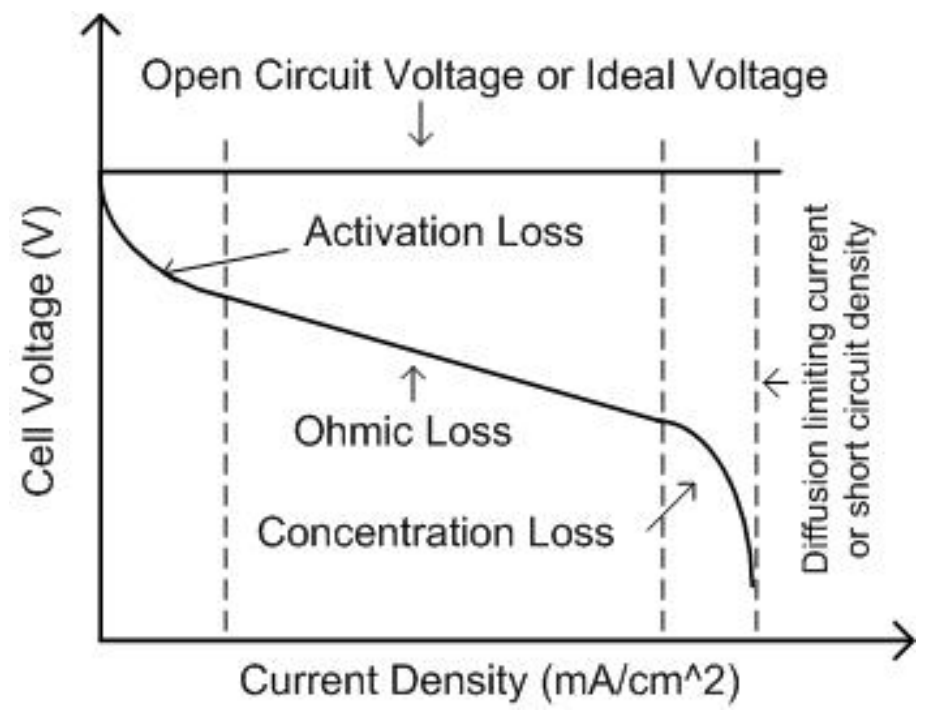

Figure 2.2: Typical Voltage-Current Curve for a Fuel Cell.

There are always some irreversibilities during the operation of a fuel cell and consequently the actual working voltage produced by the cell is less than the ideal value. The losses occurring in fuel cells, also known as overpotentials, are categorized as activation, ohmic, and concentration losses. Activation losses are caused by sluggish electrochemical reactions which use 
some of the produced energy. The current flow through the cell causes the resistance losses and the diffusion is caused by inadequate mass transport rate to the active reaction sites. The contribution of these losses is different at different operating currents. A typical Voltage-Current variation (V-I curve) for a fuel supplied with a constant flow of reactant is shown in Fig. (2.2). At zero current (open circuit) of the voltage is ideal voltage and at low currents, the losses are dominated by activation over-potentials, where there is a sharp decrease in voltage for a small increase in current. The maximum current produced by a cell, known as limiting current, is dictated by mass transport limitations and when the operating current is close to this limit, the losses are dominated by concentration over-potential. The linear region of the curve in between high and low current regions is dominated by the resistance over-potential.

Efficiency of a fuel cell can be calculated either based on total enthalpy change during the reaction (first law efficiency) or the Gibbs function change during the reaction (second law or exergetic efficiency).

$$
\begin{gathered}
\eta_{I}=\frac{V I}{\dot{n}_{r} \Delta H} \\
\eta_{I I}=\frac{V I}{\dot{n}_{r} \Delta G}=\frac{V}{V_{\text {ideal }}}
\end{gathered}
$$

Note that the efficiencies in Eqs. (2-8 \& 2-9) are calculated using the actual amount of fuel used in the fuel cell. Sometimes the efficiency is reported based on the total amount of fuel supplied, which can be obtained by multiplying Eqs. (2-8 \& 2-9) by fuel utililization. Fuel utilization factor $\phi$ is defined as the ratio of the fuel utilized to the total fuel supplied. 


$$
\phi=\frac{\dot{n}_{r}}{\dot{n}_{r}^{\text {sup }}}
$$

\subsubsection{Fuel Cell Stacking and Layouts}

Since the voltage (electric potential difference) of a single cell is usually less than $1 \mathrm{~V}$, a large number of cells are stacked upon each other (connected in series) to generate useful amount of power. An interconnect (also known as a bipolar plate) connects the anode of one cell to the cathode of the adjacent cell in the stack. The gas channels are also formed on the interconnect to distribute the gasses along the electrodes. There are a number of possible arrangements (see Fig. 2.3) in which the basic components of a solid oxide fuel cells can be put together. Commonly used designs are (Minh [5])

1. Tubular cell

2. Segmented cell

3. Monolithic cell

4. Flat plate or planar cell. 


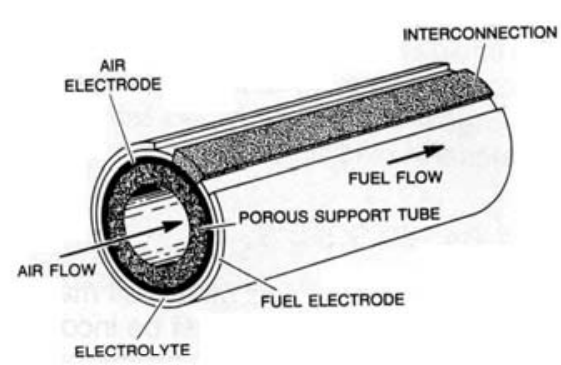

Seal-less Tubular Design

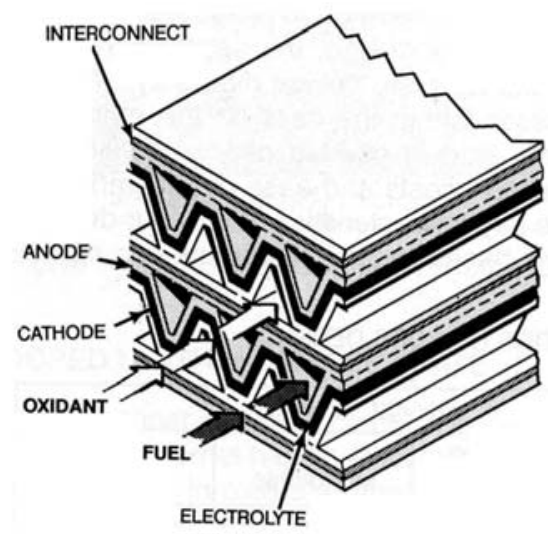

Monolithic Design

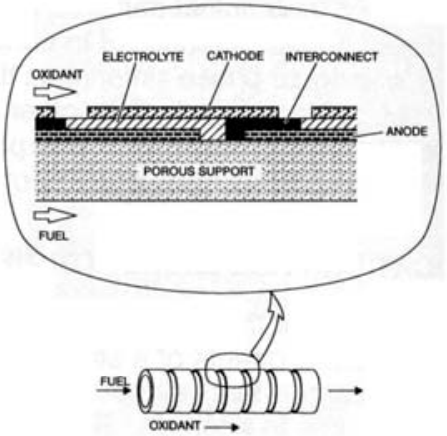

Segmented-Cell-in-Series Design

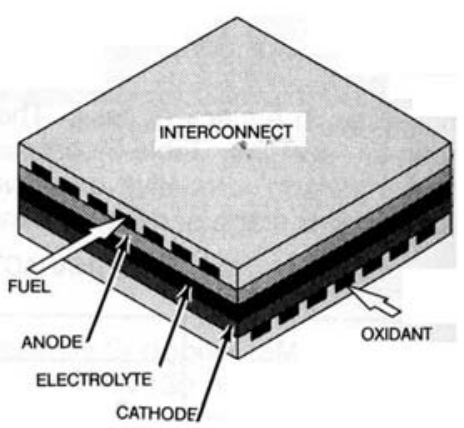

Flat-plate Design

Figure 2.3: Various designs of Solid Oxide Fuel Cells. (after Minh, [5])

In planar solid oxide fuel cells, gas channels formed on the interconnect distribute the reactants across the fuel channel. Different arrangements are possible depending on the relative positioning of fuel and air channels. Figure 2.3 shows the three different layouts of channels employed in fuel cells, namely co-flow, counter-flow and cross-flow configurations (see Fig.2.4). 

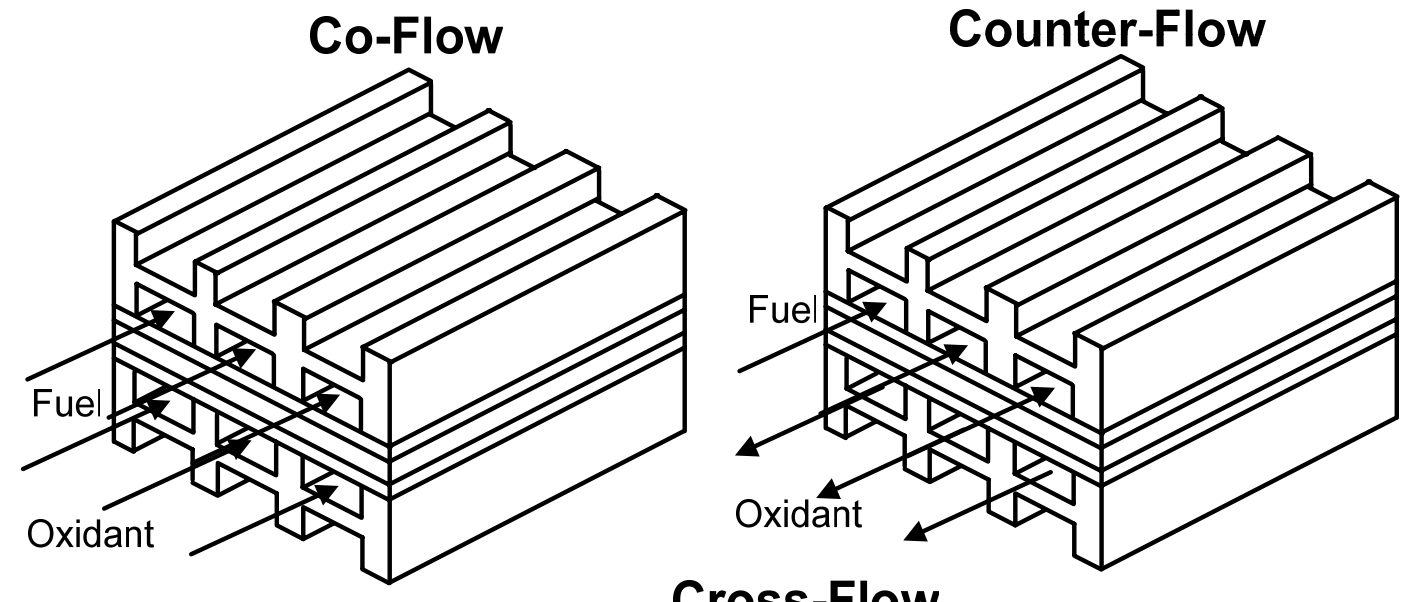

Cross-Flow

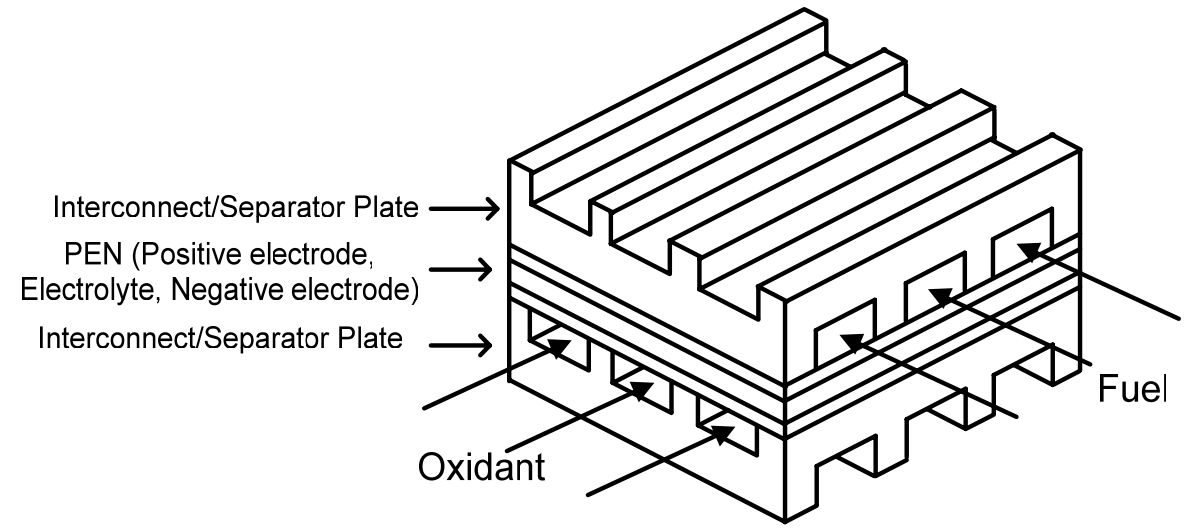

Figure 2.4: Various configurations of Solid Oxide Fuel Cells. (after Burt [6])

\subsubsection{Solid Oxide Fuel Cell Materials}

Due to high operating temperature, solid oxide fuel cells are almost exclusively made of ceramic materials. Since electrolyte is the central element of the fuel cell, all other materials are chosen based on the selection of electrolyte material. Electrolyte is required to conduct ions and insulate electrons. Yttria Stabilized Zirconia (YSZ) is the most popular electrolyte material which exhibits good oxide ionic conductivity at temperatures around $1000{ }^{\circ} \mathrm{C}$. Since metals cannot withstand such high temperatures in oxidizing atmospheres, suitable ceramic materials were initially used for the cathode and the interconnect too. The cathode needs to be electronically conductive and stable in oxidizing atmospheres at high temperatures. Lanthanum 
Strontium Manganite (LSM) is the usual choice. A composite of ceramic (YSZ) and metal (nickel), Ni-YSZ cermet, is the commonly used material for anode which is required to be stable in reducing environment at high temperatures and possess good electronic conductivity. Interconnect is exposed to both oxidizing and reducing environments and serves as electrical connection between the adjacent cells of a stack. Lanthanum Chromite $\left(\mathrm{LaCrO}_{3}\right)$ was the standard material for interconnect. Presently, the research trend under SECA program is towards reducing the operating temperature of SOFCs to around $650-850{ }^{\circ} \mathrm{C}$ by using novel electrolyte materials and by reducing electrolyte thickness [7]. Metallic interconnects made of chromic stainless steels are being used in such intermediate temperature SOFCs. Another important requirement for the SOFC materials is to have closely matching thermal expansion coefficients. Given the brittleness of the ceramic materials and high operating temperatures, mechanical failure due to thermal stresses caused by non uniform thermal expansion is a major problem for SOFC stacks.

Ceria based materials are being investigated as alternatives to YSZ for electrolyte. Doped ceria exhibits high oxide ion conductivity at temperatures around $700 \mathrm{~K}$. Use of such material can bring down the SOFC operating temperature to $600-800 \mathrm{~K}$ range which can solve some material related problems in SOFCs resulting from high operating temperatures. However, ceria based materials possess some electronic conductivity which seriously affects the efficiency of the fuel cell.

In conclusion, solid oxide fuel cells are most suitable candidates for stationary applications because of their high operating temperature. Their main advantage over the other types of fuel cells is greater fuel flexibility. In theory SOFCs can be used to oxidize any fuel. Also, as they operate at high temperature, the exhaust gases contain high quality thermal energy which can be used in a turbine, further augmenting the power output or for heating 
purposes and thus increasing the overall efficiency. Due to their high efficiency, low emissions and fuel flexibility, SOFCs are promising power source for future. Recent reviews on SOFC technology (McIntosh and Gorte [8], Ormerod [9]) highlight the research aimed at solving the problems involved in direct use of hydrocarbons in SOFCs. Such possibility will open the doors for use of natural gas, coal syngas or biogas in SOFCs. However, much research is still needed to develop efficient designs of SOFCs that could compete with conventional power generators and modeling is expected to play an important role in such endeavors as pointed out by Von Spakovsky and Olsommer [10].

\subsection{Fuel Cell Modeling}

The main advantages of numerical modeling are relatively low cost of development, speed, and relative ease with which detailed parametric studies and other tests can be conducted, once the model is programmed and validated. However, experiments are still needed to validate the numerical models. For best results at low cost, an optimum balance should be maintained between experiments and modeling. Numerical modeling is particularly valuable when experimental investigation is difficult due to instrumentation or other problems. It is for these reasons that numerical modeling is widely used in fuel cell research and development.

Numerical modeling of a physical process involves formulating relationships between the important process variables and then solving them numerically to predict the behavior of the process for different sets of input conditions that can be controlled. The mathematical relationships are derived from the physical laws that govern the process. Due to complex nature of exact physics, simplifying assumptions are usually made to reduce the number of variables and/or to obtain simpler equations. Also, at times empirical methods are used to model some processes for which underlying 
physics is either not fully known or is complex. The quality of data obtained from a numerical model depends upon the plausibility of the assumptions made. Numerical predictions usually contain various errors. The errors that arise from assumptions are called modeling errors. In addition to these, there could be numerical errors that arise from solving the equations by discretization. In order to make sure that the errors are in tolerable limits, it is required to validate a numerical model by comparing the results with the experiments. Once the validity of a numerical model has been established, it can be used to simulate other cases.

As a research tool, fuel cell modeling can be used to understand the processes that occur inside the fuel cells and to identify the critical ones which limit the others. Also, the effects of various parameters on different processes inside the fuel cell can be studied and understood. Such knowledge is useful in devising better designs. Fuel cell modeling has also become a design tool lately. Commercial Computational Fluid Dynamics (CFD) software packages now come with a designated module for fuel cell modeling. As a design tool, fuel cell modeling can be used to predict the performance of a particular design of fuel cell under various operating conditions. Such a study usually gives the information such as safe operating conditions, key parameters which affect the efficiency etc. Also, modeling can be used to determine the most appropriate geometric proportions for fuel cells by conducting a parametric study with various geometries. Fuel cell models are available in published literature for a range of applications from detailed modeling of reaction kinetics inside the fuel cells to modeling the environmental and economical impact of incorporating fuel cell technology into power infrastructure. Given the wide scope of applications, the models developed for various purposes are at different levels of complexity and detail. Though there is no clear-cut delineation, fuel cell models are usually classified into component/electrode-, cell- , stack- and system- level models. Other general classifications for numerical models are zero-, one-, two- and three-dimensional models, and steady and transient models. 


\subsubsection{Electrode Level Modeling}

At a single electrode level, computational modeling is mainly used to explore the reactions at the electrode/electrolyte interfaces and the transport processes inside the porous electrodes. Reaction mechanisms at cathode/electrolyte interface with platinum catalyst were identified and kinetic parameters estimated by Mitterdorfer and Gauckler $[11,12,13]$ using numerical modeling of electrochemical kinetics. The same modeling strategy was used for a similar study of anode/electrolyte interface with Ni pattern anode (Bieberle and Gauckler [14]) and Ni-YSZ anode (Bieberle and Gauckler [15]) in subsequent studies. An electrode level model was developed by Lehnert et. al. [16] that simulated the transport of fuel gas inside the anode. The model was one dimensional and accounted for diffusion, permeation, reforming reaction kinetics, and electrochemical kinetics, and a parametric study on the effects of structural parameters of an anode on reforming reaction was conducted. A detailed three dimensional modeling of flow inside an anode supported SOFC is done by Yakabe et. al. [17]. The model also calculated the species concentrations, Nernst potential, and over potential distributions. It was concluded that concentration polarization increases along the flow path in case of reformed fuel and that the shift reaction helps reduce the concentration polarization.

Theoretical modeling of ionic and electronic conductivities of composite electrodes was performed by Wu and Liu [18] and it was demonstrated that such investigations can be employed to design the volume fractions of various phases inside a composite electrode for optimum performance. The effects of electrode microstructure on activation and polarization in SOFC has been studied by Virkar et al. [19] considering only a steady-state, onedimensional model for gas diffusion, and it was demonstrated that polarization losses can be minimized by optimization of electrode micro structure. 


\subsubsection{Cell level modeling}

Cell level models, on the other hand, can be used to study the performance of cells with different designs under various operating conditions. These models could be zero-, one- or multi-dimensional depending on the research needs. The model used by Hall and Colclaser [20], for example, is a transient one dimensional model for tubular SOFCs. The model calculated temperature and current density distributions. The response of the SOFC to the sudden changes in load was studied. Gemmen and Leise [21] developed a one dimensional model, where it was assumed that variations occur only in the direction of reactant flow. Standaert et al. [22] developed an analytical method for one dimensional modeling of fuel cells and reported analytical expressions for variations of current and temperature variation along the reactant flow direction. While these models give sound results at reasonable computational cost, they need some model parameters as input to account for the details that were omitted for the purpose of simplicity. These parameters, such as limiting current, heat transfer coefficients for gas channels etc, are critical for the performance of the simplified model and have to be determined either experimentally or through detailed modeling. Yuan et al. [23] simulated the flow inside fuel channels with fully developed flow assumptions and reported the friction factors and Nusselt numbers in various scenarios. A Cell model completely based on experiments (with little basis on physics) developed using control theory was used by Schichlein et al. [24] to predict the impedance behavior of the SOFCs. Also at the cell level are the models to predict the long term performance degradation of the fuel cells. Huang and Reifsnider [25], for example, proposed a mechanistic approach to model the long term behavior of SOFC that also uses the model parameters determined using experiments.

One of the early multi-dimensional models is a two dimensional model for planar cross flow solid oxide fuel cells (SOFC) developed by Vayenas and 
Debenedetti [26], which computes distributions of current density, specie concentration and temperature. The unit cell in the model which repeats itself in two directions consisted of two phases viz., solid and gas channels. It was assumed that the temperature is uniform in solid phase and uniform but different from each other and different from that in solid for each of the gas channels. Results were presented for current density and temperature. The model predicted the location of maximum current density and maximum temperature to be the same. It was also concluded that higher flow rates make the fuel cell more isothermal and decrease the performance as a result of lower overall temperature. A more detailed three-dimensional SOFC model was developed by Ferguson et. al. [27] that could handle the tubular geometry of SOFC too. The model calculated the distribution of temperature, species concentrations, electric potential and current density inside the electrodes. Thus it was possible to study the effect of the geometric proportions on the performance of the cell.

Yakabe et al. [28] developed a three dimensional model for a single cell. The model used finite volume method for the calculations of flow temperature and specie concentrations inside the cell and then used finite element method to calculate the stress distribution within the cell at the obtained temperature distribution. The working of a cell in the middle of a stack was simulated and the effects of cell size, operating voltage and thermal conductivity of the cell components on the performance of the cell were investigated. Aguiar et. al. [29] developed a model to study the thermal balance between steam reforming reaction for methane and the SOFC cell reaction in an indirect internal reforming SOFC. The model calculated the distributions of temperature, specie concentrations, current density and potential along the length of a tubular SOFC. The results presented showed undesirable cooling at the entrance for fuel, due to rapid reforming. It was shown that decreasing fuel inlet temperature and catalyst activity in the reformer makes the temperature more uniform. 


\subsubsection{Stack Level Modeling}

Stack Level models simulate the operation of two or more cells in a stack arrangement. A three dimensional transient model for SOFC stack was described by Achenbach [30]. The model included internal reforming of methane and computed spatial distributions of species and temperature and current density. Some of the conclusions from the parametric study using the model were that counter flow cells were most efficient and that recycling of anode gas would increase efficiency. Commercial CFD software, PHOENICS, was used for molten carbonate fuel cell (MCFC) stack modeling by $\mathrm{He}$ and Chen [31]. Their model was three dimensional and solved for flow field inside the fuel cell. Thus the model included the effect of variable flow rate from cell to cell in a stack and at different points in the same cell. The parametric study was demonstrated to be useful for optimization of a design. In a later work He and Chen [32] presented a transient three dimensional model for MCFC stack. The model was similar to the previous one but it was capable of doing transient calculations. The model was used to investigate the response of the stack to sudden changes in load.

The effect of non uniformity of gas flow along the stacking direction and planar direction in a MCFC was investigated by Hirata and Hori [33] using a model similar to that of Vayenas and Debenedetti. [26]. The parametric study on the effect of various inlet flow distributions on temperature and current distributions was presented. The conclusion was that the lack of uniformity in planar direction was not critical whereas the effect of non uniformity in stacking direction is much larger since in this case the fuel and air utilizations change from cell to cell in the stack. Parallel computing was used by Burt et al. $[35,34]$ to simulate stacks using a celllevel model and the effect of non-uniform flow distribution and radiation heat transfer were studied. Stacks of up to 40 cells were simulated and it was concluded that non-uniform flow distribution among the cells of a stack leads 
to voltage variations among the cells. It was also shown that including radiation heat transfer gives significantly different results.

\subsubsection{System Level Modeling}

System level models include separate models for each component of a complete fuel cell system and interface for them to communicate. Each sub model, depending on the requirements, could be at different level of complexity. These models predict the interaction between various components of a fuel cell system during operation. Selimovic and Palsson [36] demonstrated that cascading fuel cell stacks in a hybrid Solid Oxide Fuel Cell, Gas Turbine (SOFC/GT) system increases the overall efficiency of the system. The study used a two dimensional model for the stack in conjunction with the commercial process simulation tool Aspen plus ${ }^{\circledR}$ to simulate the whole SOFC/GT system. The system model described in Stiller et al. [37] was a combination of one-dimensional model for planar/tubular SOFC and a commercial process simulation tool Pro/II for other components. A zerodimensional model was used for SOFC reactor in the system model developed by Freeh et al. [38] for use in conjunction with a propulsion simulation model to study the suitability of SOFCs for aerospace applications. Freeh et al. [38] also demonstrated that the performance of simplified lumped model for SOFCs and hence that of the complete system model is sensitive to the empirical model parameters, as it was already mentioned above. From thermodynamics perspective, a computational model was developed by Bedringas et al. [39] to calculate the exergy balance for each component in a fuel cell system which enables the identification of the components and processes that involve most irreversibilities.

At the extreme end of the spectrum are the models to predict the impact of introducing the SOFC technology into power grid. Koyama et al. [40] predicted that SOFC power plants would receive stiff competition from nuclear plants in Japanese power sector. Their model is built on an internet 
based distributed object-based modeling environment (DOME) with zero dimensional models for different types of power plants .

\subsubsection{Summary}

Detailed multi-dimensional modeling of transport processes inside the fuel cells is very useful in design and research studies. Such modeling, while being widely used for steady state electrode and cell level simulations, is not popular in stack and system level simulations and transient simulations. In some literature ( $\mathrm{He}$ and Chen [31, 32]) the modeling terminology used is somewhat confusing, in that three-dimensionality only refers to the stack being treated as a continuum media, with point sources representing the energy and mass sources contributed by the individual fuel cells. The details of the fuel cells are left out. Strictly speaking, three-dimensionality should also imply the details of the transport processes that occur within each cell. There are also some studies where a three-dimensional model seems to imply that only the energy equation being three dimensional (Achenbach [30] ). The main difficulty encountered in using strictly multi-dimensional modeling for stack and system models is their inherent complexity. They are computationally intensive and usually very time consuming. Given the small length scales of a single electrode of a fuel cell, three-dimensional modeling of a stack with tens of cells requires large number of grid points leading to longer computational time. To achieve truly three-dimensional simulation of stacks, there is need for a reduced order model that can simulate detailed distributions inside the fuel cell. 


\section{CHAPTER 3: \\ MATHEMATI CAL MODEL}

\subsection{I ntroduction}

In this chapter the mathematical equations that constitute the reduced order model are presented. The main transport processes inside the solid oxide fuel cells that are considered in this model are mass transfer, heat transfer, and charge transfer. Partial differential equations are derived for each of these phenomena as applied to fuel cells. The model for electrochemistry is treated separately in chapter 5.

There are solid, gaseous and porous regions in a solid oxide fuel cell and the transport equations are slightly different for each of them. This is due to fact that solid and gaseous regions are single phase medium and porous regions are two-phase medium. In order to reduce the intricacy of the model, it is proposed to use a simple one dimensional modeling for the gaseous regions that comprise of the gas channels. This is advantageous because solving three-dimensional transport equations for fluids, namely Navier-Stokes equations, could be very time consuming whereas more important from fuel cell modeling perspective are the processes inside the porous electrodes. Also, gas flow inside the channels is very well understood and can be accurately predicted using one-dimensional modeling.

The reduced order model presented in this chapter is a combination of a one-dimensional model for gas channels and a three-dimensional model for solid and porous regions. Three dimensional model equations for solid and 
porous regions are briefly derived starting from a generic scalar transport equation for a multiphase medium followed by the derivation of onedimensional equations.

\subsection{Three-Dimensional Model}

The general scalar transport equation for an individual phase within a multiphase medium, where each phase is continuous, is given by (Pakalapati $[2])$.

$$
\frac{\partial}{\partial t}\left(\varepsilon_{k} \rho_{k} \phi_{k}\right)+\nabla \cdot\left(\varepsilon_{k} \rho_{k} \vec{u}^{\text {eff }} \phi_{k}\right)=\nabla \cdot\left(\varepsilon_{k} \Gamma_{\phi}^{\text {eff }} \nabla \phi_{k}\right)+\varepsilon_{k} \rho_{k} S_{\phi_{k}}+f_{k \ell}
$$

Where " $k$ " represents the $k^{\text {th }}$ phase (e.g. $k=1$ solid, $k=2$ gas, $k=3$ liquid, etc.). $\phi$ is a conserved, intrinsic quantity, per unit mass of the continuum material, e.g. enthalpy of solid, $\mathrm{h}_{\mathrm{s}}$, or enthalpy of gas, $\mathrm{h}_{g}$, etc, $\varepsilon_{k}$ is the volume fraction of phase $k, \rho$ is the density, $\mathrm{S}_{\phi}$ is the net generation or destruction (source or sink) of $\phi[\phi / s e c], f_{k l}$ is the is the interfacial flux at the interface with the other phases, $\Gamma^{\mathrm{eff}}$ is an effective diffusion coefficient, and $u^{\text {eff }}$ is an effective phase volume averaged velocity.

The porous electrodes consist of solid and gas phases and the transport equation for the mixed phase can be written as

$$
\frac{\partial}{\partial t}(\rho \phi)+\nabla \cdot\left(\rho \vec{u}^{e f f} \phi\right)=\nabla \cdot\left(\Gamma_{\phi}^{e f f} \nabla \phi\right)+\rho S_{\phi}
$$

The variable and properties in Eq. (3-2) are the so called "mixture variables" defined by 


$$
\begin{gathered}
\rho=\varepsilon_{p} \rho_{p}+\varepsilon_{s} \rho_{s} \\
\rho \phi=\varepsilon_{p} \rho_{p} \phi_{p}+\varepsilon_{s} \rho_{s} \phi_{s} \\
\vec{f}=\varepsilon_{p} \vec{f}_{\phi_{p}}+\varepsilon_{s} \vec{f}_{\phi_{s}} \\
\rho S_{\phi}=\varepsilon_{p} \rho_{p} S_{\phi_{p}}+\varepsilon_{s} \rho_{s} S_{\phi_{s}}
\end{gathered}
$$

Here, $\varepsilon_{p}$ and $\varepsilon_{s}$ are the volume fractions of pore and solid phases, respectively.

\subsubsection{Species Concentration Field}

Species transport equation is written for the gas phase in terms of the mass fraction of $\mathrm{j}^{\text {th }}$ species in pore (gas) phase ' $p$ ', $x_{p}^{j}$, as

$$
\frac{\partial}{\partial t}\left(\varepsilon_{p} \rho_{p} x_{p}^{j}\right)+\nabla \cdot\left(\varepsilon_{p} \rho_{p} u_{p}^{e \text { eff }} x_{p}^{j}\right)=\nabla \cdot\left(\varepsilon_{p} \Gamma_{p}^{\text {eff }} \nabla x_{p}^{j}\right)+\varepsilon_{p} \rho_{p} S_{p}^{j}+a_{s_{p}} f_{I_{p}}^{j}
$$

The first term on the right hand side represents the total diffusion resulting from concentration gradients. The effective diffusion is modified such that the diffusion term includes molecular diffusion terms as well as the Knudsen diffusion term. The source term includes chemical reaction rates, $S_{c h e m}^{j}$ (i.e. mass source or sink per unit mass) due to ionization or other chemical reactions. It should be noted that for now convection inside the pores is neglected. Due to the electrode reactions involving ions at the electrolyte-electrode interface, the interface transfer term, should include the transfer of ions through the active surfaces. According to Grens and Tobias [41] the interfacial source term is given by 


$$
\rho_{k} f_{I . k}^{j}=\frac{M_{j} v_{j}}{n F} i_{k}^{s}
$$

where $v_{j}$ is the stoichiometric coefficient of the $j^{\text {th }}$ species in the electrochemical reaction, $F$ is the Faraday constant, $\mathrm{n}$ is the number of electrons involved in the reaction, $M_{j}$ is the molecular weight, and $i_{k}^{s}$ is the interfacial current which is determined from electric potential field solution.

\subsubsection{Temperature Field}

Energy equation for the mixture can be obtained by replacing $\phi$ in Eq. (3-2) with $h$. Using $d h=C_{p} d T$ and neglecting the convection inside the pores, the energy equation becomes.

$$
\frac{\partial}{\partial t}\left(\rho C_{p} T\right)=\frac{\partial}{\partial x}\left(k \frac{\partial T}{\partial x}\right)+\rho S_{h}
$$

The source term includes ohmic heating, which is distributed throughout the current conducting regions and heat produced due to the electrochemical reactions near the active electrolyte/electrode interfaces.

$$
s_{k}=s_{\text {elec }}^{\prime \prime}+s_{\text {echem }}^{\prime \prime}
$$

The ohmic heat source (Ferguson,1996) is given by

$$
s_{p, \text { lec }}^{\prime \prime \prime}=\sigma_{p}^{\text {eff }} \vec{\nabla} \varphi_{p} \cdot \vec{\nabla} \varphi_{p}
$$


Where $\sigma^{\text {eff }}$ is the effective electric conductivity. $s_{p, \text { chem }}^{\prime \prime \prime}$ needs to be calculated as the algebraic sum of heat released from all electrochemical reactions taking place in the continuum. In the present study, the heat due to electrochemical reactions is assumed to be produced at the anode/electrolyte interface. Inside each computational cell at this interface, the heat source term is proportional to the current density through the amount of hydrogen used. The relationship is given by

$$
s_{p, \text { chem }}^{\prime \prime \prime}=\dot{m}_{H_{2}}^{\text {reac }} T \Delta s_{\text {reac }}
$$

\subsubsection{Electric Potential (Current) Field}

The equation of conservation of electric charge is given by

$$
\nabla \cdot \vec{I}=\nabla\left(\sigma^{e f f} \nabla \varphi\right)=s
$$

The electric potential $\varphi$ is assumed to be continuous throughout the electrodes and electrolyte except at the electrode/electrolyte interfaces. These discontinuities are usually modeled by Nernst's law. The model to calculate the potential jumps at each electrolyte/electrode interface is described in Chapter 5. The source term in Eq. (3-13) is non-zero only near the electrode/electrolyte interfaces to account for the potential jumps. The methodology to include these discontinuities into the electric potential field is presented in Chapter 4.

\subsection{One Dimensional Model for Gas Channels}

The specie, temperature, and velocity distributions inside the gas channels may be assumed to be varying only in the direction of gas flow. 
With this assumption, a one-dimensional model can be formulated for a cross-section averaged value of each of the variables along the length of the gas channels. First, a one dimensional scalar transport equation for a fuel cell gas channel is derived.

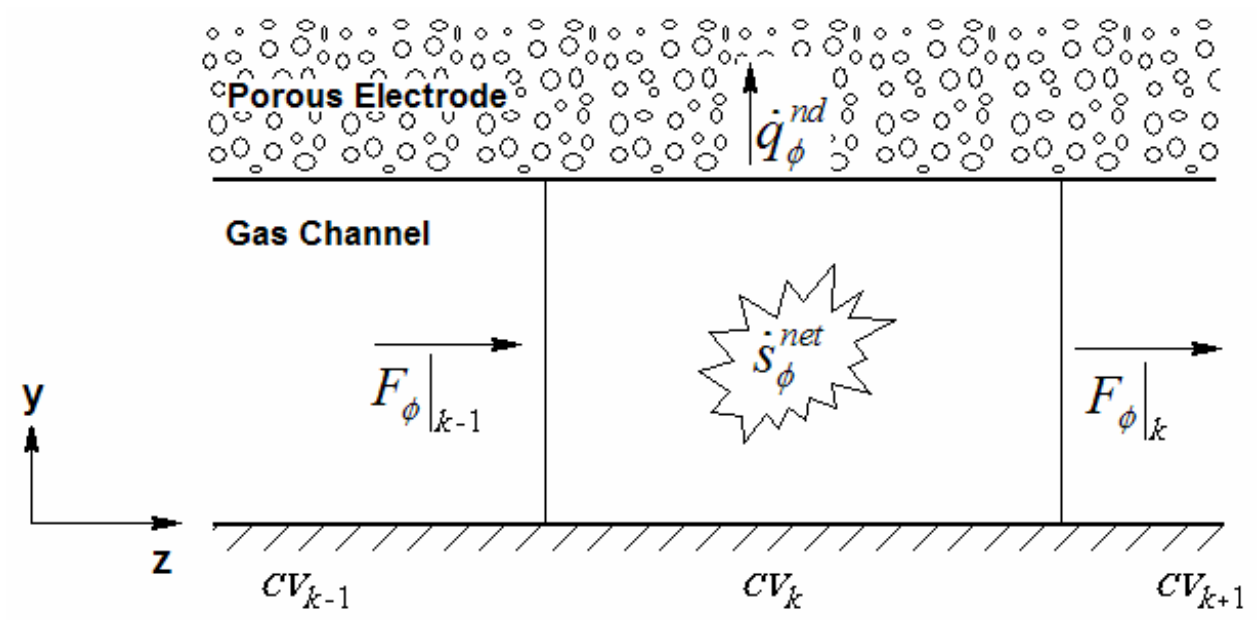

Figure 3.1: Control volume used for one dimensional gas channel model

Consider a fuel cell gas channel as shown in Fig.3.1. The control volume, under study encompasses the whole cross-section of the gas channel in $x$ - and $y$-directions ( $x$-direction is normal to the plane of the paper) and is one grid length deep in z-direction. Let $\phi$ be the cross-section averaged value of a conserved scalar expressed in per unit mass basis. The conservation equation for $\phi$ can be written as

$$
\frac{\partial}{\partial t}(\rho A \phi)=-\frac{\partial}{\partial z}(A \rho u \phi)+\frac{\partial}{\partial z}\left(A \Gamma \frac{\partial \phi}{\partial z}\right)-\dot{Q}_{\phi}^{n d}+A \dot{s}_{\phi}^{\text {net }}
$$

Where $A$ is the cross-sectional area of the channel, $u$ is the velocity, $\Gamma$ is the effective diffusion coefficient, $B$ is the perimeter of the channel, $\dot{q}_{\phi}^{\text {nd }}$ is the normal flux (across the channel walls) of the scalar, and $\dot{S}_{\phi}^{\text {net }}$ is the net 
source. The conservation equation for any particular scalar can be derived form Eq. (3-14) by substituting appropriate variables, constants, and expressions. It has to be noted that, in the present case, the normal flux of the scalar, $\dot{q}_{\phi}^{\text {nd }}$, is calculated from the three-dimensional solution inside the solid and porous regions as.

$$
\dot{Q}_{\phi}^{\text {nd }}=\int_{\text {wall surface }} \varepsilon_{p} \dot{q}_{\phi}^{\text {nd }} d b
$$

\subsubsection{Mass conservation}

The mass conservation equation for a gas channel can be obtained by substituting $\phi=1$ in the general scalar transport equation Eq.(3-14)

$$
\frac{\partial(\rho A)}{\partial t}=-\frac{\partial(\rho A u)}{\partial z}-\dot{Q}_{m}^{n d}
$$

\subsubsection{Specie conservation}

For the specie conservation equation, the general scalar $\phi$ is replaced by the specie mass fraction $X_{s}$ in Eq. (3-14).

$$
\frac{\partial\left(\rho A X_{s}\right)}{\partial t}=-\frac{\partial\left(\rho A X_{s}\right)}{\partial z}-\dot{Q}_{s}^{n d}
$$

Here, the diffusion in the direction of flow is neglected as the transport process is dominated by convection.

The normal diffusion flux of the specie, $\dot{Q}_{s}^{n d}$, is calculated using Eq. (3-15) where $\dot{q}_{s}^{\text {nd }}$ is given by 


$$
\dot{q}_{s}^{n d}=K_{s}^{c}\left(X_{s}-X_{s}^{w}\right)
$$

where $K_{s}^{c}$ is the mass transfer coefficient between the gas channel and the porous electrode surface (channel wall) and $X_{s}^{w}$ is the mass fraction of the specie inside the porous electrode near the surface. The total normal flux of mass into the porous electrode, as used in Eq. (3-16), is given by

$$
\dot{Q}_{m}^{\text {nd }}=\sum_{\text {all s }} \dot{Q}_{s}^{\text {nd }}
$$

\subsubsection{Momentum conservation}

Momentum equation can be obtained by substituting velocity for the generic scalar in Eq. (3-14).

$$
\frac{\partial(\rho A u)}{\partial t}=-\frac{\partial}{\partial z}\left(\rho A u^{2}\right)-\dot{Q}_{m}^{n d} u+A \frac{d P}{d z}-\left(1-\varepsilon_{p}\right) B \frac{C_{f}}{2} \rho|u| u
$$

Here, $C_{f}$ is the friction factor. Note that the factor $\left(1-\varepsilon_{p}\right)$, which represents the fraction of wall surface with solid interface, takes into account the area on the surface of the channels, where there is suction or injection. The source terms in Eq. (3-20) are the contributions from pressure gradient and friction loss. Also, note that the diffusion in the direction of flow is neglected.

\subsubsection{Energy conservation}

For the energy equation, the generic scalar in Eq. (3-14) is replaced by enthalpy (note that the ideal gas approximation, $d h=C_{p} d T$, is used). 


$$
\begin{aligned}
\frac{\partial}{\partial t}\left(\rho A C_{p} T\right)= & -\frac{\partial}{\partial z}\left(\rho A u C_{p} T\right)+\frac{\partial}{\partial z}\left(A \Gamma \frac{\partial C_{p} T}{\partial z}\right)-\sum_{\text {all s }} \dot{Q}_{s}^{n d} C_{p s} T \\
& -\left(1-\varepsilon_{p}\right) B h_{\text {con }}\left(T-T_{w}\right)+A \frac{D P}{D t}+\left(1-\varepsilon_{p}\right) B \frac{C_{f}}{2} \rho|u| u^{2}
\end{aligned}
$$

Here, $C_{p s}$ is the specific heat of the specie ' $s$ ' and $h_{c o n}$ is the convection heat transfer coefficient between channel and wall. The source terms in Eq.(3-21) are the contributions of convection heat transfer to walls, pressure work and frictional heating.

Equations (3-7) through (3-21), along with the electrochemistry model described in Chapter 5, completely describe the transient operation of a fuel cell. When solved simultaneously, they produce three-dimensional distributions of scalars inside the solid and porous regions and onedimensional variations inside the channels. 


\section{CHAPTER 4: \\ NUMERI CAL I MPLEMENTATI ON}

\subsection{I ntroduction}

The mathematical model presented in chapter 3 consists mostly of partial differential equations representing conservation laws for which Computational Fluid Dynamics (CFD) methods are the best suited as solution techniques. The partial differential equations are first reduced to a linear system of equations in terms of variable values at discrete points inside the calculation domain by a process called discretization. The system of linear equations is then solved to obtain a discrete numerical solution. In this chapter, the discretization process for the general transport equation is presented which can be used for each of energy, species, current and pressure equations is.

Applying boundary conditions is straight forward if the derivative (Neumann condition) or the value (Dirichelet condition) at the boundary is given. However, special approaches were needed for setting up boundary conditions for electric potential field based on prescribed total current, which are described in Sec. 4.3. Discretization schemes used for one-dimensional equations are presented in Sec. 4.4. Numerical techniques used in combining the two models are presented in Sec 4.5 followed by a description of the computer code used for the solution at the end of the chapter. 


\subsection{Discretization of Three Dimensional Equations}

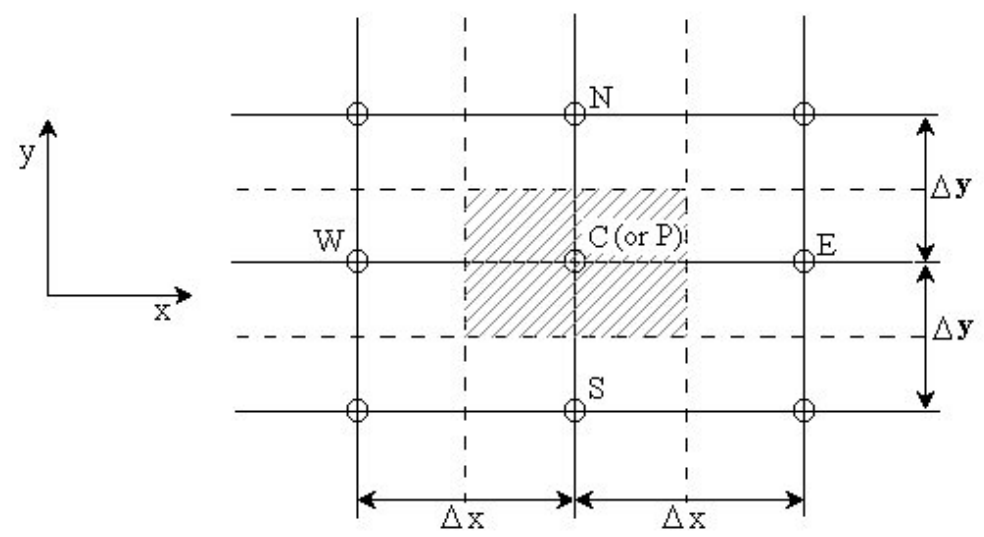

Figure 4.1: Geometry of the system used in the simulations.

The conservation equation in terms of a general scalar, $\phi$ is

$$
\frac{\partial}{\partial t}(\varepsilon \rho \phi)+\frac{\partial}{\partial x_{j}}\left(\varepsilon \rho u_{j} \phi-\varepsilon \Gamma^{e f f} \frac{\partial \phi}{\partial x_{j}}\right)=\varepsilon \rho S_{\phi}+a_{s p} f_{I, \phi}
$$

In the above equation, $\phi$ is generalized scalar variable, $\varepsilon$ is the volume fraction, $\rho$ is the density of the medium, $u_{j}$ is the $j^{\text {th }}$ component of effective velocity, $\Gamma$ is the effective diffusion coefficient, $S_{\phi}$ is the source term and $f_{I}$ is the interface flux transfer, $a_{s p}$ is the specific surface area( i.e. area per unit volume)

Control volume method was used for discretization with fully explicit discretization for the convection term (Note: in fuel cell applications, convection in the pores is very small compared to diffusion or conduction) and Crank Nicolson scheme applied to diffusion terms to stabilize the method. Control volume method involves integrating the PDE (partial differential equation) over a small control volume encompassing a grid node. A typical control volume is shown in Fig 4.1 where solid lines are the grid lines joining the adjacent grid nodes and the dashed lines represent the 
control volume faces. It is customary in CFD literature to refer to the neighboring nodes around the control volume of interest as north, east, south and west nodes. Adjacent nodes in the other direction (normal to the plane of the paper), not shown in the figure are referred to as top and bottom nodes. The variables at various nodes are accordingly subscripted using the letters $N, E, S$ etc. The variables at the faces of the control volume are subscripted using same convention but small letters $n, e, s$ etc. Explicit discretization of a space derivative means that the values from known previous time solution are used whereas unknown new time step values are used in implicit discretization. Crank Nicolson method utilizes an average of new and old time values and thus is more accurate. Integration of Eq. (4-1) over a control volume(see Fig. 4.1) will yield

$$
\begin{aligned}
\frac{\partial}{\partial t}(\varepsilon \rho \phi \Delta \forall)= & -F_{C}^{0}+\alpha F_{D}^{0}+(1-\alpha) F_{D}+(1-\alpha)\left(\varepsilon \rho \Delta \forall S_{\phi} \phi\right)_{p}^{0}+\varepsilon \rho \Delta \forall S_{\phi, c}^{0} \\
& +\alpha\left(\varepsilon \rho \Delta \forall S_{\phi} \phi\right)_{p}
\end{aligned}
$$

Where the superscript $\left({ }^{0}\right)$ denotes a value evaluated at the old time level, $\alpha$ is the implicitness factor, $F_{C}$ and $F_{D}$ denote the net convection and diffusion fluxes through the control volume faces which are given respectively, by

$$
\begin{gathered}
F_{D}=-\left[D_{e}-D_{w}+D_{n}-D_{s}+D_{t}-D_{b}\right] \\
F_{c}=-\left[C_{e}-C_{w}+C_{n}-C_{s}+C_{t}-C_{b}\right]
\end{gathered}
$$

Here ' $C$ 's and ' $D$ 's are the convection and diffusion fluxes through a face as indicated by their subscript. For examples convection and diffusioin fluxes for east and north faces are 


$$
\begin{gathered}
C_{e}=\left(A_{e} \varepsilon \rho u \phi\right)_{e} ; \quad C_{n}=\left(A_{e} \varepsilon \rho v \phi\right)_{n} \\
D_{e}=\left(A \Gamma \varepsilon \frac{\partial \phi}{\partial x}\right)_{e} ; \quad D_{n}=\left(A \Gamma \varepsilon \frac{\partial \phi}{\partial y}\right)_{n}
\end{gathered}
$$

Where $A$ is the cell face area. Similar expressions were used for the other faces.

If the source term is a non-linear function of the dependent variable, it is linearized such that

$$
\bar{S}_{\phi}=\frac{1}{\varepsilon \rho \Delta \forall} \int S_{\phi} d \forall=S_{p} \phi_{P}+S_{c}
$$

With the condition $S_{p} \leq 0$ for stability requirements.

Eq. (4-2) can be written as

$$
\begin{aligned}
& (\varepsilon \rho)^{0} \frac{\partial \phi}{\partial t}=F_{R H S}^{0}+\frac{\alpha}{\Delta \forall} F_{D}-\phi \frac{\partial}{\partial t}(\varepsilon \rho)+\left(\frac{1}{2} \varepsilon \rho S_{\phi} \phi\right)_{P} \\
& F_{R H S}^{0}=\frac{1}{\Delta \forall}\left(-F_{C}^{0}+(1-\alpha) F_{D}^{0}\right)
\end{aligned}
$$

The diffusion fluxes are discretized implicitly for example

$$
D_{e}=\left(\frac{A \Gamma \varepsilon}{\Delta x}\right)_{e}\left(\phi_{E}-\phi_{P}\right) ; \quad D_{n}=\left(\frac{A \Gamma \varepsilon}{\Delta y}\right)_{n}\left(\phi_{N}-\phi_{P}\right)
$$

Similar expressions were used for the other terms. The time derivative is discretized as 


$$
\frac{\partial \phi}{\partial t}=\frac{\phi_{p}-\phi_{p}^{o}}{\Delta t}
$$

Substituting Eqs. (4-9 \& 4-10) into (4-8) and rearranging yields

$$
\begin{gathered}
\left(a_{P}^{o}-\rho_{p}^{o} \varepsilon_{p}^{o} S_{p}+a_{p}\right) \phi_{P}=\sum a_{n n} \phi_{n n}+F_{R H S}^{o}-\phi_{P}^{o} S_{m}+a_{P}^{o} \phi_{P}^{o} \\
a_{P}^{o}=\frac{\varepsilon \rho}{\Delta t} ; \quad S_{m}=\frac{\partial}{\partial t}(\varepsilon \rho) \\
a_{P}=\sum a_{n n} ; \quad n n: E, W, N, S, T, B
\end{gathered}
$$

"nn" denotes neighboring nodes. The neighboring node coefficients are as follows for east and north respectively

$$
a_{E}=\left(\frac{A \Gamma \varepsilon}{\Delta x}\right)_{e}, \quad a_{N}=\left(\frac{A \Gamma \varepsilon}{\Delta y}\right)_{n}
$$

When written for each node in the calculation domain, Eq. (4-11) will form a linear system of equations in terms of $\phi$ at the discrete locations. The system of equations can be solved numerically to obtain the solution. For the details of the finite volume method employed for discretization, the reader is referred to Patankar [42].

\subsection{Boundary Conditions}

It is quite straight forward to set the boundary conditions for the numerical method described above if either scalar value (Dirchlet condition) or the derivative of the scalar (Neumann condition) is given at the 
boundaries. However, sometimes we may be given some other condition. Here, we formulate procedures to set up boundary conditions for electric potential equation given the total current as the constraint.

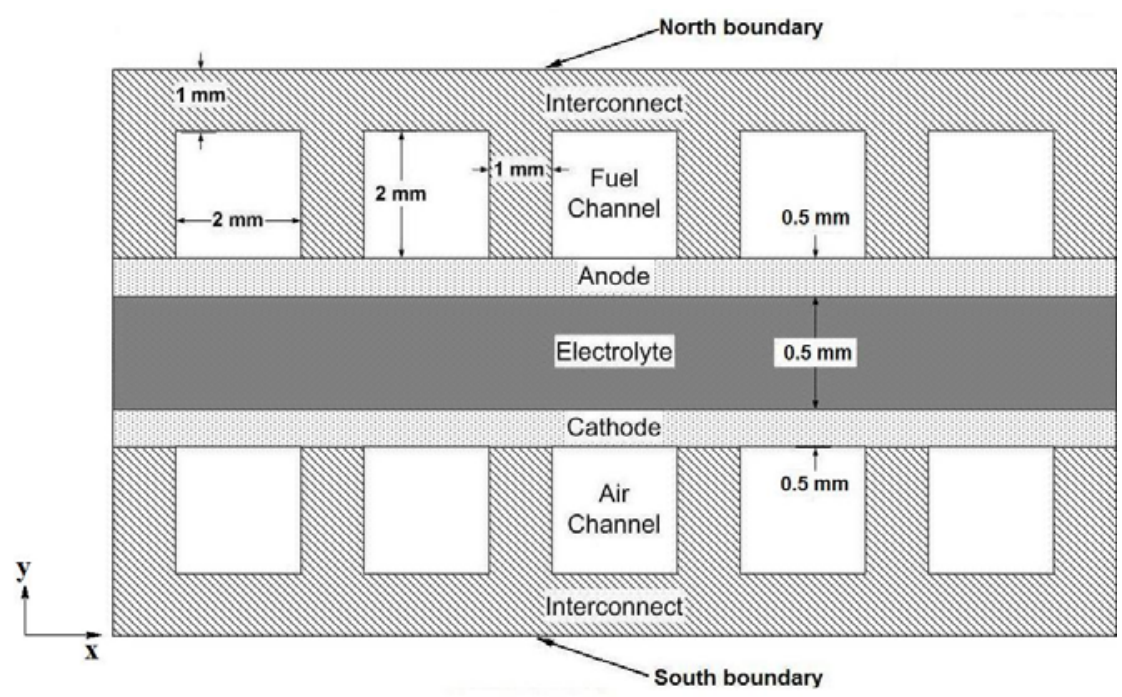

Figure 4.2: Schematic of the boundaries of the test domain

\subsubsection{Drichlet boundary condition for electric potential}

If one makes the assumption that the north boundary in Fig. 4.2 is a constant potential line and let $\varphi=\varphi_{\mathrm{nb}}$, this unknown value can be determined using an iterative technique. To start the calculations, we let

$$
\varphi_{n b}^{*}=-\frac{\left(I / A_{n b}\right)}{\sigma_{r e f}} y_{T}+\varphi_{s b}
$$

Where $I$ is the total current, $A_{n b}$ is the surface area available to current flow, $\mathrm{y}_{\mathrm{T}}$ is the total height of the calculation domain, $\sigma_{\mathrm{ref}}$ is a properly selected reference electric conductivity, and $\varphi_{\mathrm{sb}}$ is the value of the potential at the south boundary which is arbitrarily chosen to be 0 . 
In the subsequent iterative calculations, a correction should be applied to $\varphi_{\mathrm{nb}}{ }^{*}$ so that

$$
\Delta I=I-I^{*}=I-\sum_{j k} \sigma \frac{\partial \varphi^{*}}{\partial y} \Delta A
$$

is driven to zero such that the final solution satisfies the prescribed total current constraint. The summation is over the computational cells on the north boundary. Let $(\partial \varphi / \partial y)$ be the desired derivative at the north boundary. $\mathrm{Eq}(4-15)$ can be written as

$$
\Delta I=-\sum \frac{\sigma \Delta A}{\Delta y / 2}\left[\left(\varphi_{n b}-\varphi_{n y m 1}\right)-\left(\varphi_{n b}^{*}-\varphi_{n y m 1}^{*}\right)\right]
$$

Here the starred variables denote the approximate values evaluated with $\varphi_{\mathrm{nb}}{ }^{*}$ from the previous iteration, and the subscript 'nym1' denotes the values at the grid node $j=n y-1$. Note also that $\Delta y$ is the length of the computational cell; the north boundary is located in the middle of this cell. We seek a correction of the form

$$
\Delta \varphi_{n b}=\left(\varphi_{n b}-\varphi_{n b}^{*}\right)=\text { const }
$$

If we assume that

$$
\Delta \varphi_{n y m 1}=\varphi_{n y m 1}-\varphi_{n y m 1}^{*}=\gamma^{*} \Delta \varphi_{n b}
$$

$\mathrm{Eq}(4-16)$ can be solved to determine $\Delta \varphi_{\mathrm{nb}}$ form 


$$
\Delta \varphi_{n b}=\frac{\gamma \Delta I(\Delta y / 2)}{-\sum-\sigma \Delta A}
$$

where $\gamma=1 /\left(1-\gamma^{*}\right)$ can be interpreted as a relaxation factor. Both under relaxation and over relaxation may be necessary to achieve convergence. Thus, the iterative correction to $\varphi_{n b}$ becomes

$$
\varphi_{n b}^{\text {new }}=\varphi_{n b}^{\text {old }}+\gamma \Delta \varphi_{\text {old }}
$$

\subsubsection{Neumann boundary for Electric Potential}

The derivative of the electric potential at the E/C interface (see Fig. 4.2) can be specified if the current density is known. The following iterative procedure has been formulated for the present application. Let initially

$$
i^{*}=-\left(\sigma \frac{\partial \varphi}{\partial y}\right)_{n b}^{*}=\frac{I}{A_{E / C}}
$$

where $A_{E / C}$ is the active surface area of the electrolyte- cathode interface. Subsequently, the current density $i^{*}$ should be corrected to match the required total current.

We assume that the current density profile at the $\mathrm{E} / \mathrm{C}$ interface is similar to that which is computed at the last grid node, i.e. $\mathrm{j}=\mathrm{ny}-1=\mathrm{nym} 1$ just inside the cathode, and postulate that

$$
i_{n b}=i_{\text {nym } 1}^{*}+\Delta i
$$




$$
\int_{A} i d A=I
$$

Eq. (4-23) yields

$$
\Delta i=\frac{\left(I-I^{*}\right)}{A_{n b}}=\frac{\Delta I}{A_{n b}}
$$

After each iteration $\Delta I$ is calculated from (4-23) and $i_{n b}$ is calculated from Eq. (4-22), which in turn, yield a Neuman condition on $\varphi$, i.e.

$$
\left(\frac{\partial \varphi}{\partial y}\right)_{n b}= \begin{cases}-i_{n b} / \sigma_{n b} & \text { if } i_{n b}>0 \\ 0 & \text { otherwise }\end{cases}
$$

Eventually, when the iterations converge, $\Delta \mathrm{i}=\Delta \mathrm{I}=0$. This means that

$$
\left(\sigma \frac{\partial \varphi}{\partial y}\right)_{n b}=\left(\sigma \frac{\partial \varphi}{\partial y}\right)_{n y m 1}
$$

\subsection{Discretization of One-Dimensional Equations}

The one-dimensional general scalar transport equation and the mass conservation equation for a gas channel are

$$
\begin{gathered}
\frac{\partial}{\partial t}(\rho A \phi)=-\frac{\partial}{\partial z}(A \rho u \phi)+\frac{\partial}{\partial z}\left(A \Gamma \frac{\partial \phi}{\partial z}\right)+s_{p} \phi+s_{p} \\
\frac{\partial(\rho A)}{\partial t}=-\frac{\partial(\rho A u)}{\partial z}+s_{m}
\end{gathered}
$$


Which are same as Eqs. (3-14 \& 3-16) except that the source terms are redistributed as a linear function of $\phi\left(s_{p} \phi\right)$ and a constant $\left(s_{c}\right)$ in Eq. (3-14) and the source term in Eq. (3-16) is renamed as $s_{m}$. This was done for the purpose of brevity during dicretization. Equation (4-28) is multiplied by the scalar $\phi$ and discretized along with Eq. (4-27) using same technique as used in Sec. 4.2 for discretization of three-dimensional equations. The discretized equations are

$$
\begin{aligned}
& \frac{\Delta x\left[(\rho A \phi)_{P}^{n+1}-(\rho A \phi)_{P}^{n}\right]}{\Delta t}=-\left[(\rho A u \phi)_{e}^{n+1}-(\rho A u \phi)_{w}^{n+1}\right]+ \\
&\left(A \Gamma \frac{\partial \phi}{\partial z}\right)_{e}^{n+1}-\left(A \Gamma \frac{\partial \phi}{\partial z}\right)_{w}^{n+1}+s_{p} \phi \Delta x+s_{c} \Delta x \\
& \frac{\Delta x \phi_{p}^{n+1}\left[(\rho A)_{P}^{n+1}-(\rho A)_{P}^{n}\right]}{\Delta t}=-\phi_{p}^{n+1}\left[(\rho A u)_{e}^{n+1}-(\rho A u)_{w}^{n+1}\right]+s_{m} \phi^{n} \Delta x
\end{aligned}
$$

Subtracting

$$
\begin{array}{r}
\frac{\Delta z}{\Delta t}(\rho A)_{P}\left(\phi_{P}^{n+1}-\phi_{P}^{n-1}\right)=-\left[(\rho A u)_{e}\left(\phi_{e}^{n+1}-\phi_{P}^{n+1}\right)-(\rho A u)_{w}\left(\phi_{w}^{n+1}-\phi_{P}^{n+1}\right)\right] \\
\left(A \Gamma \frac{\phi_{E}-\phi_{P}}{\Delta z}\right)_{e}^{n+1}-\left(A \Gamma \frac{\phi_{P}-\phi_{W}}{\Delta z}\right)_{w}^{n+1}+s_{p} \phi \Delta z+s_{c} \Delta z-s_{m} \phi^{n} \Delta z
\end{array}
$$

The values of the scalar at the cell faces, $\phi_{e}$ and $\phi_{w}$, need to chosen depending on the direction of flow and the relative significance of convection and diffusion. A clever scheme (Patankar [42]) is used to automatically select the appropriate approximation for the cell face value during the calculations. The resulting equation is 


$$
a_{P} \phi_{P}=a_{E} \phi_{E}+a_{W} \phi_{W}+q_{P}
$$

where

$$
\begin{gathered}
a_{E}=\max \left\|(A \rho u)_{e},\left(A \rho u-\frac{A \Gamma}{\Delta x}\right)_{e}, 0\right\| ; a_{W}=\max \|(A \rho u)_{w},\left(A \rho u-\frac{A \Gamma}{\Delta x}\right)_{w}, 0 \rrbracket \\
a_{P}=\frac{\rho A \Delta z}{\Delta t}+a_{E}+a_{W}-s_{p} \Delta z \\
q_{p}=\frac{\Delta z}{\Delta t}(\rho A \phi)_{P}^{n}+s_{c} \Delta z
\end{gathered}
$$

The scheme used above is known as hybrid scheme where the average of adjacent node values is used as the cell face value when diffusion is important. When the flow is dominated by convection, one of the node (upwind) values is used depending on the direction of flow. The resulting linear system of equations can be solved using Tri-Diagonal Matrix Algorithm (TDMA).

The above method is used for specie and temperature equations, Eqs. (3-17 \& 3-21). The mass and momentum equations, Eqs. (3-16 \& 3-20), are used to solve for velocity and pressure variations along the channels. Explicit discretization was used for these equations and their final forms are

$$
(v)_{i}^{n+1}=\frac{(\rho A v)_{i-1}^{n+1} \Delta t-\left[(\rho A)_{i}^{n+1}-(\rho A)_{i}^{n}\right] \Delta z+B \dot{q}_{m}^{n d} \Delta z \Delta t}{(\rho A)_{i}^{n+1} \Delta t}
$$

and 


$$
P_{i}^{n}=\frac{\left[\left(\rho A v^{2}\right)_{i}^{n}-\left(\rho A v^{2}\right)_{i-1}^{n}\right] \Delta t+\left[(\rho A v)_{i}^{n}-(\rho A v)_{i}^{n-1}\right] \Delta x+A P_{i-1}^{n} \Delta t+s \Delta t \Delta x}{A \Delta t}
$$

where

$$
s=\left(B \frac{C_{f}}{2} \rho|v| v+B \dot{q}_{m}^{n d} v\right)
$$

is the source (or sink) of momentum due to pressure wall friction and mass flux across the wall.

\subsection{Modeling I ssues}

There are some other issues that need to be addressed before the model equations can be solved. They are handling of the discontinuity in electric potential at the electrode/electrolyte interfaces, heat and mass fluxes across the channel walls and the reacting species at the active areas. This section describes the methodologies adopted for these aspects.

\subsubsection{Source Term for Electric Potential Field.}

A novel approach was proposed in Celik et al. [43] to incorporate the potential jump at the electrode/electrolyte interfaces using dipole disribution. Subsequently, it was discovered that the new technique was using the following source terms at the interfaces which are directly used in the current study.

If the potential jump across the interface is known to be $\mathrm{V}$ volts, then the source term in the computational cell immediately before the interface is 


$$
s_{\varphi}=-V\left(\frac{\sigma A}{\Delta y}\right)_{\text {int erface }}
$$

The source term for computational cell immediately after the interface is

$$
S_{\varphi}=V\left(\frac{\sigma A}{\Delta y}\right)_{\text {interface }}
$$

\subsubsection{Convective Heat and Mass Transfer in Gas Channels}

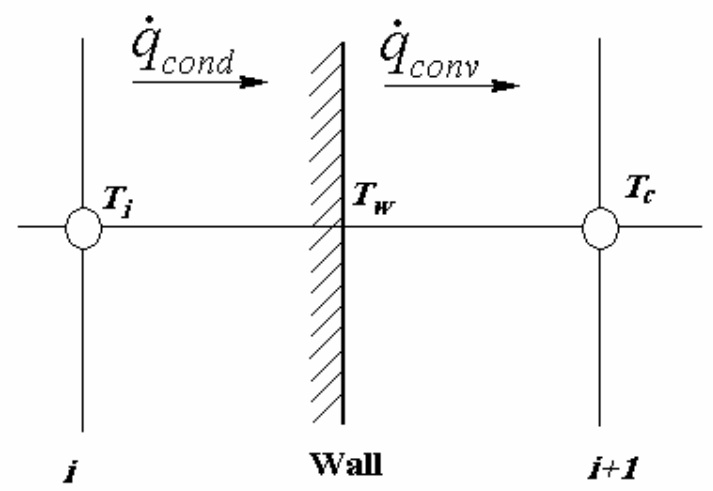

Figure 4.3: Schematic of gas channel solid region interface

When solving the three-dimensional equations, the temperature and concentrations inside the channels are assigned fixed values as calculated from the one-dimensional model. The three-dimensional model still sees the channel regions as a part of domain but is not allowed to alter the solution in those regions. During the calculations, the heat flux at the interface of a wall and a gas channel (shown in Fig. 4.3) should be set to the convective heat flux given by 


$$
\dot{q}_{\text {conv }}=h A\left(T_{i}-T_{c}\right)
$$

Here, the temperature inside the channel $T_{c}$ is assumed to be known. $h$ is the convection heat transfer coefficient and $A$ is the surface area. However, the general equation for heat flux across any cell face is given by the conduction equation

$$
\dot{q}_{\text {cond }}=-\left.k A \frac{d T}{d x}\right|_{\text {interface }}
$$

This in discretized form is

$$
\dot{q}_{\text {cond }}=-k_{i} A \frac{\left(T_{c}-T_{i}\right)}{\Delta x}
$$

Here $k_{i}$ is the thermal conductivity at the interface. The heat flux given by Equation.(4-43) can be easily set to the flux given by Equation.(4-41) by altering the thermal conductivity at the interface as.

$$
k_{i}=h \Delta x
$$

This, in effect, alters the conductivity at the interface solely depending on the convection heat transfer coefficient between the wall and the gas channel. By doing so, it is ensured that the heat flux at the gas channel wall interface is convection flux rather than diffusion (conduction) flux. Hence, the required modification is achieved by simply changing the property value, rather than changing the equation itself. 
On similar lines, the mass flux of specie ' $s$ ' across the gas channel and the porous electrode should be set to the convective mass flux given by the equation

$$
\dot{m}_{s}^{\text {conv }}=k_{c, s} A\left(X_{c}-X_{s, j}\right)
$$

instead of the general diffusion flux equation used for all other cell faces

$$
\dot{m}_{s}^{\text {diff }}=-\left.\Gamma_{s}^{e \text { eff }} \frac{\partial X_{s}}{\partial y}\right|_{\text {electrode/ gaschannel interface }}
$$

Here the concentration of specie $\mathrm{s}$ inside the gas channel $X_{c}$ is assumed to be known. $k_{c, s}$ is the mass transfer coefficient of specie s.

This is achieved by altering the diffusion coefficient at the interface using the equation

$$
\Gamma_{s}^{e f f}=k_{c, s} \Delta y
$$

The heat transfer coefficient $h$ and the mass transfer coefficient $k_{c, s}$ are calculated using reasonable estimates for the channel Nusselt number and Sherwood number for the mass transfer across porous wall channel interface. The Sherwood number used was 2.0 for both air and fuel channels, and Nusselt numbers used were in the range $1.0-5.0$. 


\subsubsection{Heat Sources Due to Specie Fluxes}

Since convection inside the porous regions is neglected, the enthalpy entering the electrodes at the electrode/gas channel interface due to the mass flux is accounted for using the following source term in the energy equation.

$$
s_{h}^{m f}=\sum_{\text {all } s} \dot{q}_{s}^{\text {nd }} C_{p s}
$$

Similarly at the Cathode/Electrolyte interface, some of the oxygen inside the pores enters the electrolyte as an oxide ion producing ions. Thus, corresponding amount of enthalpy is used as a sink in the energy equation near the interface. Also at the Anode/Electrolyte interface, where hydrogen reacts with the oxide ions to form water vapor, appropriate source terms are included in the enthalpy equation. i.e at Cathode/Electrolyte interface

$$
S_{h}^{C / E}=-\dot{m}_{O_{2}}^{\text {reac }} C_{p, O_{2}}
$$

and at Electrolyte/Anode interface

$$
s_{h}^{E / A}=-\dot{m}_{H_{2}}^{\text {reac }} C_{p, H_{2}}+\dot{m}_{H_{2} \mathrm{O}}^{\text {reac }} C_{p, H_{2} \mathrm{O}}
$$

Here $\dot{m}_{\mathrm{O}_{2}}^{\text {reac }}, \dot{m}_{\mathrm{H}_{2}}^{\text {reac }}$ and $\dot{\mathrm{m}}_{\mathrm{H}_{2} \mathrm{O}}^{\text {reac }}$ are the rates of consumption or production of oxygen hydrogen and water vapor respectively due to the electrochemical reactions at the active interfaces. 


\subsection{I mplementation of the Model}

The FORTRAN program that solves the model equations is developed on the foundation of a multi-dimensional CFD code, DREAM (Badeau [44], Li [45], and Hu [46]) originally developed by Dr. Ismail Celik and hence is named as DREAM-SOFC. The three dimensional model of the DREAM-SOFC is mostly based on DREAM. The one dimensional model is built on a onedimensional transient solver for transport phenomenon, also originally developed by Dr. Celik (Celik et al [47]). DREAM-SOFC is written for transient simulations and the sequential steps for the solution are as follows

1. Intialize all the variables

2. Start the time loop

3. Solve for electric potential inside the solid and porous regions

4. Calculate the fluxes of heat and mass across the channel walls

5. Solve for velocity pressure, concentrations and temperature inside the channels using the calculated fluxes

6. Solve for temperature inside the solid and porous regions

7. Solve for concentrations inside the gas phase of porous regions

8. Solve the electrochemistry model 


\section{End time iterations}

The model uses rectangular grid. The grid employed is usually a block uniform grid to accommodate components with different length scales using reasonable number of grid locations. The geometry of the fuel cell is input through a three-dimensional integer array. The array can be easily created using a simple computer program given the dimensions of the cell. This is an advantage over commercial modeling tools which require a considerable amount of time to create or modify a geometry due to their generic nature. 


\section{CHAPTER 5: \\ ELECTROCHEMI STRY MODEL}

\subsection{I ntroduction}

Detailed micro-modeling of fuel cells using computational fluid dynamics (CFD) requires constitutive equations for the electro-chemistry. These models require that physical parameters as well as material properties such as transfer coefficient, exchange current density, effective diffusivity, the limiting current etc be empirically determined. Moreover, in most studies the Nernstian potential (also referred to as electromotive force, e.m.f) is used as an input to the computational model with some estimated values for the above mentioned parameters. In many such studies (see for example Achenbach [30], He and Chen [31, 32], Aguiar et al [29]) usually the variation of partial pressures inside the electrolyte is neglected and only the over all reaction is considered for the purpose of calculation of the ideal cell voltage, which is later corrected for other losses. For example, for a purely $\mathrm{H}_{2}-\mathrm{O}_{2}$ solid oxide fuel cell (SOFC), the overall reaction is given by

$$
\mathrm{H}_{2}+\frac{1}{2} \mathrm{O}_{2} \rightarrow \mathrm{H}_{2} \mathrm{O}(\mathrm{g})
$$

The Nernst potential for this reaction, for a fuel cell operating at atmospheric pressure (pressurized fuel cells are not considered in this study), is given by 


$$
\Delta E_{E q}=-\frac{\Delta G^{0}}{2 F}-\frac{R T}{2 F} \ln \left(\frac{Y_{\mathrm{H}_{2} \mathrm{O}}}{Y_{\mathrm{H}_{2} \mathrm{O}_{2}}}\right)
$$

Where, $\Delta G^{0}$ is the standard Gibbs free energy change for the reaction in Eq. (1), $F$ is the Faraday's constant, $R$ is universal gas constant, $T$ is the temperature, $Y_{\mathrm{H}_{2}}$ and $Y_{\mathrm{H}_{2} \mathrm{O}}$ are the mole fractions of hydrogen and water vapor on the anode side and $Y_{\mathrm{O}_{2}}$ is the mole fraction of oxygen on the cathode side. This approach does not discriminate between the electrochemical processes that occur on the cathode side and those that occur on the anode side. Thus, it is not suitable for detailed micro-modeling especially when the variations within the electrolyte can be significant, e.g. in case of electrolyte supported fuel-cells.

In more careful studies ( e.g. Ferguson et al [27] and Barrendrecht [48]), the total e.m.f is divided into two parts, namely one part for the cathode/electrolyte $(\mathrm{C} / \mathrm{E})$ interface, $\Delta E_{C / E}$, and one for the electrolyte/anode (E/A) interface, $\Delta E_{E / A}$ (see Fig. 5.1) . Following Ferguson et al, one can write

$$
\begin{gathered}
\Delta E_{C / E}=\frac{R T}{2 F} \ln \left(Y_{O_{2}}^{1 / 2}\right)-\eta_{C} \\
\Delta E_{E / A}=-\frac{\Delta G^{0}}{2 F}-\frac{R T}{2 F} \ln \left(\frac{Y_{H_{2} O}}{Y_{H_{2}}}\right)-\eta_{A}
\end{gathered}
$$

Where $\eta_{C}$ and $\eta_{A}$ are the polarization losses at cathode and anode respectively. These equations indicate that total Gibbs free energy that results from the over all reaction (Eq. (5-1)) is arbitrarily assigned to the E/A 
interface. Moreover, the oxide ion activity at either interface is not accounted for. Thus, this equation may not lead to a true picture as far as the variations of electric potential and hence the current density is concerned inside the electrolyte. A more appropriate model would be to include the activity of oxygen ion at both interfaces as, indeed, is done by Barrendrecht [48] Moreover, it seems reasonable to split the Gibbs free energy into two parts one for the overall reaction occurring at the $\mathrm{C} / \mathrm{E}$ interface, and one for those occurring at the $\mathrm{E} / \mathrm{A}$ interface.

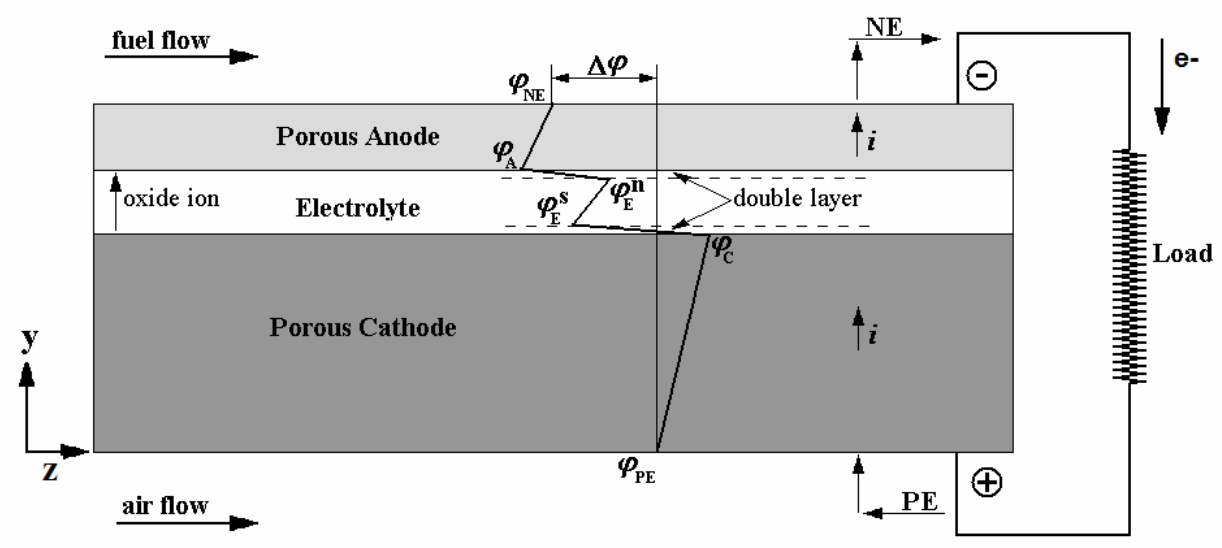

Figure 5.1: Schematic of variation of electric potential across a SOFC

The objective of this chapter is to lay the theoretical ground for such a formulation where the potential differences at the C/E and E/A interfaces are treated somewhat independently so that, for example, if a malfunctioning occurs at the C/E interface it can be detected by computer simulations. Further, the temperature, as well as the current density distributions within each component, i.e., C/E/A should also be modeled properly in order to study the transient behavior, structural compatibility and durability issues for fuel cells in general.

The ultimate goal is to use the proposed model in conjunction with the pseudo three dimensional transient CFD code, DREAM-SOFC. This chapter is devoted to the presentation and testing of theory underlying the proposed method within the framework of a simple SOFC arrangement. Though most 
of the equations in the model are valid regionally at each location, certain equations like the ohmic overpotential, limiting current for concentration potential are valid for the whole cell. These were required in order to model the whole cell as one unit, for simplicity, during testing.

\subsection{Theory And Analysis}

The overall half cell reactions in a SOFC are

At $C / E$ interface

$$
\frac{1}{2} \mathrm{O}_{2}+2 e^{-} \rightarrow \mathrm{O}^{=}
$$

At $\mathrm{E} / \mathrm{A}$ interface

$$
\mathrm{H}_{2}+\mathrm{O}^{=} \rightarrow \mathrm{H}_{2} \mathrm{O}+2 e^{-}
$$

The electric potential variation across the Positive electrodeElectrolyte-Negative electrode (PEN) assembly of a SOFC is depicted in Fig. 5.1. The sharp jumps in electric potential observed across the $C / E$ and $E / A$ interfaces due the electrochemical reactions Eq.(5-5) and Eq.( 5-6) respectively are given by (Barrendrecht [48] and Celik et al [43])

At the $C / E$ interface

$$
\varphi_{C}-\varphi_{E}^{s}=\Delta E_{C / E}=-\frac{\Delta G_{C / E}^{0}}{2 F}+\frac{R T}{2 F} \ln \left(\frac{Y_{O_{2}}^{1 / 2}}{Y_{O^{=}}}\right)_{C}-\eta_{C}
$$


At the $E / A$ interface

$$
\varphi_{E}^{n}-\varphi_{A}=\Delta E_{E / A}=-\frac{\Delta G_{E / A}^{0}}{2 F}-\frac{R T}{2 F} \ln \left(\frac{Y_{H_{2} O}}{Y_{H_{2}} Y_{O^{-}}}\right)_{A}-\eta_{A}
$$

Where $\Delta G_{C / E}^{0}$ and $\Delta G_{E / A}^{0}$ are the Gibbs free energy changes for the half cell reactions ( Eqs. 5-5 \& 5-6) at C/E and E/A interfaces respectively and $Y_{O}$ is the mole fraction of oxide ions inside the electrolyte. Here only electrolytes with negligible electron conductivity are considered, i.e. the ionic conductivity is dominant (see Zha et. al. [49] for more elaborate account of electrolytes with mixed conductivity). A possible reaction mechanism at the $C / E$ and $E / A$ interfaces may be written as follows

At the C/E interface

$$
\begin{gathered}
\frac{1}{2} O_{2(g)}+s \rightleftarrows O_{a} \\
O_{a}+V_{O}^{* *}+2 e_{(\text {cathode })}^{\stackrel{k_{f}}{\rightleftarrows}} O_{(Y S Z)}^{=}+s
\end{gathered}
$$

At $E / A$ interface

$$
\begin{gathered}
\mathrm{H}_{2}+2 \mathrm{~s} \rightleftarrows 2 \mathrm{H}_{a} \\
2 \mathrm{H}_{a} \rightleftarrows 2 \mathrm{H}^{+}+2 e^{-}+2 s \\
\mathrm{O}^{=}+2 \mathrm{H}^{+} \rightarrow \mathrm{H}_{2} \mathrm{O}(g)
\end{gathered}
$$


Where $s$ is a free adsorption site on the active surface, $V_{O}^{* *}$ is oxygen ion vacancy in the electrolyte lattice and subscript ' $a$ ' denotes adsorbed phase. Some investigators consider the presence of $\mathrm{O}_{2}$ on the anode side, albeit in very small concentrations (partial pressures in the order of $10^{-18}$ to $10^{-22}$ bars [49]). But, as a result of the above mechanism $\mathrm{O}_{2}$ concentrations cancel out of the e.m.f equation for the E/A interface.

Equations (5-7) \& (5-8) will reduce to those used by Ferguson et. al. [27] under the conditions that $\Delta G_{C / E}^{0}=0$ and, the mole fraction of Oxygen ion is equal to 1.0 , but the indication from experiments is that it is not. Bieberle and Gauckler [15] suggest that the concentration of oxide ions in YSZ is $4.45 \times 10^{4} \mathrm{~mol} / \mathrm{m}^{3}$ at $973 \mathrm{~K}$. Calculation of oxide ion concentration is described later in the section on bulk concentrations. The overall potential difference across the cell will be given by

$$
\varphi_{P E}-\varphi_{N E}=\Delta E_{\text {Cell }}=\Delta E_{C / E}+\Delta E_{E / A}-\eta_{R}
$$

Where $\eta_{R}$ is the ohmic loss due to cell resistance.

\subsubsection{Gibbs Free Energy Change for Half Reactions}

While the Gibbs free energy change for the overall cell reaction (Eq. (5-1)), $\Delta G^{0}$, is available in literature, that for either of the half reactions Eqs $(5-5) \&(5-6)$ is hard to find. It is proposed to calculate the standard Gibbs free energy change for the reaction in Eq. (5-5), $\Delta G_{C / E}^{0}$, from the reaction kinetics data from the literature (Bieberle and Gauckler [15]). Then the Gibbs free energy for the other half reaction can be calculated using $\Delta G_{E / A}^{0}=\Delta G^{0}-\Delta G_{C / E}^{0}$ 
Here, it is assumed that Eq. (5-10) is the rate determining step of the mechanism and that the reaction given in Eq. (5-9) does not cause any significant change in Gibbs free energy. Hence the Gibbs free energy change $\Delta G_{C / E}^{0}$ would be that for reaction in Eq. (5-10). In general, the standard Gibbs free energy change for a reaction is related to the equilibrium constant for the reaction (Moran and Shapiro [50] and Folger [51]) through

$$
\Delta G^{0}=-R T \ln (K)
$$

Where $K=k_{f} / k_{b}, k_{f}$ and $k_{b}$ being the forward and backward reaction rates, respectively (Fogler, [51]). These rate constants for reaction in Eq. (5-10) are estimated by Bieberle and Gauckler to be.

$$
k_{f}=k_{f}^{0} \exp \left(-\alpha_{C}^{f} f \eta_{C}\right) ; k_{b}=k_{b}^{0} \exp \left(-\alpha_{C}^{b} f \eta_{C}\right)
$$

Here $\alpha_{C}^{f}$ and $\alpha_{C}^{b}$ are the cathodic (forward) and anodic (backward) transfer coefficients at the $\mathrm{C} / \mathrm{E}$ interface and $f=n F / R T$. It was assumed that $k_{f}^{0}$ and $k_{b}^{0}$ are constants for the purpose of this study and they were calculated from the values given for $k_{f}\left(=2 \times 10^{0} \mathrm{~s}^{-1}\right)$ and $k_{b}\left(=6 \times 10^{-4} \mathrm{~s}^{-1}\right)$ by Bieberle and Gauckler [15] at a specific temperature. At electrochemical equilibrium, the overpotential, $\eta=0$. Thus, the equilibrium constant of the reaction will be $K=k_{f}^{0} / k_{b}^{0}$.

\subsubsection{Overpotentials}

The over-potentials are the losses in potential when there is a net current flowing through the cell. These can be determined from the over 
potential equation (Bard and Faulkner [52]). At C/E interface, corresponding to overall cathode reaction Eq. (5-5):

$$
i=i_{0}^{c}\left[\frac{C_{O_{2}}}{C_{O_{2}}^{*}} \exp \left(-\alpha_{C}^{f} f \eta_{C}\right)-\frac{C_{O^{=}}}{C_{O^{=}}^{*}} \exp \left(\alpha_{C}^{b} f \eta_{C}\right)\right]
$$

where $i_{0}^{c}$ is the exchange current, $\alpha_{c}^{f}$ and $\alpha_{c}^{b}$ are the forward and backward transfer coefficients $\eta \mathrm{c}$ is over potential at cathode, $C_{\mathrm{O}_{2}}$ and $C_{\mathrm{O}_{2}}^{*}$ are the concentrations of Oxygen, $C_{O^{=}}$and $C_{O^{=}}^{*}$ are the concentrations of the oxide ion near the reaction site and away from it (bulk concentration inside the gas channel), respectively. The corresponding equation for the E/A interface for reactinon in Eq. (5-6) is

$$
i=i_{0}^{a}\left[\frac{C_{\mathrm{H}_{2}} C_{\mathrm{O}^{=}}}{C_{\mathrm{H}_{2}}^{*} C_{\mathrm{O}^{=}}^{*}} \exp \left(\alpha_{A}^{f} f \eta_{\mathrm{A}}\right)-\frac{C_{\mathrm{H}_{2} \mathrm{O}}}{C_{\mathrm{H}_{2} \mathrm{O}}^{*}} \exp \left(-\alpha_{A}^{b} f \eta_{\mathrm{A}}\right)\right]
$$

\subsubsection{Transfer Coefficients}

The transfer coefficients for an electrode reaction involving more than one elementary reaction step are given by Rubenstein [53]

$$
\alpha^{f}=\frac{\beta n_{R D S}+n_{\text {before }}}{v} ; \alpha^{b}=\frac{(1-\beta) n_{R D S}+n_{\text {after }}}{v}
$$

Here $\beta$ is the transfer coefficient for an elementary reaction, $n_{R D S}$ is the number of electrons transferred during the rate determining step(RDS) of the complex mechanism, $n_{\text {before }}$ is the number of electrons transferred before the rate determining, $n_{\text {after }}$ is the number of electrons transferred after the 
rate determining step for the overall reaction to be complete, and $v$ is the stoichiometric number (i.e., the number of times the RDS must take place in order for the overall reaction to occur once). In the present study, however, the transfer coefficients are assumed to be $\alpha^{f}=\beta$ and $\alpha^{b}=(1-\beta)$, which is the same as assuming the behavior to be similar to a single step reaction.

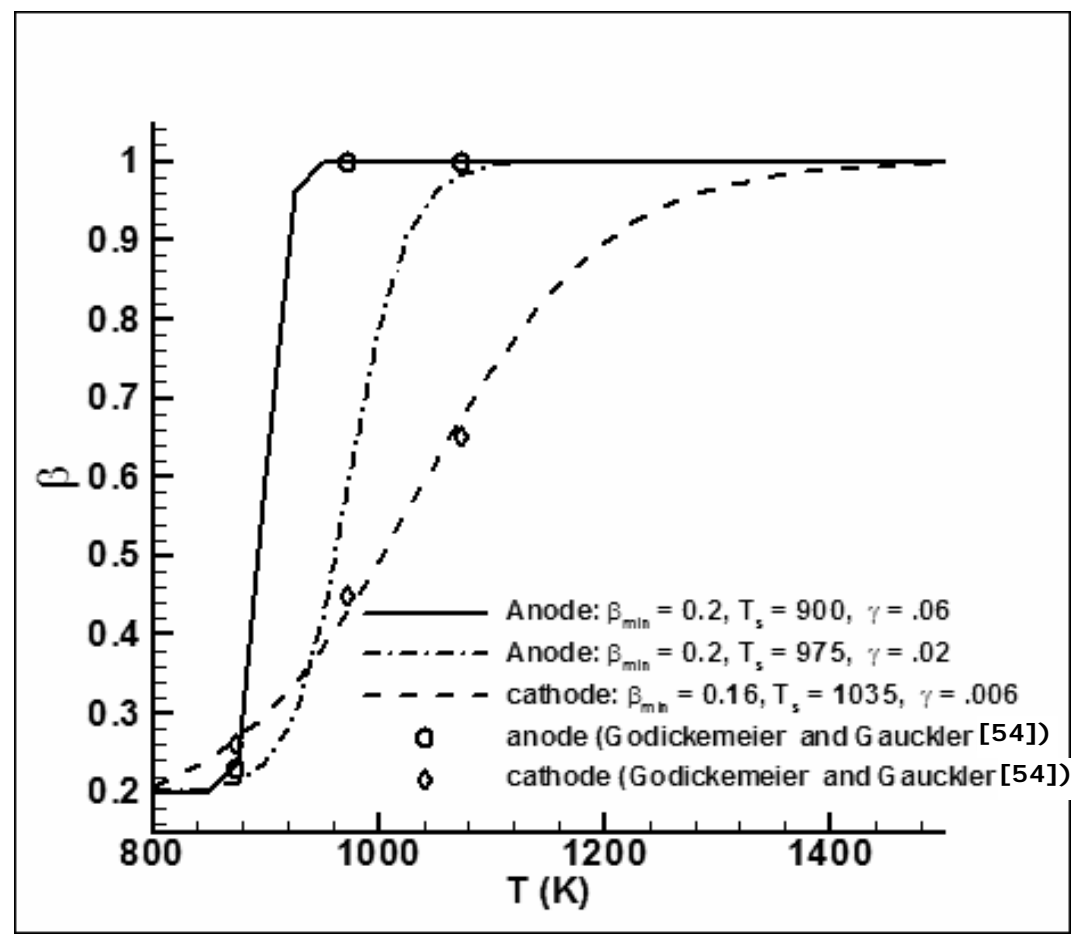

Figure 5.2: Variation of transfer coefficient with temperature

Though $\beta$ is usually assumed to be 0.5 , it is actually a function of temperature and takes a value between $\beta_{\min }$ and $\beta_{\max }$. In this work, it is assumed that $\beta_{\max }=1$. The following empirical equation is suggested for estimation of $\beta$

$$
\beta=0.5\left(1+\beta_{\min }\right)+0.5\left(1-\beta_{\min }\right) \operatorname{Tanh}\left(\gamma\left(T-T_{s}\right)\right)
$$

Where $\gamma$ and $T_{s}$ are model parameters which were obtained by curve fitting using the data reported by Godickemeier and Gauckler [54] as guide. 
The empirical relation Eq. (5-20) is plotted against suggested values (not measured) by Godickemeier and Gauckler [54] in Fig. 5.2 The values of $\gamma$ and $T_{s}$ for cathode and anode are given in the legend of the plot. This information indicates that there is a range where $\beta$ is very sensitive to temperature. At relatively lower and higher temperatures, the sensitivity decreases significantly and $\beta$ reaches asymptotic values $\beta_{\min }$ and $\beta_{\max }$ respectively. It should be noted that the transfer coefficients for more complex mechanisms involving more species other than $\mathrm{H}_{2}-\mathrm{O}_{2}$ may be larger than one as indicated by Eqs. (5-19 a \& b). Equation (5-20) and the suggested coefficients are derived from the data presented in Godickemeier and Gauckler [54], hence it may be limited to the conditions of there experiments.

\subsubsection{Exchange Current Density}

The exchange current density at an Electrode/Electrolyte (E/E) interface can be calculated using either of the following relations (Bard and Faulkner [52]).

$$
i_{0}=n F K_{f} C_{r}^{*} ; i_{0}=n F K_{b} C_{p}^{*}
$$

Here, $K_{f}$ (in $\mathrm{m} / \mathrm{s}$ ) is forward reaction rate, $K_{b}$ is the backward (or reverse) reaction rate, and $C_{r}^{*}$ and $C_{p}^{*}$ are the bulk concentrations of the reactant and product species, respectively. By introducing a reference exchange current density $i_{\text {ref }}^{0}$ and assuming exponential temperature dependency for $K_{f}$ and, $K_{b}$ Eq. (5-21) can be cast into a more amenable form, that is 


$$
i_{0}=i_{0}^{r e f} \exp \left(\frac{-A}{T}\right) \frac{C_{r}^{*}}{C_{r}^{r e f}}
$$

Where, $C_{r}^{r e f}$ is the bulk concentration of the reactant at the reference conditions. This equation is similar to the equations used by Costamagna and Honegger [55]. The constants $i_{0}^{\text {ref }}$ and $A$ are obtained by curve fitting using experimental data for exchange currents at different temperatures and concentration, $C_{r}^{r e f}$. The values of $i_{0}^{r e f}$ and $A$ calculated using data reported in the literature by various authors (Godickemeir and Gauckler [54], Co et al.[56], Esquirol [57])are given in Table 5.1. The large variations seen in the model parameters in Table 5.1 are to be expected since the reaction kinetics are strongly dependent on the material properties and processing techniques used.

Table 5.1. Model constants for exchange current equation (Eq. 5-22)

\begin{tabular}{|c|c|c|c|}
\hline Case & $i_{0}^{\text {ref }}\left(\mathrm{A} / \mathrm{cm}^{2}\right)$ & $A(\mathrm{~K})$ & Reference \\
\hline Cathode 1 & $6.5 \times 10^{9}$ & 14534 & Co et. al. [56] \\
\hline Cathode 2 & $2.0 \times 10^{12}$ & 21391 & Esquirol et. al. [57] \\
\hline Cathode 3 & $1.0 \times 10^{7}$ & 8170 & Godickemeier et. al. [54] \\
\hline Anode 1 & $1.6 \times 10^{7}$ & 8427 & Godickemeier et. al. [54] \\
\hline
\end{tabular}

\subsubsection{I nterface Concentrations}

As it was mentioned already the preliminary testing and validation of the electrochemistry model was done in a zero-dimensional setting. For this purpose bulk models were needed for concentration and ohmic over potentials. These bulk models would not be required when the electrochemistry is incorporated into the three dimensional model as the ohmic and concentration losses are resolved through the electric potential field and concentration field respectively. 
For a given bulk concentration, $C_{r}^{*}$ of a reactant the concentration at the $E / E$ interface, $C_{r}$ can be approximated to be a function of the current density (Bard and Faulkner [52]).

$$
\frac{C_{r}}{C_{r}^{*}}=1-\frac{i}{i_{L}}
$$

where $i_{L}$ is the current at which the concentration of the reactant at the interface is (almost) zero. Although Eq. (5-23) is very commonly used, the assumption of a linear relationship between interfacial concentration and current, and neglecting convection in derivation of Eq. (5-23) may not always be valid. Nevertheless, the limiting current for a simple geometry can be related to the flux of the reactant specie by (Bard and Faulkner [52]).

$$
i_{L}=\frac{n F D_{r}^{e f f} C_{r}^{*}}{\delta}
$$

Where, $D_{r}^{\text {eff }}$ is effective diffusivity of the reactant inside the porous electrode and $\delta$ is the diffusion layer thickness that is simply set equal to that of the electrode. Eq. (5-24) is only valid for an ideal case when the area of electrode/gas channel ( $E / G$ ) interface is equal to the area of $E / E$ interface. In an actual planar solid oxide of fuel cell the area of $E / G$ interface is less than the area of $E / E$ interface. The effective limiting current in such cases can be estimated by multiplying $i_{L}$ obtained from Eq. (5-24) by an area factor $a_{f}$ defined as $a_{f}=\frac{\text { Area }_{E / G}}{\operatorname{Area}_{E / E}}$ 


\subsubsection{Effective diffusivity}

The effective diffusivity of species in porous medium can be calculated using the relation (for example, for $\mathrm{H}_{2}, \mathrm{H}_{2} \mathrm{O}, \mathrm{Ar}$ mixture as ) (Bird et al [58], Cussler, [59], Zhao et al, [60] and Jiang and Virkar, [61])

$$
D_{H_{2}}^{\text {eff }}=\frac{\varepsilon}{\tau}\left(\frac{1}{D_{\mathrm{H}_{2}}^{k}}+\frac{Y_{\mathrm{Ar}}}{D_{\mathrm{H}_{2}-\mathrm{Ar}}}+\frac{1-Y_{\mathrm{Ar}}}{D_{\mathrm{H}_{2}-\mathrm{H}_{2} \mathrm{O}}}\right)^{-1}
$$

Where $D$ is the diffusivity of the specie inside the pore fluid, $D^{k}$ is the Knudsen diffusivity, $\varepsilon$ is the porosity of the electrode and $\tau$ is the tortuosity. The binary diffusivities are calculated using Chapman-Enskog model (Bird et al. [58], Cussler [59]) that is briefly described in the appendix. The Knudsen diffusion is important when the pore size is smaller than the mean free path of the gas molecules. Knudsen diffusivity of a specie, $D_{r}^{k}$, can be calculated using the relation (Cussler [59])

$$
D_{r}^{k}=\frac{d_{p}}{3} \sqrt{\frac{8 R T}{\pi M_{r}}}
$$

Where $d_{p}$ is the pore diameter and $M_{r}$ is the molecular weight of the specie. The limiting current was calculated for electrodes used in an experimental study by Godickemeier and Gauckler. [54] using Eq. (5-24) for different temperatures and pore sizes (Knudsen diffusivities). The results are shown in Fig.5.3. The corresponding $D^{\text {eff }}$ and limiting current density for a cathode pore size of 0.45 micron and anode pore size of 0.25 micron are listed in Table 5.2 along with the values of exchange current density. 
It is seen that the present model shows reasonable sensitivity to the properties of anode and cathode used as well as to the temperature changes. Fig. 5.3 depicts the variation of the limiting current as a function of the pore diameter. It seems that the Knudsen diffusivity starts to play a significant role below pore size of $d_{p}=2 \mu \mathrm{m}$. Also in this range, it is seen that temperature dependence of $i_{L}$ is not as strong (Fig. 5.3). There even seems to be a reverse dependence on temperature, i.e. when pore diameter is very small, the limiting current may slightly decrease with temperature. However, these observations need to pass the scrutiny of experimental evidence before they can be accepted. Of course, at such high temperatures, the pore sizes may also change with temperature due to thermal expansion or contraction.

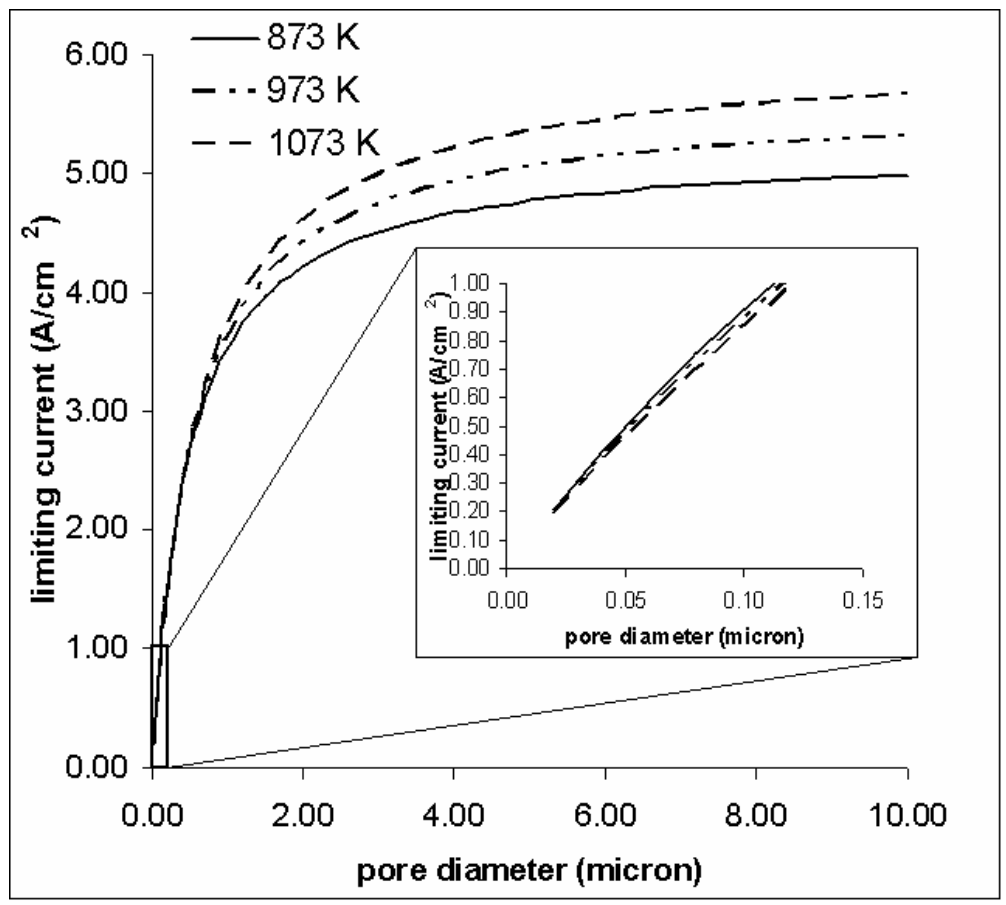

Figure 5.3: Variation of anode limiting current with pore size 
Table 5.2: Validation with the experimental data from Godickemeier et. al.

\begin{tabular}{|c|c|c|c|c|c|c|}
\hline \multicolumn{2}{|c|}{ Temperature (K) } & \multirow{3}{*}{$\begin{array}{c}\text { Experimental } \\
i_{0} \\
\left(\mathrm{amp} / \mathrm{cm}^{2}\right)\end{array}$} & \multirow{3}{*}{$\begin{array}{c}\text { estimated } \\
i_{L} \\
\left(\mathrm{amp} / \mathrm{cm}^{2}\right) \\
>0.4\end{array}$} & \multicolumn{3}{|c|}{ Calculated } \\
\hline & & & & \multirow{2}{*}{$\begin{array}{c}i_{0} \\
\left(\mathrm{amp} / \mathrm{cm}^{2}\right)\end{array}$} & \multirow{2}{*}{$\begin{array}{c}D^{e f f} \\
\left(\mathrm{~cm}^{2} / \mathrm{s}\right)\end{array}$} & \multirow{2}{*}{$\begin{array}{c}i_{L} \\
\left(\mathrm{amp} / \mathrm{cm}^{2}\right) \\
1.80\end{array}$} \\
\hline Anode & 873 & & & & & \\
\hline & 973 & 0.3 & $\sim 0.9$ & 0.28 & 0.0228 & 1.78 \\
\hline & 1073 & 0.6 & $>1.0$ & 0.62 & 0.0248 & 1.76 \\
\hline \multirow[t]{3}{*}{ Cathode } & 873 & 0.094 & $>0.4$ & 0.09 & 0.0075 & 2.85 \\
\hline & 973 & 0.18 & $>0.9$ & 0.23 & 0.0084 & 2.86 \\
\hline & 1073 & 0.55 & $>1.0$ & 0.49 & 0.0093 & 2.86 \\
\hline
\end{tabular}

\subsubsection{Ohmic losses}

The ohmic losses due to cell resistance are given by the relation

$$
\eta_{R}=I R^{\text {eff }}=I \sum_{\text {all layers }}\left(\frac{1}{\sigma_{\text {layer }}}\right) \frac{\delta_{\text {layer }}}{A_{\text {layer }}}
$$

where I is the total current through the cell and $R^{\text {eff }}$ is the effective

resistance of the cell, $\sigma$ is the electric conductivity, $\delta_{\text {layer }}$ is the thickness and $A_{\text {layer }}$ is the cross-sectional area of the layer available for conduction of electricity. The summation is over all the layers in the fuel cell (interconnect, current collectors, etc.) that conduct the electricity

\subsubsection{Bulk Concentrations}

The mean bulk mole fractions of species on cathode and anode sides are calculated using 


$$
Y_{O_{2}}^{*}=\frac{\left(1-\lambda \phi_{O_{2}}\right) Y_{O_{2}}^{\text {inlet }}}{1-\lambda \phi_{O_{2}} Y_{O_{2}}^{\text {inlet }}}
$$

and

$$
Y_{\mathrm{H}_{2}}^{*}=\left(1-\lambda \phi_{\mathrm{H}_{2}}\right) Y_{\mathrm{H}_{2}}^{\text {inlet }} ; Y_{\mathrm{H}_{2} \mathrm{O}}^{*}=Y_{\mathrm{H}_{2} \mathrm{O}}^{\text {inlet }}+\lambda \phi_{\mathrm{H}_{2}} Y_{\mathrm{H}_{2}}^{\text {inlet }}
$$

Here $\lambda$ is the progress variable ( or extent of reaction) which is between zero and one. The subscript " ${ }_{\text {inlet }}$ " denotes that the value is at the inlet. $\phi_{\mathrm{O}_{2}}$ and $\phi_{\mathrm{H}_{2}}$ are the utilizations of oxygen and hydrogen given by

$$
\phi_{\mathrm{O}_{2}}=\frac{I}{4 F \dot{N}_{\text {air }} Y_{\mathrm{O}_{2}}^{\text {inlet }}} ; \phi_{\mathrm{H}_{2}}=\frac{I}{2 F \dot{N}_{\text {fuel }} Y_{\mathrm{H}_{2}}^{\text {inlet }}}
$$

where $\dot{N}_{\text {air }}$ and $\dot{N}_{\text {fuel }}$ are the molar flow rates of air and fuel in anode and cathode channels respectively.

\subsubsection{Oxygen I on Concentration}

In the present model, the Oxygen ion concentration inside the solid electrolyte is retained as an independent physical parameter. This parameter is difficult to determine either experimentally or theoretically. For brevity, a simple functional dependency on temperature, such as the following relations is suggested.

$$
Y_{O^{=}}=Y_{O^{=}}^{r e f}\left(\frac{T}{T^{r e f}}\right)^{m} ; Y_{O^{=}}^{r e f}=\frac{C_{O^{=}}^{r e f} M_{Y S Z}}{\rho_{Y S Z}}
$$


where appropriate values for " $\mathrm{m}$ " can be selected as more information become available in the literature. $\rho_{Y S Z}$ is the density of Yittria Stabilized Zirconia (YSZ), $M_{Y S Z}$ is the molecular weight of YSZ, and $C_{0^{=}}^{r e f}$ is the molar concentration of oxide ions in YSZ reported to be $4.5 \times 10^{4} \mathrm{~mol} / \mathrm{m}^{3}$ at $973 \mathrm{~K}$ by Bieberle and Gauckler [15]. The resulting reference values were $Y_{O^{=}}^{\text {ref }}=0.1$ and $T^{\text {ref }}=973 \mathrm{~K}$ using the data reported in Bieberle and Gauckler [15]. It should be noted that these reference values may vary significantly among different materials used as electrolyte.

Table 5.3: Parameters of Experiments by Godickemeier and Gauckler [54]

\begin{tabular}{|c|c|}
\hline Component & Description \\
\hline $\begin{array}{c}\text { Electrolyte (SDC - Samaria Doped } \\
\text { Ceria) }\end{array}$ & $\begin{array}{r}250 \mu \mathrm{m} \text { thick, with Conductivities: } 1.65,3.47,7.2 \mathrm{~S} / \mathrm{m} \text { at } \\
873,973 \text { and } 1073 \mathrm{~K} \text { respectively }\end{array}$ \\
\hline Anode $(\mathrm{NCC}-$ & $\begin{array}{c}\left.\mathrm{Ni}-\mathrm{C}_{0.9} \mathrm{Ca}_{0.1} \mathrm{O}_{1-x}\right) \\
\text { gas: } 87 \% \text { Ar }+10 \% \mathrm{H}_{2}+3 \% \mathrm{H}_{2} \mathrm{O}\end{array}$ \\
\hline $\begin{array}{c}\text { Cathode (LSC - Lanthanum } \\
\text { Strontium Cobaltite) }\end{array}$ & $15 \mu \mathrm{m}$ thick, Porosity: $\begin{array}{c}0.5, \text { Pore size: } 0.1 \text { to } 0.8 \mu \mathrm{m}, \text { Feed } \\
\text { gas: Air }\end{array}$ \\
\hline
\end{tabular}

\subsection{Results and Discussion}

The complete model described above has been applied to a case that is studied experimentally by Godickemeier and Gauckler [54] and Godickemeier et al. [62]. The material properties and the geometrical parameters for this case are listed in Table 5.3. In these experiments the authors had measured the over-potential separately for anode and cathode. They later proposed a curve fit to their data based on a semi-empirical consideration. The transfer coefficient was kept as a free parameter and the values for this were deduced to have the best curve fit to data. The calculated over-potentials from our model are compared with experiments 
(Godickemeier and Gauckler [54]) in Fig. 5.4 for the cathode and in Fig. 5.5 for the anode. It is seen that the variation of the over-potential over a wide range of current density and temperatures is predicted well with the current model in case of the cathode using an average pore diameter of 0.45 micron. As for the anode a good agreement could be obtained (Fig 5.5) only when the pore size (which is reported to be in the range 0.1-0.8 micron by the experimenters) is adjusted to 0.25 micron and the transfer coefficients were calculated from Eq. (5-20) (with $\beta_{\min }=0.2, \gamma=0.02, T_{s}=975$ ). When the transfer coefficients suggested by the Godickemeier and Gauckler [54] were used and the limiting currents were calculated from Eq. (5-24) there was significant disagreement between calculation and measurements especially for the case with $T=973 \mathrm{~K}$. These results indicate that the transfer coefficient values suggested in Godickemeier and Gauckler [54] as 1.0 for T>973K for the anode do not seem to capture the physics of what might really be occurring within this anode material. Indeed for $T=973 \mathrm{~K}$ case when limiting current is adjusted to be c.a $1.0 \mathrm{~A} / \mathrm{cm}^{2}$, the present model yields very good agreement (Fig. 5.5). It is possible that during this particular experiment some unknown factor has hindered the diffusion of gasses leading to a much smaller limiting current. 


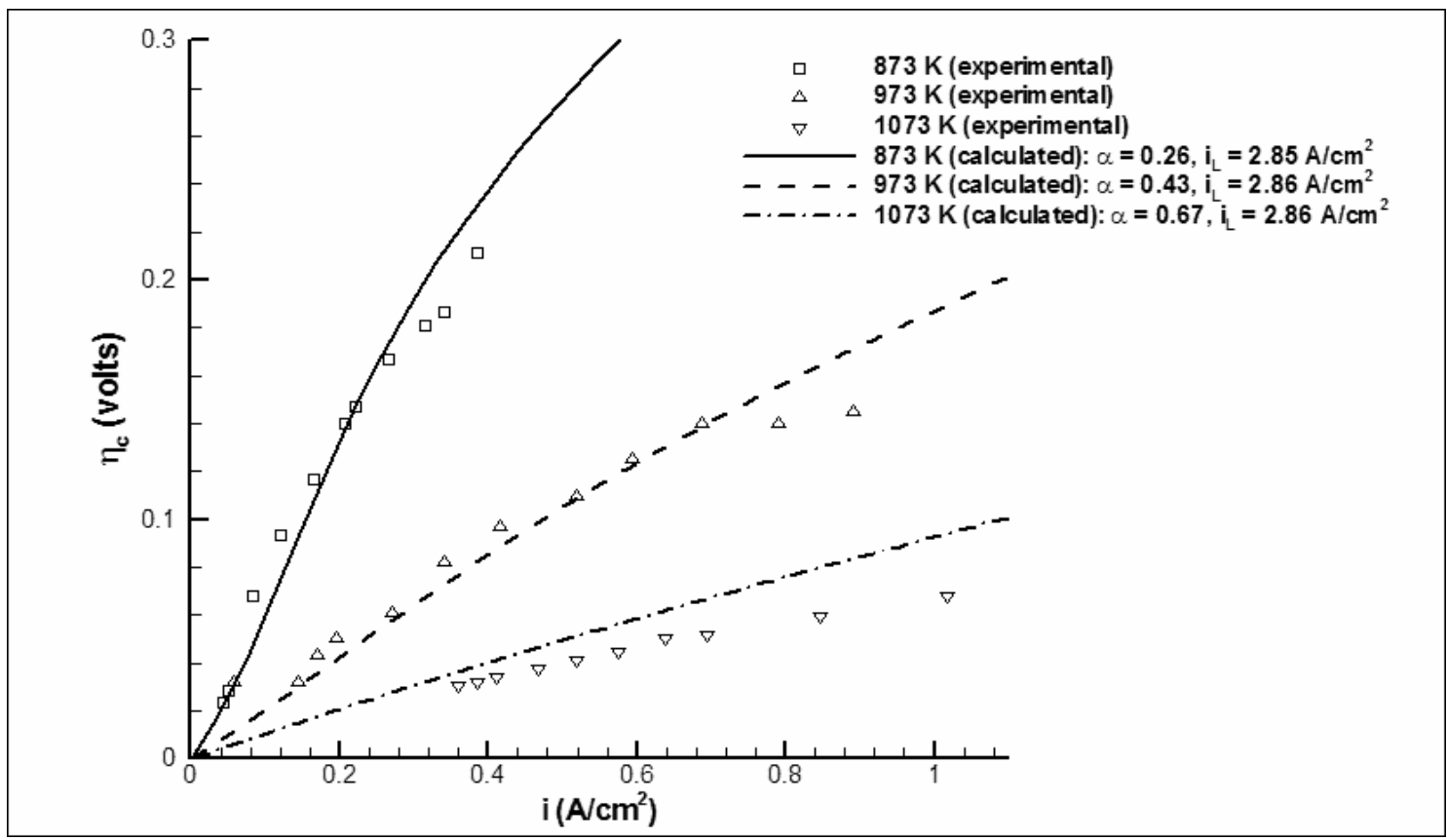

Figure 5.4: Comparison of experimental [54] and calculated cathode overpotentials: transfer coefficients from Eq. (5-20) with

$$
\beta_{\text {min }}=0.116, \gamma=0.06, T_{s}=1035: \text { pore size }=\mathbf{0 . 4 5} \text { micron }
$$

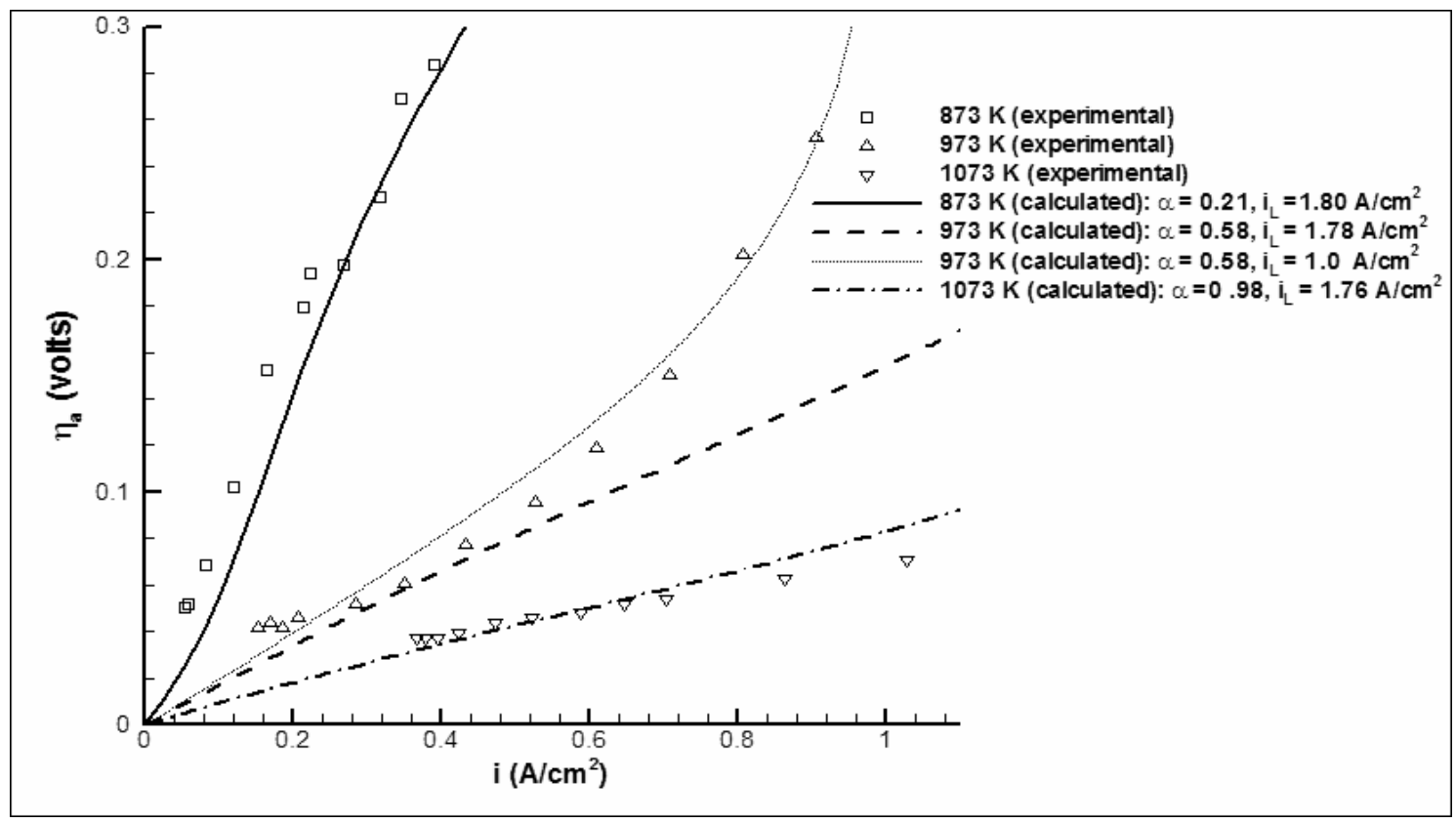

Figure 5.5: Comparison of experimental [54] and calculated anode overpotentials: transfer coefficients from Eq. (5-20) with

$$
\beta_{\min }=0.2, \gamma=0.02, T_{s}=975: \text { pore size }=.25 \text { micron. }
$$


After successfully predicting the overpotentials, it was possible to calculate the V-I curves for the SOFC used in the same experiments as mentioned above by estimating the cell voltage at various currents. Using Eqs. (5-31a \& b) as a guide and the reference values suggested in Bieberle and Gauckler [15], the mole fraction of oxygen ion in YSZ electrolyte was calculated to be 0.1 at $973 \mathrm{~K}$. In the case of Godickemeier and Gauckler [54] the electrolyte was Samaria Doped Ceria (SDC). Since there was no information on the $Y_{O^{\prime}}$, calculations were performed with different values $Y_{O^{=}}$. In these calculations, the ohmic losses are also included using Eq. (5-27). Due to this it is possible that the potential difference at either interface $C / E$ or $A / E$ is larger than the total potential difference for the cell (See Fig. 5.1) depending on the temperature and the electrical resistance especially at higher current densities. This trend is observed in V-I plots at different temperatures shown in Fig. 5.6. The calculated total potential difference across the cell, $\Delta E_{\text {cell }}$, in these plots is corrected for a leakage loss in addition to the polarization and ohmic losses. According to Godickemeier et. al. [62], the potential difference near open circuit conditions is significantly lowered due to an ionic current leakage for mixed conducting electrolytes like the ones they used. At higher loads (currents) however, the leakage loss was noted to be insignificant. Following this reasoning, a correction was made to the calculated potential. The leakage loss at opencircuit conditions $\eta_{L}^{O C}$ was estimated by comparing the theoretically calculated and experimentally observed (Godickemeier et. al., [62]) values of cell potential and it was allowed to diminish exponentially as the load approached the limiting current. Half of this leakage loss is subtracted from $\Delta E_{C / E}$ and the other half from $\Delta E_{E / A}$ calculated using Eqs. (5-7) \& (5-8), respectively. The cell potential is then calculated from Eq. (5-14). The resulting plots show a very good agreement with the experimental results. 
The oxygen ion concentration of 0.1 is used for simulations in Fig. 5.6. To study the sensitivity of the simulations to the oxygen ion concentration in electrolyte, the simulation at $973 \mathrm{~K}$ is repeated with oxygen ion mole fractions of 0.01 and 1.0. The results for these cases are shown in Fig. 5.7. The sum of the interface potentials, $\Delta E_{C / E}+\Delta E_{C / E}$, in Figs. 5.7(a) and (b) is the same as in Fig. 5.6(b), since the concentration of oxygen ions does not effect the overall cell potential. The individual values of $\Delta E_{C / E}$ and $\Delta E_{E / A}$, however, vary between these simulations. While $\Delta E_{C / E}$ and $\Delta E_{E / A}$ are about same when $Y_{0^{=}}=0.001$ (Fig. $5.7(a)$ ), they are significantly different with $\Delta E_{C / E}$ being less than $\Delta E_{E / A}$ when $Y_{O^{=}}=1.0$. Although, the real situation is not known, the case with $Y_{O^{=}}=0.01$ (Fig. 5.7(a)) seems to be a favorable for fuel cell operation due to its uniformity. In this case, the potential differences across $C / E$ and $E / A$ interface are in same range which is expected for the normal operation of a fuel cell, largely different potential differences at the E/E interfaces like in Fig. 5.7(b) could lead to cell malfunctioning. When $Y_{O^{=}}=0.1$, Fig. 5.6(a) shows that of the two potential differences at the E/E interfaces, the one at $C / E$ interface drops to zero first as current density increases at $T=873$. This trend is reversed at $T=973 \mathrm{~K}$ as the anode side reaches the limiting current of c.a $1.8 \mathrm{~A} / \mathrm{cm}^{2}$ before the cathode side does. Whether such phenomenon occurs in real life remains to be validated by experiments. 


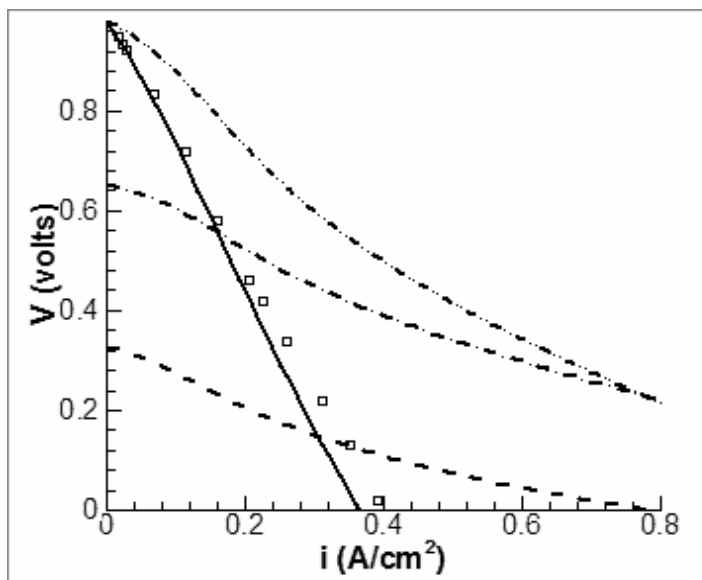

(a) $\mathrm{T}=873 \mathrm{~K}$

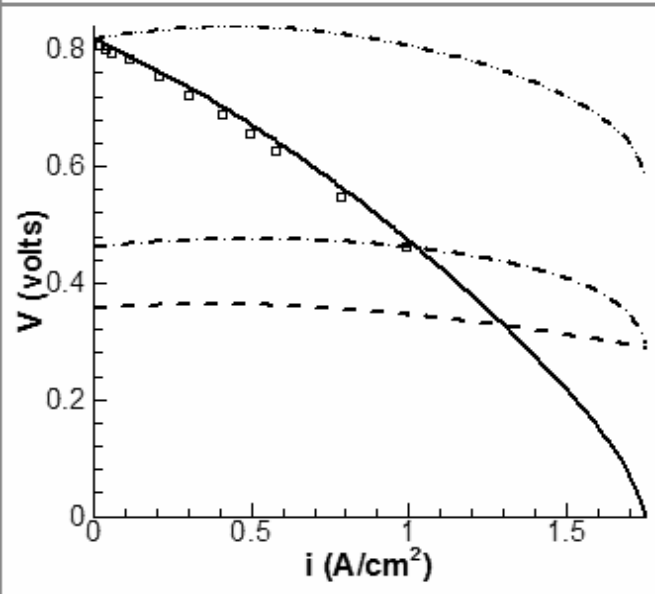

(c) $\mathrm{T}=1073 \mathrm{~K}$

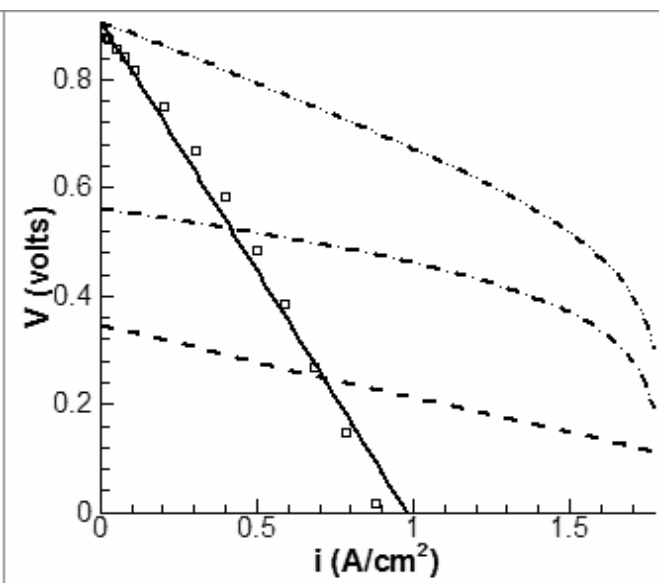

(b) $\mathrm{T}=973 \mathrm{~K}$

Legend for figures 6(a), (b) \& (c)

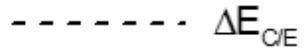

-..... $\Delta \mathrm{E}_{\mathrm{E} / \mathrm{A}}$

$\Delta \mathrm{E}_{\mathrm{CIE}}+\Delta \mathrm{E}_{\mathrm{E} / \mathrm{A}}$

$\longrightarrow \Delta \mathrm{E}_{\mathrm{Cell}}$

- $\Delta \mathrm{E}_{\text {Cell }}($ Experimental)

Figure 5.6: V-I plots at different temperatures using constant oxygen ion concentration in electrolyte at all temperatures $\left(Y_{O^{=}}=0.1\right)$ 


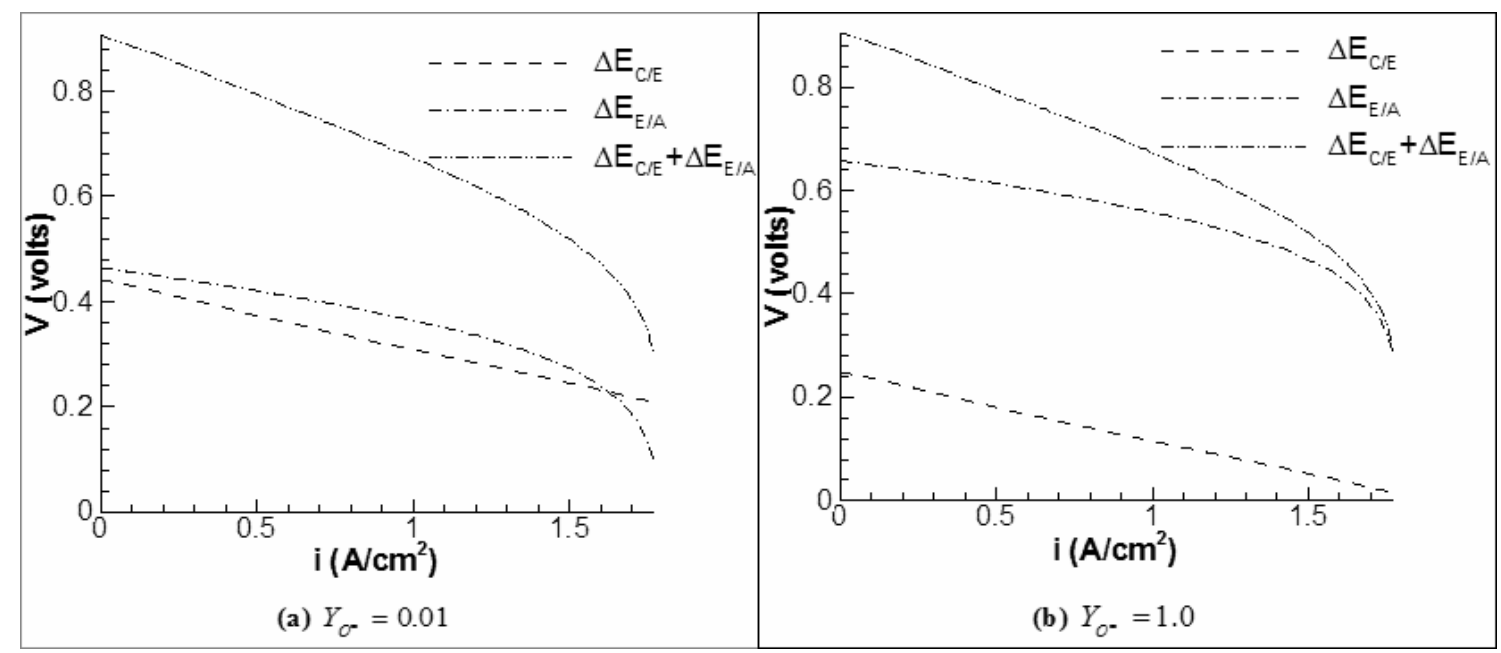

Figure 5.7: I nfluence of oxide ion concentration on $\mathrm{V}-\mathrm{I}$ plots at $\mathrm{T}=$ $973 \mathrm{~K}$

In order to validate the model independently, it was applied to a case that is studied experimentally by Jiang and Virkar [61]. The material properties and the geometrical parameters for these experiments are listed in Table 5.4. Jiang and Virkar [61] reported the V-I curves for various compositions of the fuel. The calculations were done for the case where $\mathrm{H}_{2}-$ $\mathrm{H}_{2} \mathrm{O}$ mixture is used as fuel with different proportions. The transfer coefficients were calculated from Eq. (5-20) (with $\beta_{\min }=0.2, \gamma=0.02, T_{s}=975$ for anode and $\beta_{\min }=0.16, \gamma=0.006, \quad T_{s}=1035$ for cathode). The exchange current densities were calculated from Eq. (5-22) (with $i_{0}^{\text {ref }}=1.6 \times 10^{7} \mathrm{~A} / \mathrm{m}^{2}, A=8427 \mathrm{~K}^{-1}, \quad C_{r}^{\text {ref }}=0.10$ for $\quad$ anode and $i_{0}^{r e f}=1.0 \times 10^{7} \mathrm{~A} / \mathrm{m}^{2}, A=8170 \mathrm{~K}^{-1}, C_{r}^{r e f}=0.21$ for cathode). The mean bulk concentrations of the species inside the gas channels are calculated using Eqs. (5-28 \& 5-29) (using $\lambda=0.50$ ) and Eq. (5-24) was used to estimate the limiting currents. Due to lack of information about the conductivities of the materials used in the cell, the effective cell resistance $R^{\text {eff }}$ is estimated by adjusting it to match the calculated and measured V-I plots for one case $\left(85 \% \mathrm{H}_{2}+15 \% \mathrm{H}_{2} \mathrm{O}\right)$. Then the same value is used in the rest of the calculations. The measured open circuit potential for each of the cases is 
about $0.05 \mathrm{~V}$ less then the value calculated using the Nernst Equation. Jiang and Virkar [61] note that this might be a result of pinholes in the electrolyte layer and of imperfect sealing of gasses. A correction of $0.025 \mathrm{~V}$ is hence made to electric potential calculated for each $E / E$ interface in all calculations. The VI plots thus calculated are plotted against the experimental data in Fig. 5.8 which shows a good qualitative and quantitative agreement between the experimental data and the model predictions.

Table 5.4: Parameters of Experiments by Jiang and Virkar [61]

\begin{tabular}{|c|c|}
\hline Component & Description \\
\hline Electrolyte (YSZ-SDC) & $10 \mu \mathrm{m}$ thick \\
\hline Anode $(\mathrm{Ni}+\mathrm{YSZ})$ & $\begin{array}{r}1000 \mu \mathrm{m} \text { thick, Porosity: 0.54. Pore size: } 0.5 \mu \mathrm{m}, \text { Feed } \\
\text { gas: } \mathrm{H}_{2}+\mathrm{H}_{2} \mathrm{O}, \text { Flow rate: } 140 \mathrm{ml} / \mathrm{min}\end{array}$ \\
\hline Cathode $(\mathrm{LSC})$ & $\begin{array}{r}20 \mu \mathrm{m} \text { thick, Porosity: } 0.5, \text { Pore size: } \sim 5 \mu \mathrm{m}, \text { Feed gas: } \\
\text { Air, Flow rate: } 540 \mathrm{ml} / \mathrm{min}\end{array}$ \\
\hline
\end{tabular}

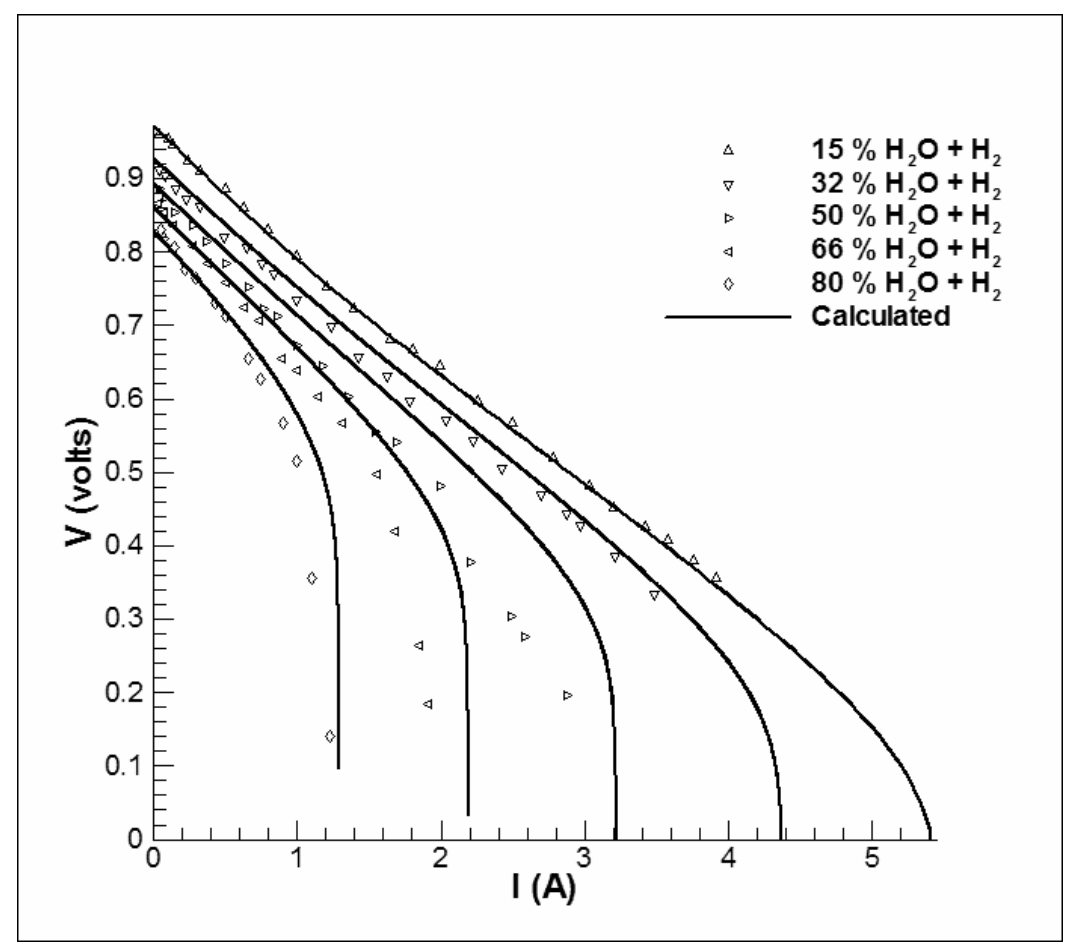

Figure 5.8: Comparision between the experimental ( $\mathrm{J}$ iang and Virkar [61]) results and model predictions of V-I plots for different fuel gas compositions. 
In Conclusion, fairly general electro-chemical sub-model is presented in this chapter for calculation of the potential variation across a solid oxide fuel cell. It is developed by specifically aiming at detailed, three-dimensional simulation of electro-chemical processes within the electrodes and electrolyte assembly. The new model explicitly accounts for the active role of Oxygen ion diffusion and its chemical potential at the cathode/electrolyte (C/E) and anode/electrolyte (E/A) interfaces separately. The calculated over-potentials and the total voltage-current relationship are in very good agreement with experiments. The separate handling of electro-chemical potential at the C/E and $E / A$ interfaces exhibit some interesting physical phenomenon. For example, it alludes to the possibility of fuel-cell operation being limited by either of the electrodes. The later feature of the model remains to be validated using specially designed experiments. 


\section{CHAPTER 6: VERI FI CATI ON AND VALI DATI ON OF THE CODE}

\subsection{I ntroduction}

First step after developing a simulation code is to verify and validate the code. The questions to be answered are: 1 ) Is the code solving the mathematical model correctly? 2) Does the solution accurately represent the reality? The activities aimed at answering the first question are referred to as Verification and those carried out to answer the second question are known as Validation. Verification and Validation of a code is usually done by comparing the results of the code to either experimental results or the results of another independent model for the same set of operating conditions. Sometimes it may not be possible to exactly match all the conditions between the model and the experiments or between different models due to limitations imposed by modeling assumptions. But, it is imperative to match the independent parameters as much as possible for a meaningful comparison.

Experimental results for solid oxide fuel cells, detailed enough to verify codes like DREAM SOFC, are currently very difficult to obtain. Even suitable numerical results are hard to find in literature. In this chapter, results from DREAM SOFC are compared to those from other numerical models available in literature. Also, comparison is done with another multi-dimensional model, FLUENT SOFC. A detailed description of the test cases is presented in section 6.2 followed by results and discussion in Section 6.3 . 
Table 6.1: Details of the geometry of SOFC used for simulation (Achenbach [63])

\begin{tabular}{|c|c|}
\hline Parameter & Value \\
\hline No of air/fuel channels & 18 \\
\hline Anode thickness $(\mu \mathrm{m})$ & 50 \\
\hline Electrolyte thickness $(\mu \mathrm{m})$ & 150 \\
\hline Cathode thickness $(\mu \mathrm{m})$ & 50 \\
\hline Active area $(\mathrm{mm} \times \mathrm{mm})$ & $100 \times 100$ \\
\hline Total interconnect thickness $(\mathrm{mm})$ & 2.5 \\
\hline Height of fuel and air channels $(\mathrm{mm})$ & 1 \\
\hline Width of fuel and air channels $(\mathrm{mm})$ & 3 \\
\hline Length of air and fuel channels $(\mathrm{mm})$ & 100 \\
\hline Width of the current collectors $(\mathrm{mm})$ & 2.56 \\
\hline
\end{tabular}

\subsection{Description of the test cases}

The test case used here is a benchmark case which was defined in Achenbach [63]. Details of the geometry of the SOFC investigated are given in Table 6.1, the material properties are given in Table 6.2 and the operating conditions for the test case are given in Table 6.3. The investigated co-flow, counter-flow and cross-flow cell configurations, have $100 \mathrm{~mm} \mathrm{X} 100 \mathrm{~mm}$ of active area with 18 channels each on fuel and air sides. The geometry for parallel channel (co-flow and counter-flow) cases is depicted in Fig. 6.1 and the grid used in depicted in Fig. 6.2. The grid consists of 207,200 nodes ( 148 X 35 X 40 nodes in $x-, y-$ and $z$ - directions respectively). The geometry and grid for the cross-flow case are similar except for the fact that the air channels and the fuel channels are perpendicular to each other. Accordingly, the grid for cross-flow configuration has 766,640 (148 X $35 \times 148)$ nodes. The cells are insulated on all external walls in all cases. For the gas channels inlet velocity, temperature, and concentration are prescribed from Table 6.3. The comparisons were made to the results of other researchers reported in Achenbach [63]. 
Table 6.2: Details of the geometry of SOFC used for simulation (Achenbach [63])

\begin{tabular}{|c|c|}
\hline Parameter & Value \\
\hline \multicolumn{2}{|l|}{ Density $\left(\mathrm{kg} / \mathrm{m}^{3}\right)$} \\
\hline Anode & 6600 \\
\hline Cathode & 6600 \\
\hline Electrolyte & 6600 \\
\hline Interconnect & 6600 \\
\hline \multicolumn{2}{|c|}{ Heat Capacity (J/kg-K) } \\
\hline Anode & 400 \\
\hline Cathode & 400 \\
\hline Electrolyte & 400 \\
\hline Interconnect & 400 \\
\hline \multicolumn{2}{|c|}{ Thermal conductivity (W/m-K) } \\
\hline Anode & 2 \\
\hline Cathode & 2 \\
\hline Electrolyte & 2 \\
\hline Interconnect & 2 \\
\hline \multicolumn{2}{|c|}{ Electrical Conductivity $\left(\Omega^{-1} \mathrm{~m}^{-1}\right)$} \\
\hline Anode & $\sigma_{A}=\frac{95 \times 10^{6}}{T} \exp \left(-\frac{1150}{T}\right)$ \\
\hline Cathode & $\sigma_{A}=\frac{42 \times 10^{6}}{T} \exp \left(-\frac{1200}{T}\right)$ \\
\hline Electrolyte & $\sigma_{A}=\frac{3.34 \times 10^{4}}{T} \exp \left(-\frac{10300}{T}\right.$ \\
\hline Interconnect & $\sigma_{A}=\frac{9.3 \times 10^{6}}{T} \exp \left(-\frac{1100}{T}\right)$ \\
\hline
\end{tabular}


Fuel Channels

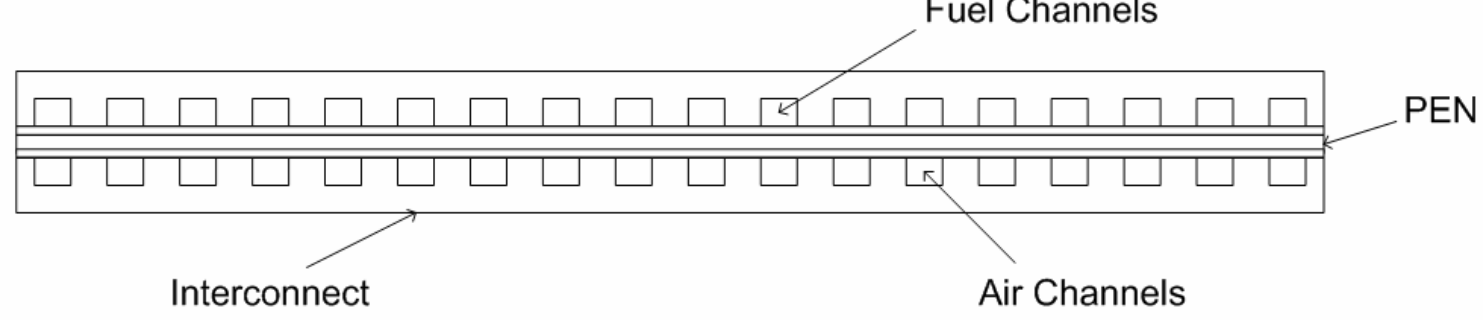

Figure 6.1: Cross-section of the parallel channel SOFC used for simulations

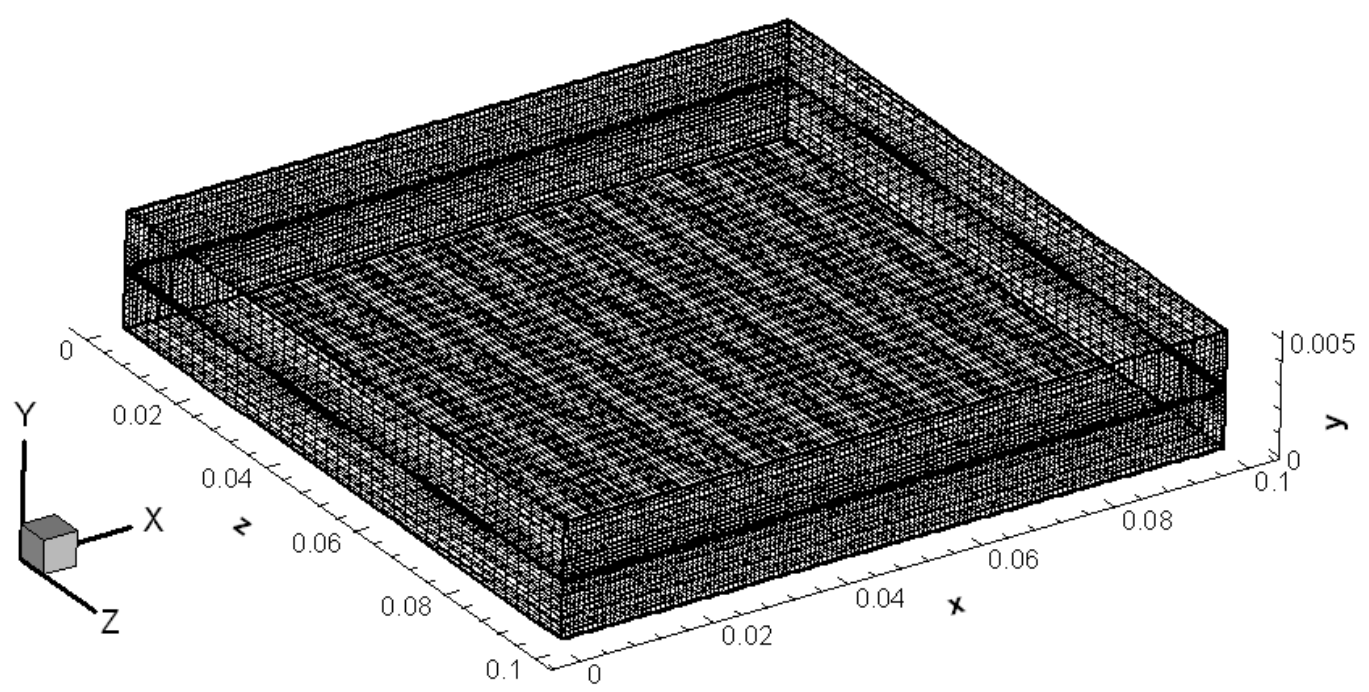

Figure 6.2: Grid used for parallel channel case

Similar test cases were used to compare DREAM SOFC with a multidimensional SOFC code, FLUENT SOFC. The only difference is that the constant electric conductivities were used instead of temperature dependent expressions given in Table. This became necessary since only electrolyte was allowed to have variable conductivity in FLUENT SOFC and its temperature dependence is hard coded in the model for a particular electrolyte. FLUENT simulations were combined effort with Dr. Ibrahim Yavuz and Mr. Francisco Elizalde-Blancas of Computational Fluid Dynamics and Applied Multi Physics (CFD\&AMP) Center at West Virginia University. 
Table 6.3: Details of the SOFC geometry used (Achenbach [63])

\begin{tabular}{|c|c|}
\hline Parameter & Value \\
\hline System pressure (atm) & 1 \\
\hline Inlet gas temperature (K) (fuel and air) & 1173 \\
\hline Fuel Utilization (\%) & 85 \\
\hline Air Utilization (\%) & 12.5 \\
\hline Mean current Density (A/m ${ }^{2}$ ) & 3000 \\
\hline Fuel Composition (by volume) & $90 \% \mathrm{H} 2 ; 10 \% \mathrm{H} 2 \mathrm{O}$ \\
\hline Air Composition (by volume) & $21 \% \mathrm{O} 2 ; 79 \% \mathrm{~N} 2$ \\
\hline
\end{tabular}

\subsection{RESULTS}

\subsubsection{Comparison with Results from Literature}

The contours of current density and temperature predicted by DREAM SOFC are directly compared to those predicted by KFA-Jülich (D) and Risø, Nat. Lab. (DK) (Achenbach [63]) in Figs 6.3 through 6.8. In addition, a detailed comparison of the predictions of key parameters is presented in the Tables 6.4 through 6.6. The location of fuel and air inlets is shown on the figures and it is same for DREAM and FLUENT plots on each figure

The contours of current density shown in Fig. 6.3a show that there is a periodic variation in the span wise direction in dream results whereas, uniform current is predicted by other authors including KFA shown in Fig. 6.3b. This is due to the three-dimensional modeling of the electric current field used in DREAM, which takes the effect of channels and ribs (current collectors) into account and produces higher currents in the regions of the cell lying under ribs than those falling under the channels. Also, it has to be noted that the contours shown in Fig 6.3a are local at the anode/electrolyte interface as opposed to the overall distribution shown in Fig. 6.3b. However, it can be seen that there is a very good quantitative and qualitative agreement between Figs. 6.3a \& 6.3b in terms of average quantities. The 
temperature contours for co-flow configuration, shown in Figs. $6.4 a \& 6.4 \mathrm{~b}$ exhibit very good agreement.

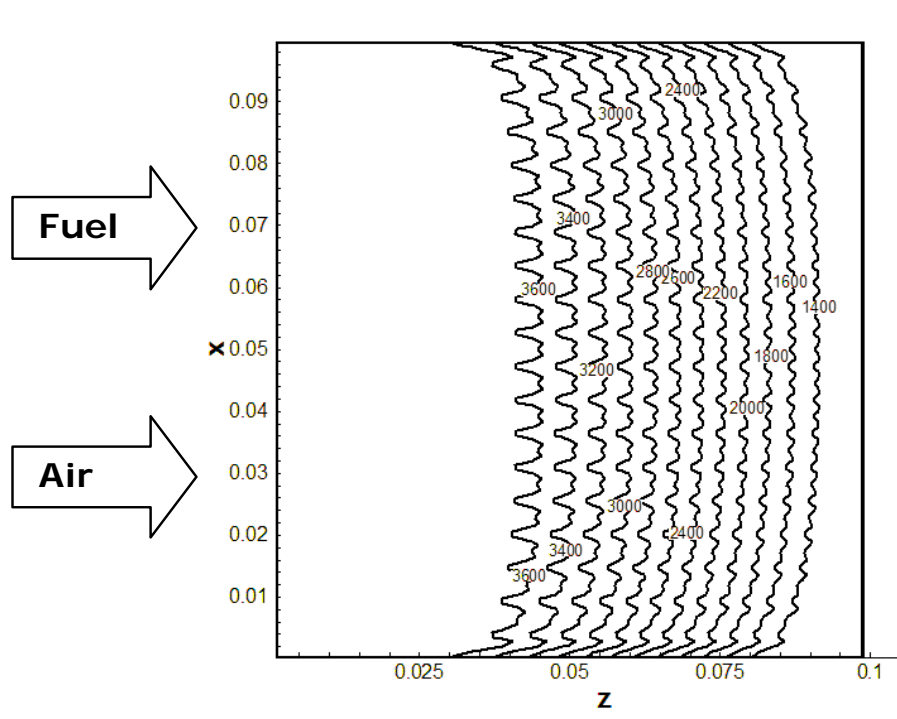

(a)

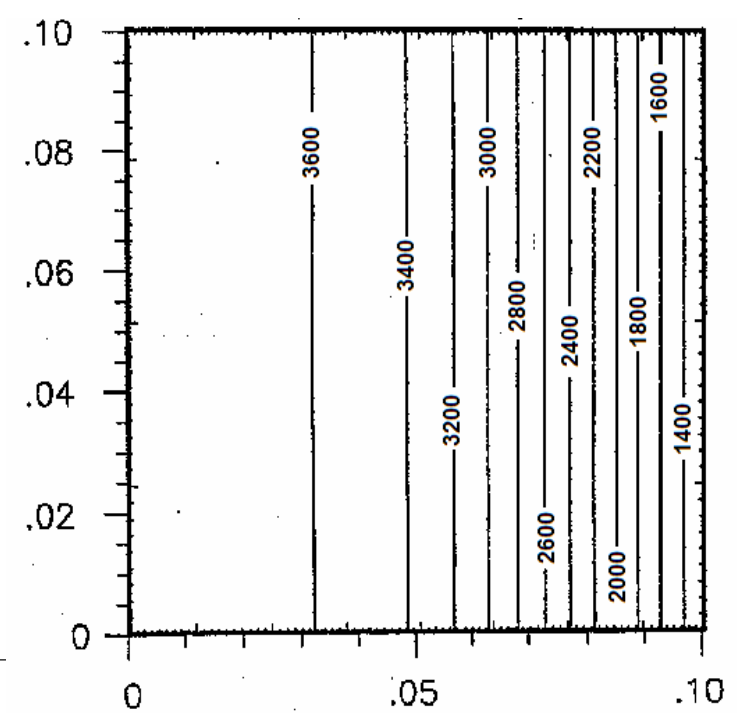

(b)

Figure 6.3: Current contours for co flow configuration; (a) DREAM, and (b) KFA (Achenbach [63])

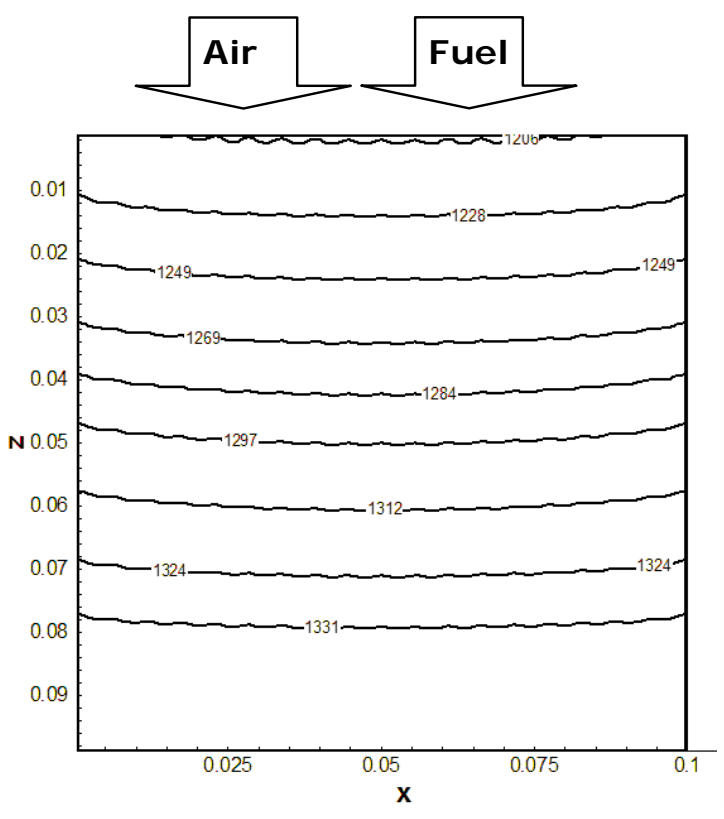

(a)

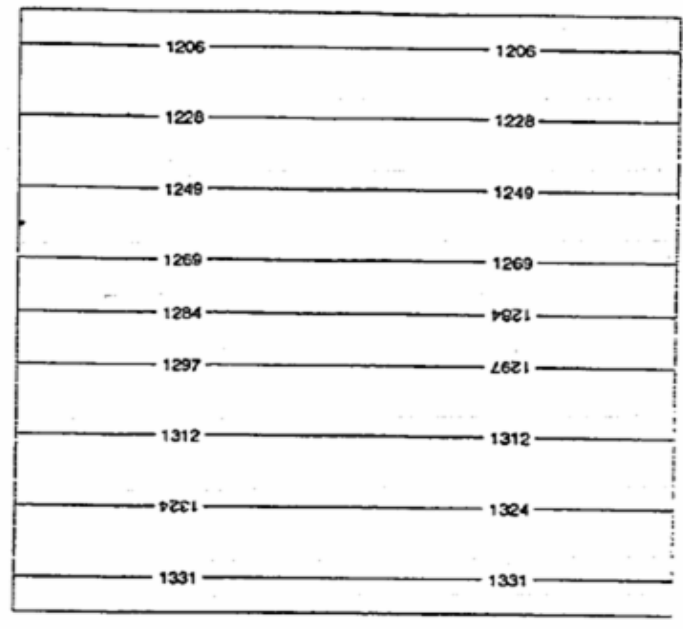

(b)

Figure 6.4: Temperature contours for co flow configuration; (a) DREAM, and (b) Risø (Achenbach [63]) 
Similarly, current distributions for counter flow and cross flow fuel cells shown in Figs. 6.5 \& 6.7 exhibit good agreement in average sense, though DREAM results have more complex distributions for reasons mentioned above. Also, Figs. $6.6 \& 6.8$ show that temperature distributions calculated by DREAM for counter- and cross- flow configurations are very similar. Comparison of key parameters for the benchmark cases predicted by DREAM with those predicted by other authors (Achenbach [63]) is presented in the Tables 6.4 through 6.6 . It can be seen from the tables that the dream calculations are within the range of the results of other models. The mean and standard deviation values for each parameter are calculated for the results other than DREAM's. The deviation is the absolute difference between the DREAM prediction and the mean of other predictions. In conclusion, DREAM SOFC is compared against less detailed models for a well defined benchmark simulation and it is demonstrated that DREAM SOFC estimates the same average behavior as the published literature.

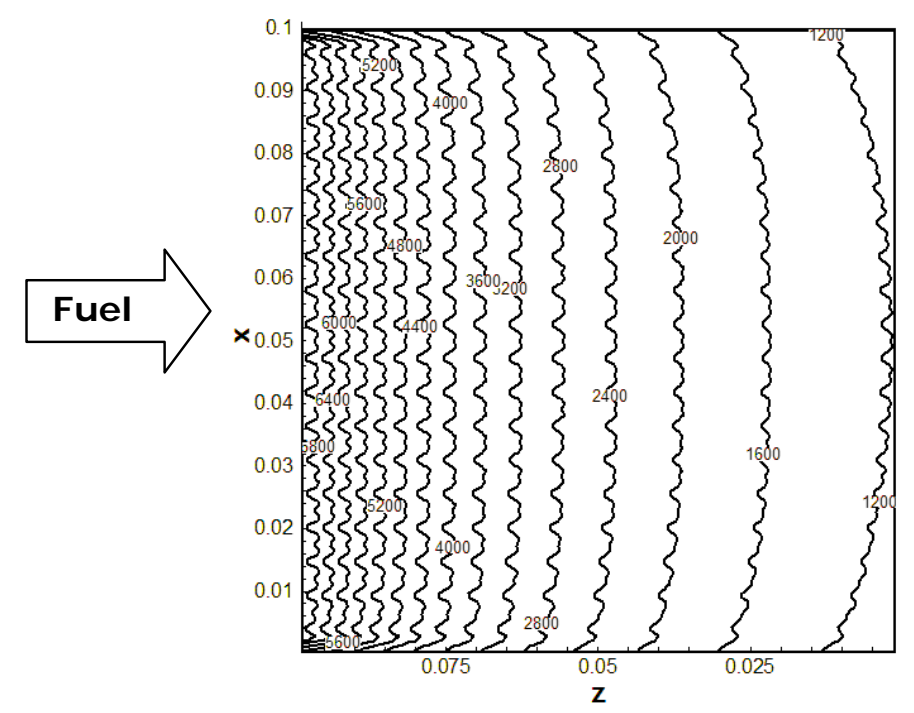

(a)

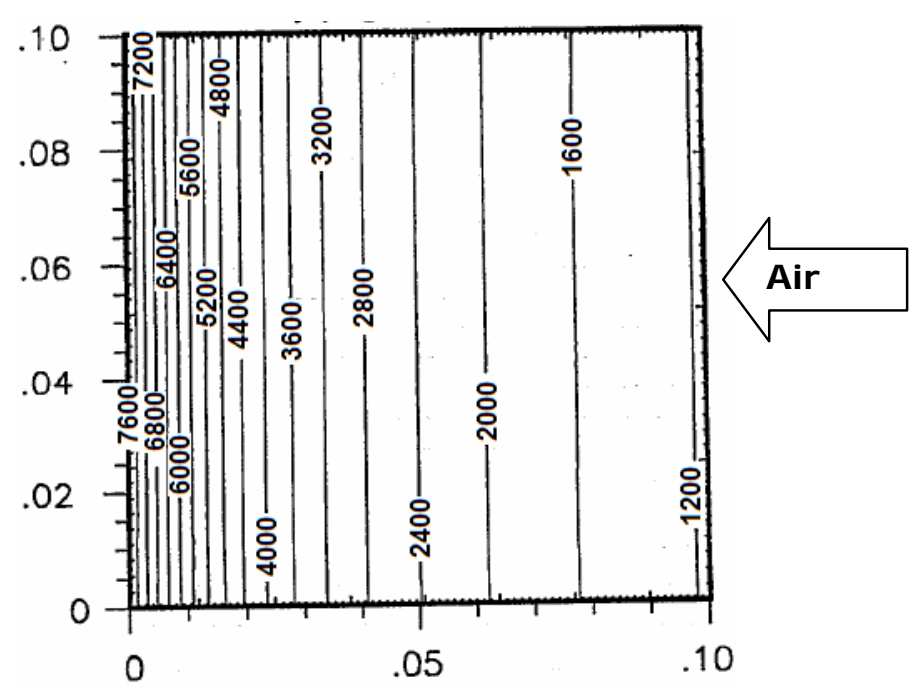

(b)

Figure 6.5: Current contours for counter flow configuration; (a) DREAM, and (b) KFA (Achenbach [63]) 


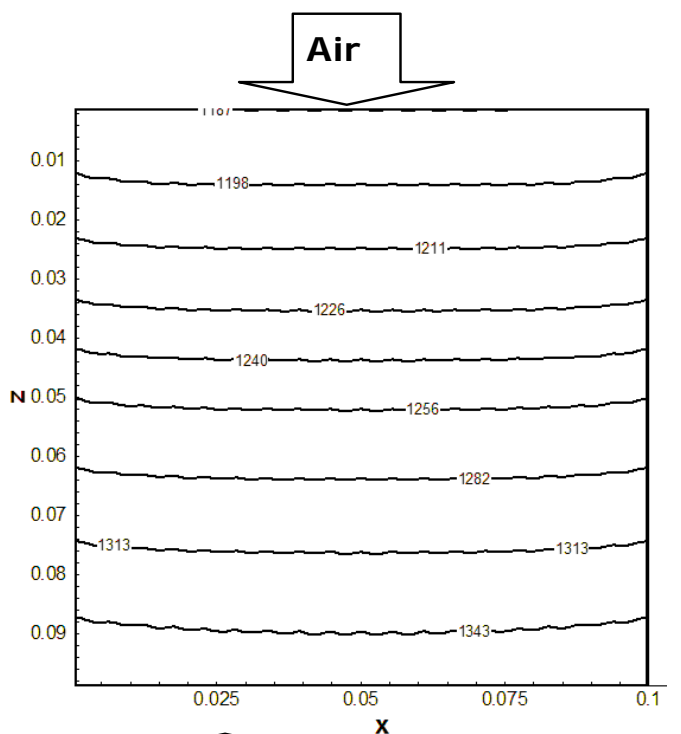

Fuel (a)

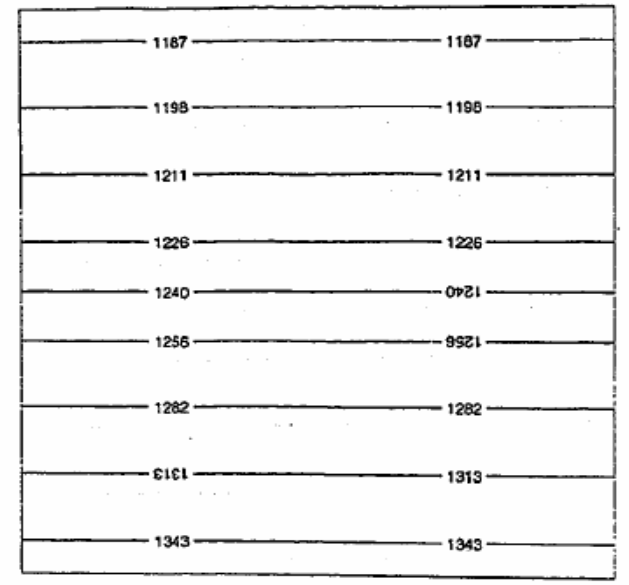

(b)

Figure 6.6: Temperature contours for counter flow configuration; (a)

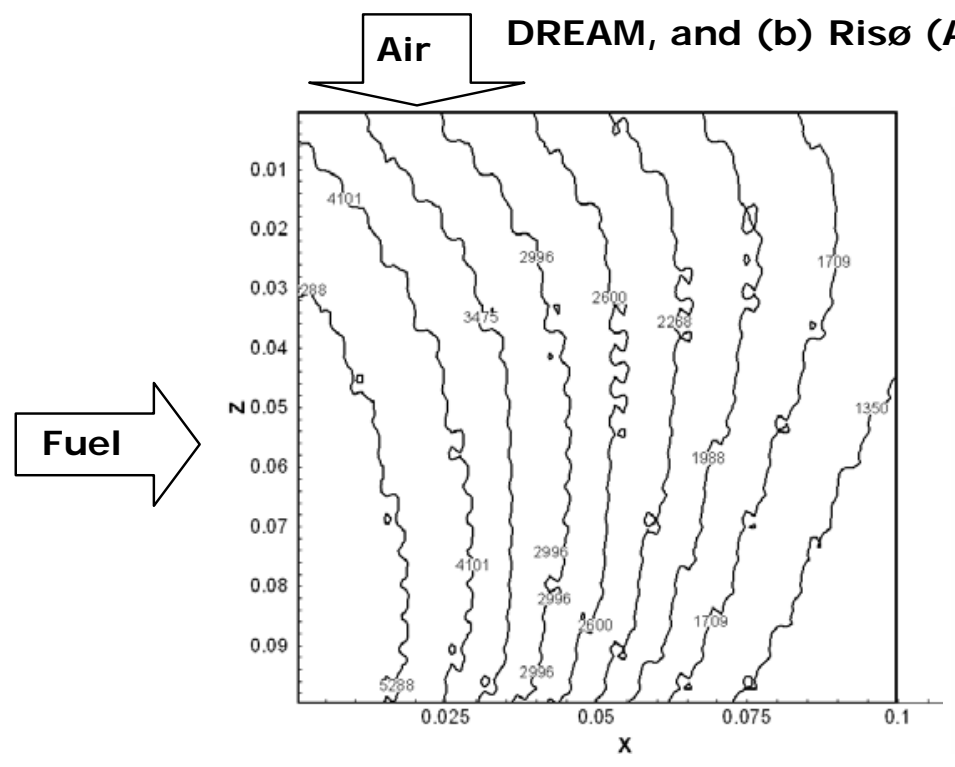

(a)

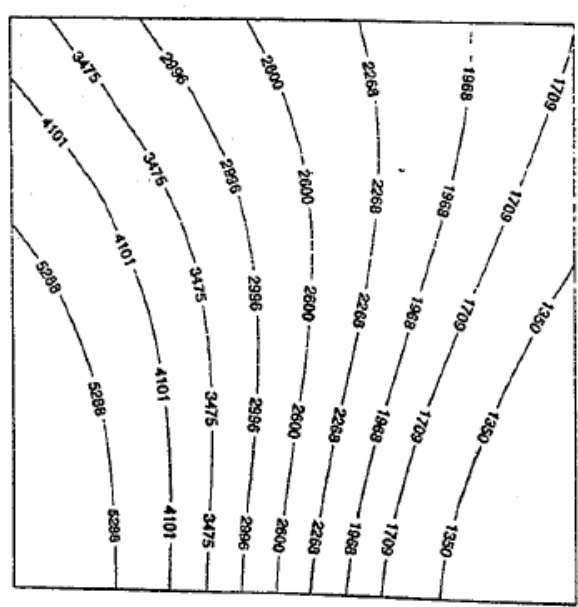

(b)

Figure 6.7: Current contours for cross flow configuration; (a) DREAM, and (b) KFA (Achenbach [63]) 


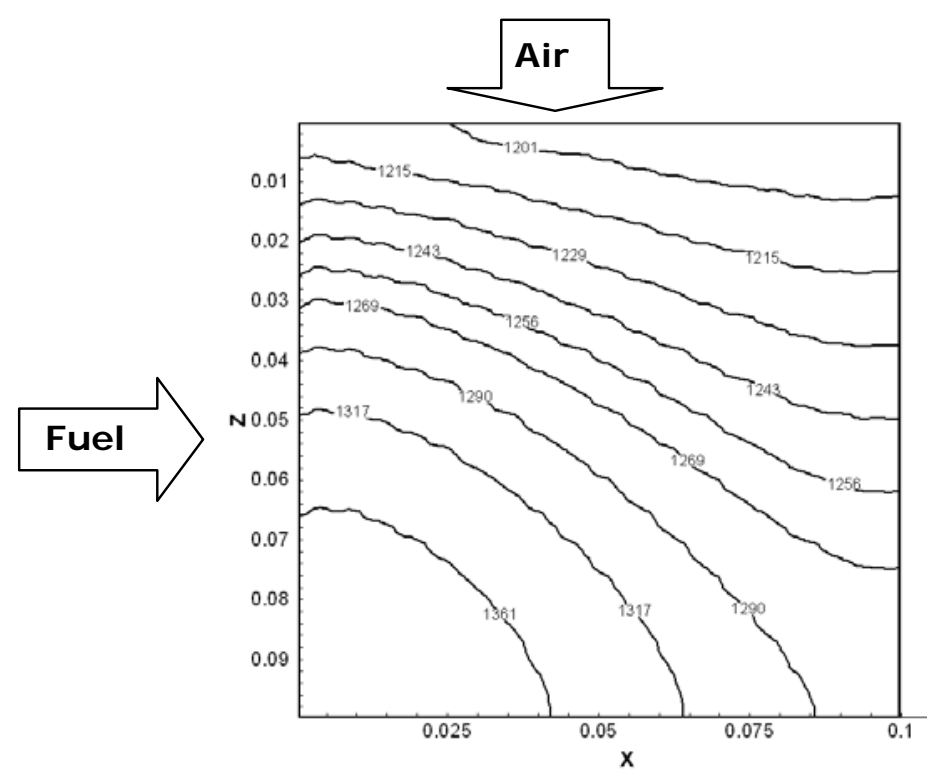

(a)

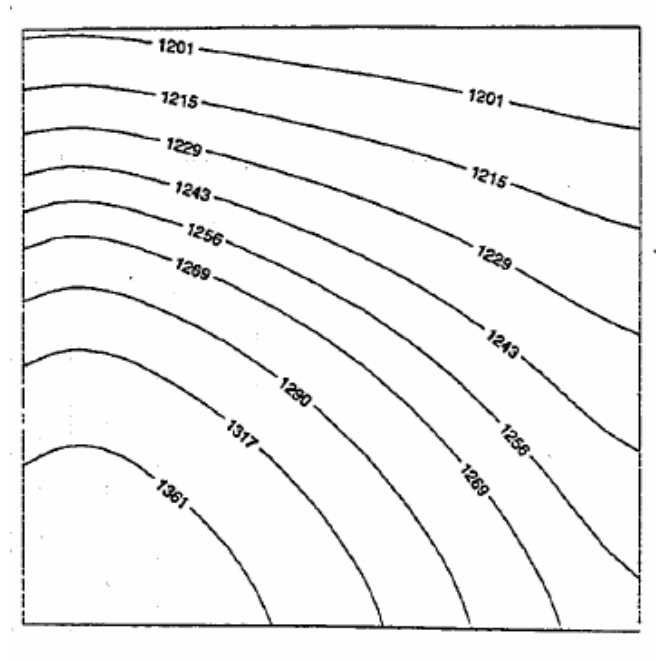

(b)

Figure 6.8: Temperature contours for cross flow configuration; (a) DREAM, and (b) Risø (Achenbach [63])

Table 6.4: Predictions for key parameters for co flow configuration

\begin{tabular}{|c|c|c|c|c|c|c|c|}
\hline Author & $\begin{array}{c}\text { Voltage } \\
(\mathrm{V})\end{array}$ & $\begin{array}{c}\mathrm{i}_{\max } \\
\left(\mathrm{A} / \mathrm{m}^{2}\right)\end{array}$ & $\begin{array}{c}\mathrm{i}_{\min }\left(\mathrm{A} / \mathrm{m}^{2}\right) \\
\text { I }\end{array}$ & $\begin{array}{c}\text { Max. solid } \\
\mathrm{T}\left({ }^{0} \mathrm{C}\right)\end{array}$ & $\begin{array}{c}\text { Min. solid } \\
\mathrm{T}\left({ }^{0} \mathrm{C}\right)\end{array}$ & $\begin{array}{c}\text { Air Exit } \mathrm{T} \\
\left({ }^{0} \mathrm{C}\right)\end{array}$ & $\begin{array}{c}\text { Fuel Exit } \\
\mathrm{T}\left({ }^{0} \mathrm{C}\right)\end{array}$ \\
\hline II & 0.714 & 3930 & 1207 & 1059 & 928 & 1055 & 1056 \\
\hline III & 0.722 & 3840 & 1020 & 1069 & 916 & 1068 & 1058 \\
\hline IV & 0.71 & 3933 & 1191 & 1058 & 930 & 1055 & 1058 \\
\hline V & 0.706 & 3725 & 1237 & 1059 & 913 & 1059 & 1059 \\
\hline VI & 0.712 & 3863 & 1236 & 1049 & 909 & 1048 & 1048 \\
\hline VII & 0.702 & 3956 & 1366 & 1098 & 970 & 1067 & 1067 \\
\hline VIII & 0.704 & 3739 & 1296 & 1061 & 924 & 1059 & 1061 \\
\hline D & 0.711 & 4191 & 718 & 1068 & 929 & 1065 & 1067 \\
\hline Mean & 0.710 & 3868 & 1240 & 1064 & 927 & 1059 & 1060 \\
\hline SD & 0.006 & 94 & 111 & 15 & 19 & 7 & 7 \\
\hline Dev & 0.001 & 323 & 522 & 4 & 2 & 14 & 7 \\
\hline
\end{tabular}


Table 6.5: Predictions for key parameters for counter flow configuration

\begin{tabular}{|c|c|c|c|c|c|c|c|}
\hline Author & $\begin{array}{c}\text { Voltage } \\
(\mathrm{V})\end{array}$ & $\begin{array}{c}\mathrm{i}_{\max } \\
\left(\mathrm{A} / \mathrm{m}^{2}\right)\end{array}$ & $\begin{array}{c}\mathrm{i}_{\min } \\
\left(\mathrm{A} / \mathrm{m}^{2}\right)\end{array}$ & $\begin{array}{c}\text { Max. solid } \\
\mathrm{T}\left({ }^{\circ} \mathrm{C}\right)\end{array}$ & $\begin{array}{c}\text { Min. solid } \\
\mathrm{T}\left({ }^{\circ} \mathrm{C}\right)\end{array}$ & $\begin{array}{c}\text { Air Exit } \mathrm{T} \\
\left({ }^{\circ} \mathrm{C}\right)\end{array}$ & $\begin{array}{c}\text { Fuel Exit } \\
\mathrm{T}\left({ }^{\circ} \mathrm{C}\right)\end{array}$ \\
\hline I & 0.713 & 7550 & 1225 & 1070 & 912 & 1064 & 911 \\
\hline II & 0.720 & 8423 & 1151 & 1078 & 909 & 1067 & 909 \\
\hline III & 0.730 & 8970 & 1080 & 1083 & 906 & 1080 & 906 \\
\hline IV & 0.71 & 7862 & 1113 & 1084 & 912 & 1073 & 912 \\
\hline V & 0.712 & 7910 & 1163 & 1073 & 906 & 1070 & 906 \\
\hline VI & 0.716 & 8513 & 1135 & 1062 & 904 & 1061 & 1064 \\
\hline VII & 0.709 & 7391 & 1235 & 1082 & 913 & 1082 & 914 \\
\hline VIII & 0.710 & 7107 & 1187 & 1075 & 910 & 1070 & 910 \\
\hline D & 0.722 & 7238 & 1004 & 1084 & 913 & 1076 & 915 \\
\hline Mean & 0.715 & 7966 & 1161 & 1076 & 909 & 1071 & 929 \\
\hline SD & 0.007 & 629 & 53 & 8 & 3 & 7 & 55 \\
\hline Dev & 0.007 & 628 & 157 & 8 & 4 & 5 & 14 \\
\hline
\end{tabular}

Table 6.6: Predictions for key parameters for cross flow configuration

\begin{tabular}{|c|c|c|c|c|c|c|c|}
\hline Author & $\begin{array}{c}\text { Voltage } \\
(\mathrm{V})\end{array}$ & $\begin{array}{c}\mathrm{i}_{\max } \\
\left(\mathrm{A} / \mathrm{m}^{2}\right)\end{array}$ & $\begin{array}{c}\mathrm{i}_{\min } \\
\left(\mathrm{A} / \mathrm{m}^{2}\right)\end{array}$ & $\begin{array}{c}\text { Max. solid } \\
\mathrm{T}\left({ }^{\circ} \mathrm{C}\right)\end{array}$ & $\begin{array}{c}\text { Min. solid } \\
\mathrm{T}\left({ }^{\circ} \mathrm{C}\right)\end{array}$ & $\begin{array}{c}\text { Air Exit T } \\
\left({ }^{\circ} \mathrm{C}\right)\end{array}$ & $\begin{array}{c}\text { Fuel Exit } \mathrm{T} \\
\left({ }^{0} \mathrm{C}\right)\end{array}$ \\
\hline I & 0.707 & 10185 & 657 & 1170 & 912 & 1063 & 952 \\
\hline II & 0.717 & 12771 & 591 & 1220 & 911 & 1066 & 948 \\
\hline III & 0.723 & 10880 & 590 & 1153 & 910 & 1079 & 952 \\
\hline IV & 0.70 & 10526 & 595 & 1182 & 915 & 1040 & 954 \\
\hline V & 0.708 & 10261 & 604 & 1157 & 907 & 1067 & 952 \\
\hline VI & 0.715 & 10727 & 578 & 1121 & 909 & 1057 & 957 \\
\hline VII & 0.704 & 9179 & 757 & 1170 & 918 & 1078 & 961 \\
\hline VIII & 0.707 & 8813 & 723 & 1162 & 913 & 1067 & 953 \\
\hline D & 0.722 & 8418 & 675 & 1155 & 914 & 1080 & 965 \\
\hline Mean & 0.710 & 10418 & 637 & 1167 & 912 & 1065 & 954 \\
\hline SD & 0.008 & 1198 & 69 & 28 & 3 & 12 & 4 \\
\hline Dev & 0.012 & 2000 & 38 & 12 & 2 & 15 & 9 \\
\hline
\end{tabular}




\subsubsection{Comparison with FLUENT}

Alterations were made to the benchmark case (Achenbach [63]) for simulations with FLUENT SOFC module. This became necessary since the conductivities of interconnect, electrodes and electrolyte are all defined as functions of temperature in the benchmark. In case of FLUENT SOFC model, the conductivities are constant except for the electrolyte for which the temperature dependence of conductivity is hard coded with values for a standard electrolyte. Thus, constant values were used for the electrical conductivities instead of temperature dependant conductivities as prescribed in the benchmark. The altered benchmark case is run using FLUENT and DREAM models for co-flow and counter-flow configurations and the results are compared. To match the diffusion coefficients used in the two models, dilute approximation is chosen in FLUENT (multi-component diffusion is the default) as was done in DREAM. The constant diffusivity values used are $1.88 \times 10^{-4} \mathrm{~m}^{2} / \mathrm{s}$ and $7.82 \times 10^{-4} \mathrm{~m}^{2} / \mathrm{s}$, for oxygen and hydrogen, respectively. Results are presented for co-flow and counter flow cases in Figs. 6.9 through 6.14

Figure 6.9 shows the details of $y$-current density distribution at the active anode/electrolyte interface as estimated by DREAM SOFC and FLUENT for the co-flow SOFC. It can be seen from Fig. 6.9 that DREAM predicts higher current densities near the entrance region, which decrease gradually along the direction of gas flow, whereas in the FLUENT results, variation is only limited to the entrance region with almost constant current through most of the active area. Qualitatively, however, the two models predict similar current distributions with high current densities occurring in the regions adjacent to the ribs. This can be clearly seen from the profiles of current density along the direction of flow shown in Fig. 6.9c. The reasons for the difference in the overall trend could be attributed to the different mass transport models used in the two codes within the porous electrodes, 
especially convection, which is accounted for in FLUENT and neglected in DREAM. Different strategies used in DREAM and FLUENT to account for the electric potential difference may also contribute to the discrepancies.

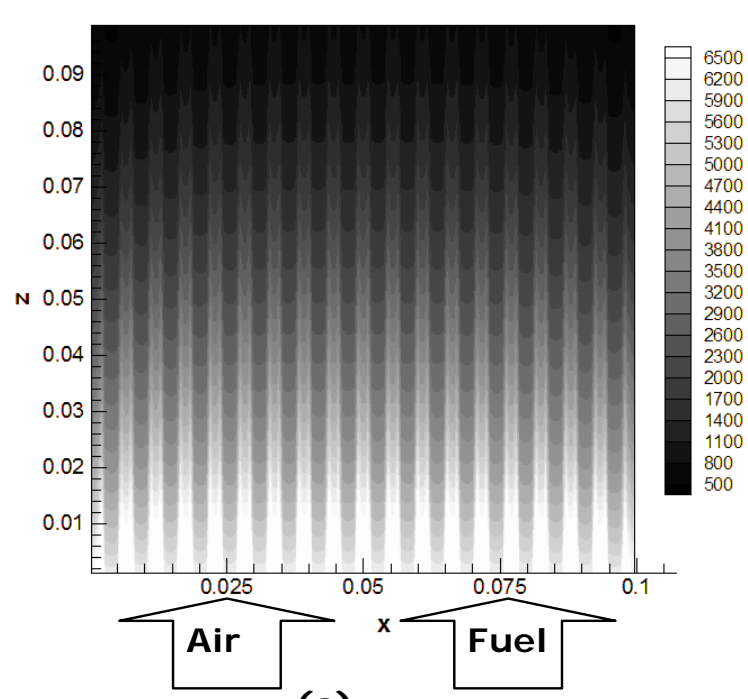

(a)

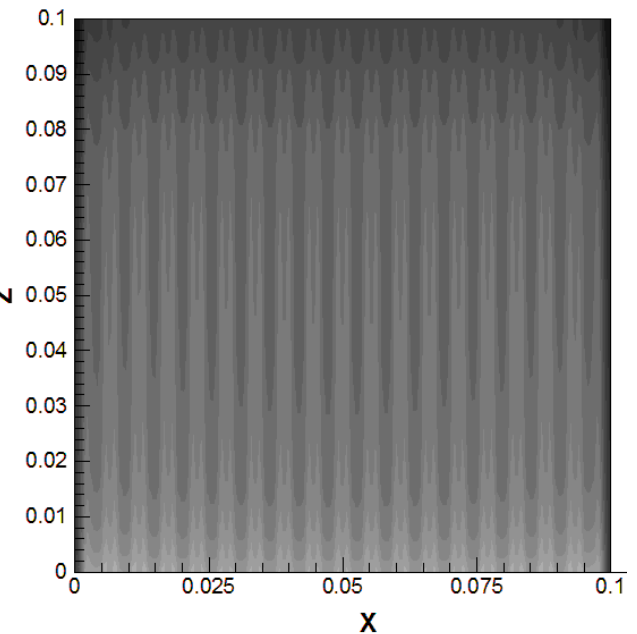

(b)

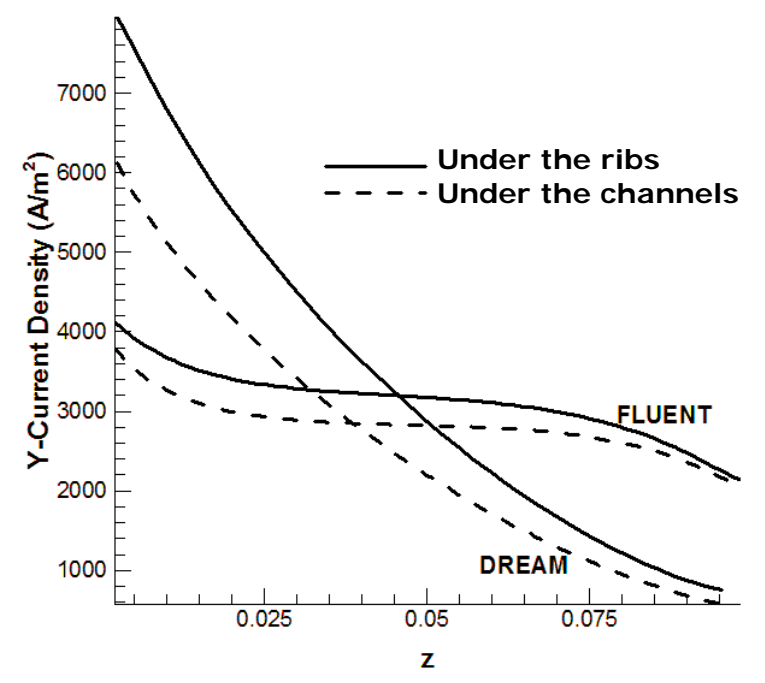

(c)

Figure 6.9: y-current density at the anode/ electrolyte interface for co-flow case; (a) DREAM (b) FLUENT, and (c) Profiles along the channel direction near the middle of the cell 


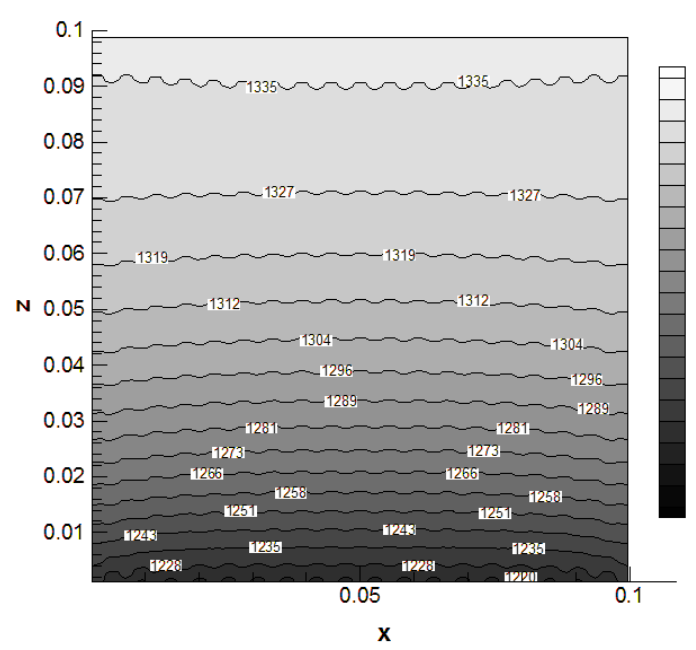

(a)

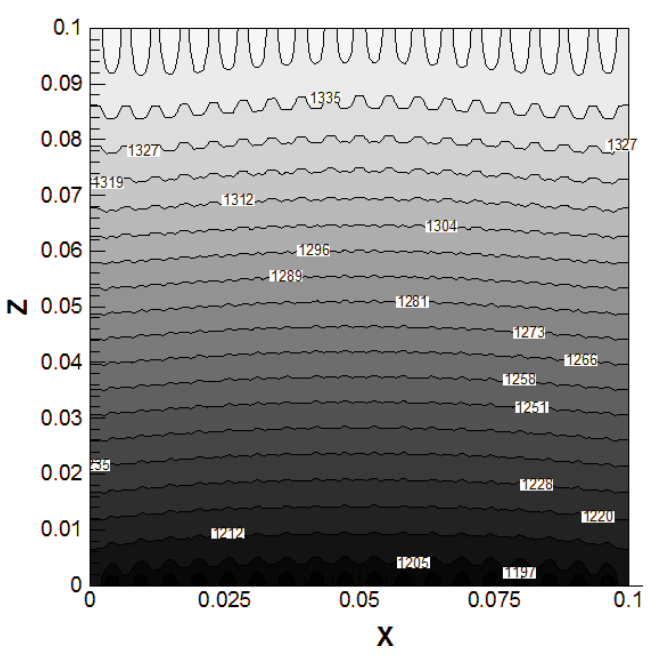

(b)

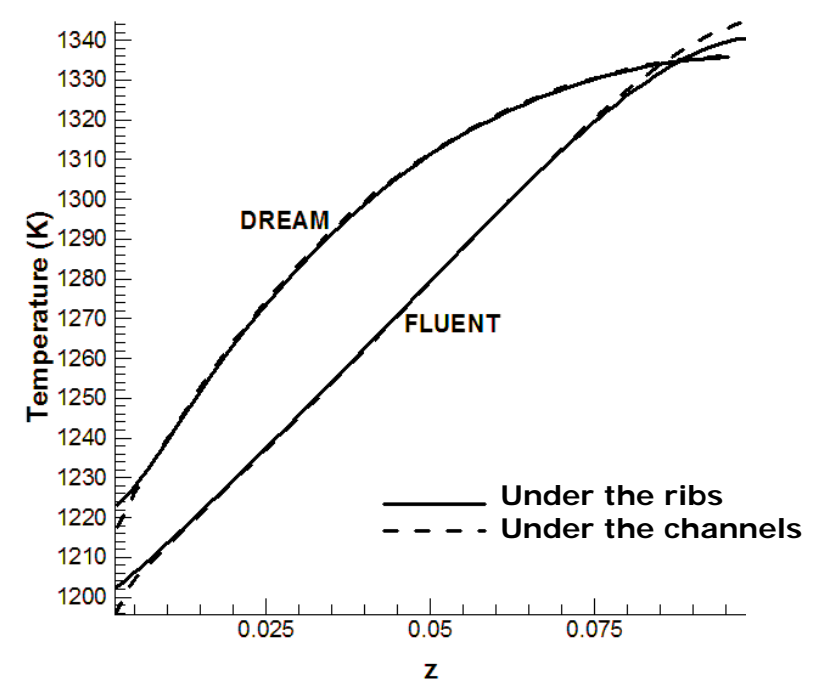

(c)

Figure 6.10: Temperature at the anode/ electrolyte interface for coflow case; (a) DREAM (b) FLUENT, and (c) Profiles along the channel direction near the middle of the cell

The temperature distributions shown in Fig. 6.10 reveal that DREAM predicts higher temperature gradients near the air entrance region compared 
to FLUENT. The reason for this disagreement, apart from the inconsistent current predictions, could be the probable mismatch of the heat transfer coefficient between gas channels and the solid walls. A Nusselt number of 20 (based on channel height) is used in DREAM, whereas in FLUENT the thermal boundary layer is supposedly resolved, which may not be accurate unless the grid is sufficiently fine. This could also be the cause for slight differences in the qualitative behavior of temperature distributions at the anode/electrolyte interface shown in Figs. 6.10a \& 6.10b. It must be noted that both models predict the cell voltage to be around $0.72 \mathrm{~V}$ (see Table 6.7). Since the same amount of fuel and air are being used and the same amount of useful work is produced (with no heat loss to the surroundings) in the two cases, the exit temperatures of the gasses should be the same according to the first law. The gas exit temperatures calculated by the two models are in close agreement and are consistent with the values estimated by the overall energy balance of the cell, a zero-dimensional model.

The hydrogen mass fraction results shown in Fig. 6.11 exhibit reasonable agreement in the overall variation along the direction of gas flow except for some minor discrepancies, which are related to the different current distributions estimated by the two models. The details of concentration distributions, however, are somewhat different. FLUENT is predicting higher levels of variation in concentrations between the regions adjacent to the channels and regions adjacent to the ribs compared to DREAM, which can be clearly seen from the profiles in Fig. 6.11c. This, once again, could be a result of different mass transport models used inside the porous electrodes. 


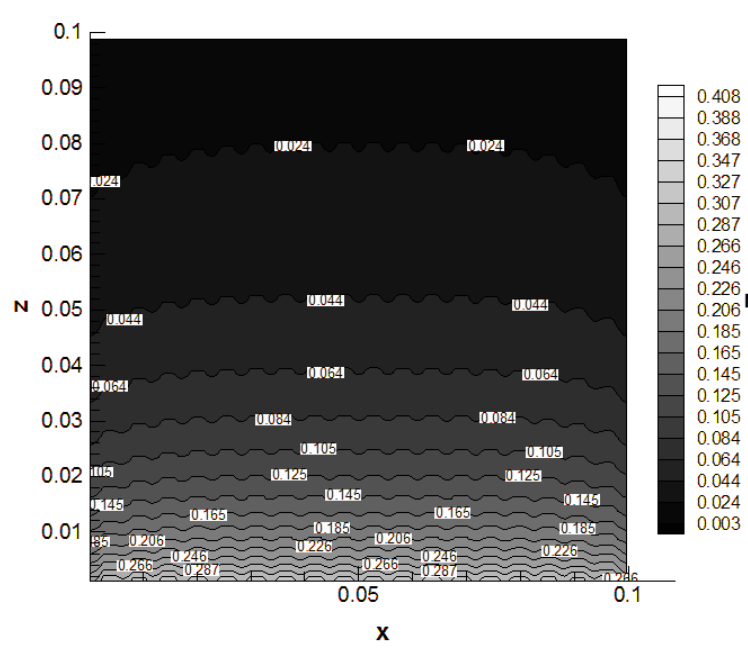

(a)

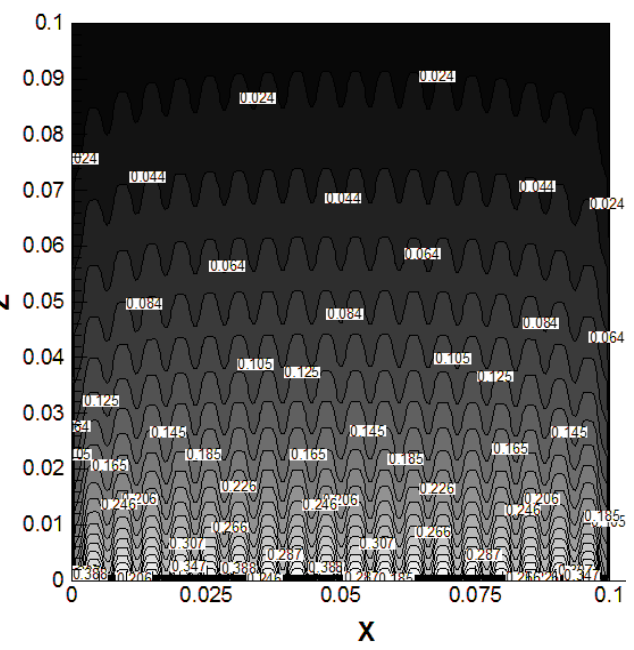

(b)

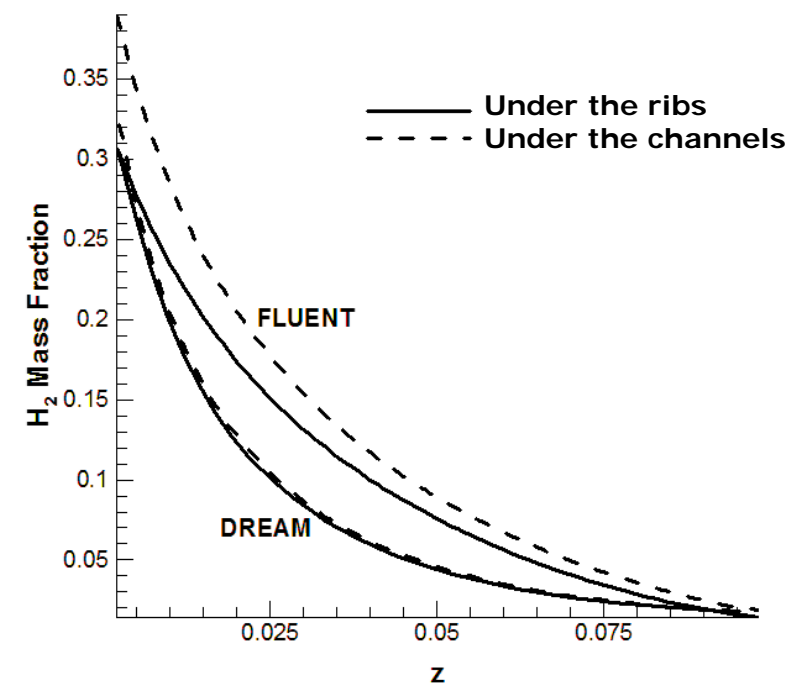

(c)

Figure 6.11: Hydrogen mass fraction at the anode/ electrolyte interface for co-flow case; (a) DREAM (b) FLUENT, and (c) Profiles along the channel direction near the middle of the cell 
Finally, current, temperature, and concentration results for the counter-flow configuration are presented in Figs. 6.12, 6.13, \& 6.14 respectively. The predictions from the two models were somewhat different as was the case in the co-flow case. The nature of differences is also similar to the ones seen in co-flow runs. Thus, it can be understood that the reasons for such disagreement could also be the same as above. Also, a comparison of the key parameters predicted by the two models is presented in Tables 6.7 $\& 6.8$.

Due to the absence of detailed experimental results, it is difficult to judge which model predictions are more accurate. Thus, it is imperative to have good agreement between different models in order to gain confidence in their accuracy. In the present study, while the two models predicted similar behavior in the average sense consistent with overall mass and energy balances, there are differences in the details of the distributions. There are some clues to the sources of the observed disagreement and further work is required to elucidate the factors that may be causing these differences.

In conclusion DREAM SOFC was validated using published results and it was shown that the results from the DREAM have almost identical average behavior as the results of models from the literature. Minor alterations were made to the benchmark case and the new case was simulated using DREAM and a fully three-dimensional model FLUENT SOFC. A comparison of the results from FLUENT and DREAM showed few discrepancies in the details of distributions. The reasons for the discrepancy could be different modeling strategies used in the two codes. Also, the difference in the modeling parameters such as Nusselt number may have contributed to the disagreement. It is believed that such differences should be kept to a minimum in order to establish confidence in the model predictions. Moreover, detailed experiments are needed to assess the correctness of any of the models. 

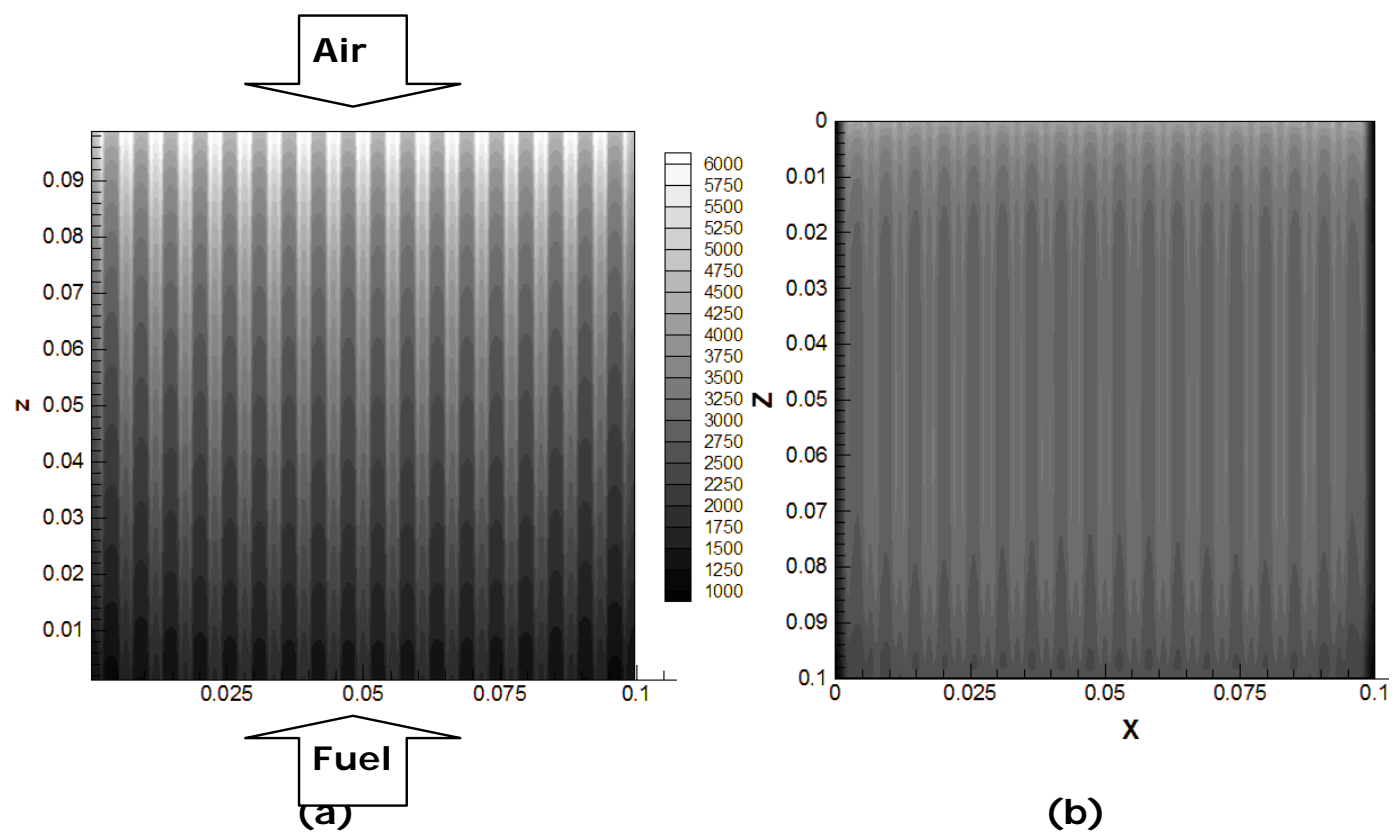

(b)

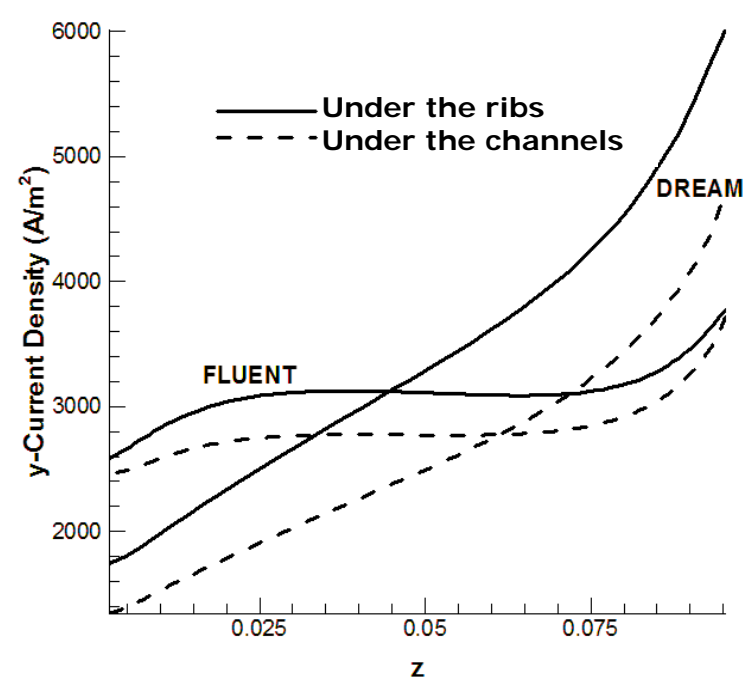

(c)

Figure 6.12: y-current density at the anode electrolyte interface for counter-flow case; (a) DREAM (b) FLUENT (c) Profiles along the channel direction near the middle of the cell 


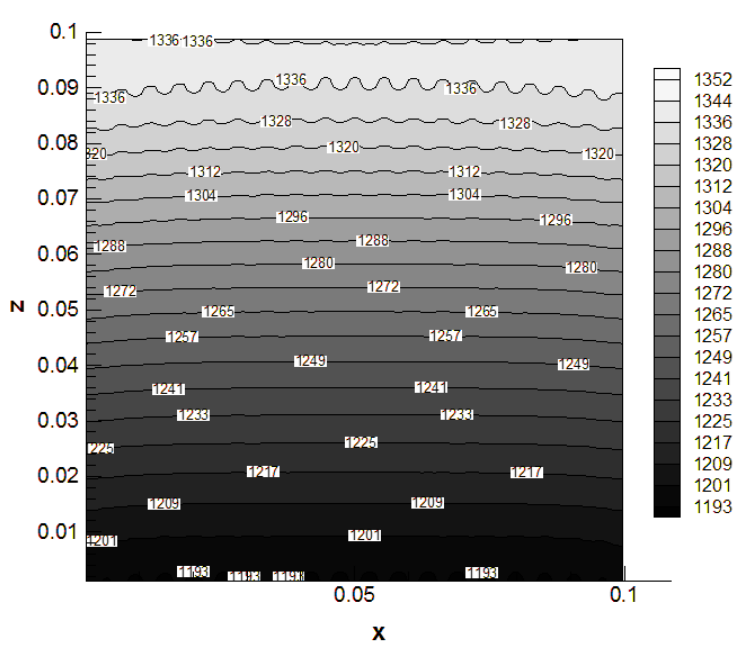

(a)

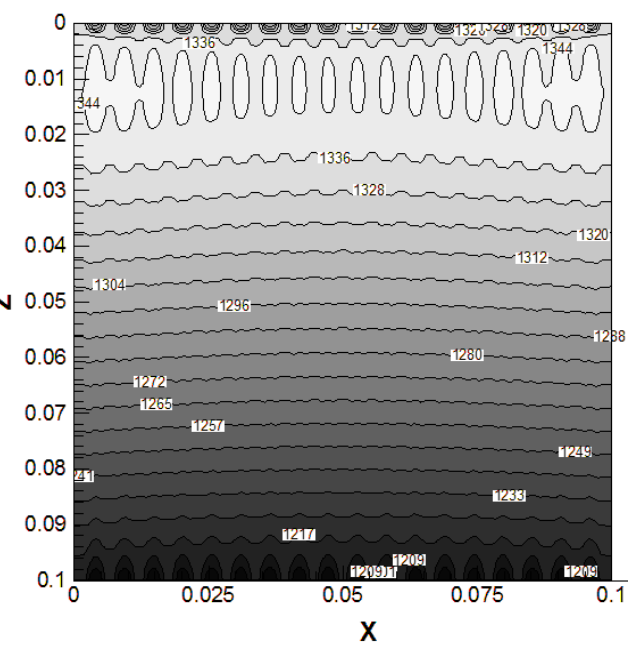

(b)

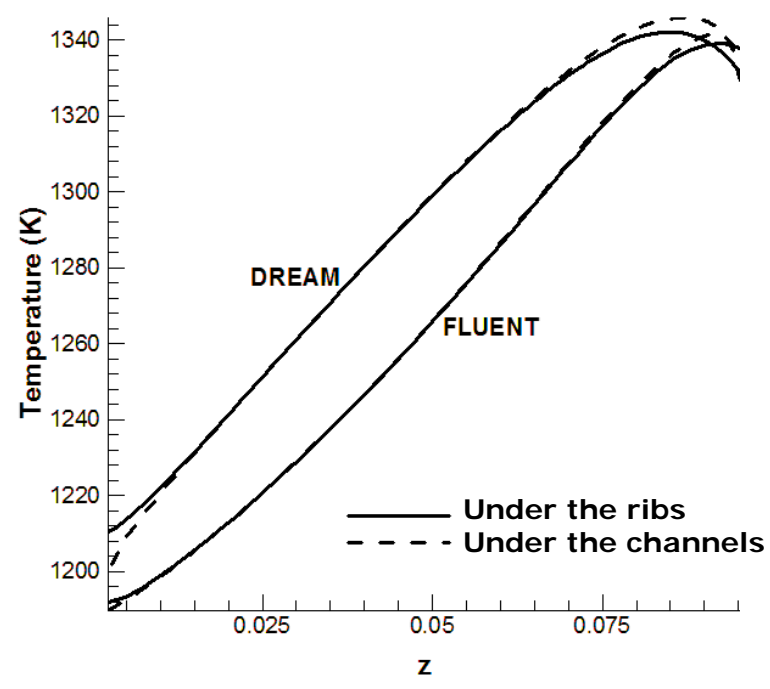

(c)

Figure 6.13: Temperature at the anode electrolyte interface for counter-flow case; (a) DREAM (b) FLUENT, and (c) Profiles along the channel direction near the middle of the cell 


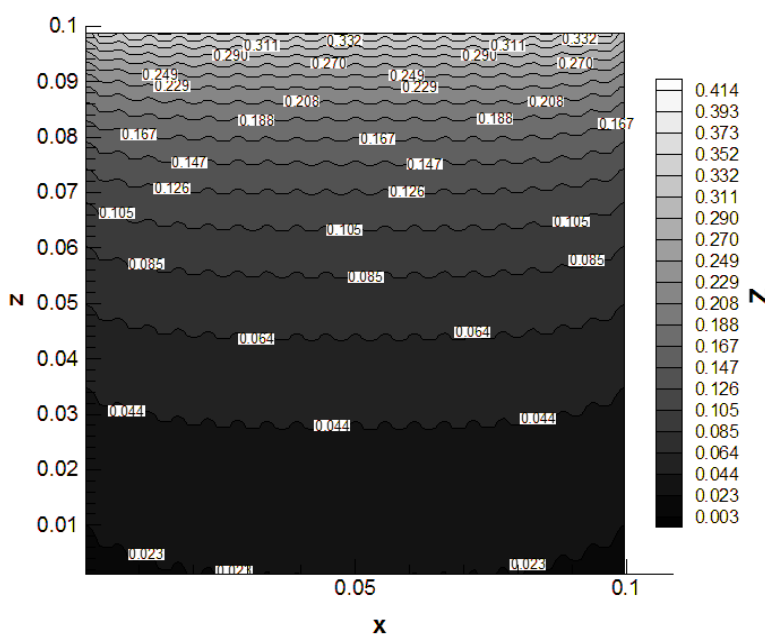

(a)

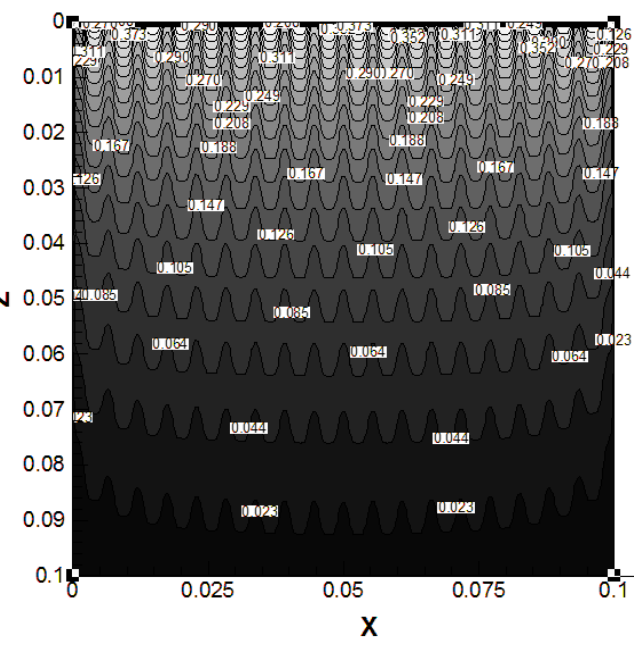

(b)

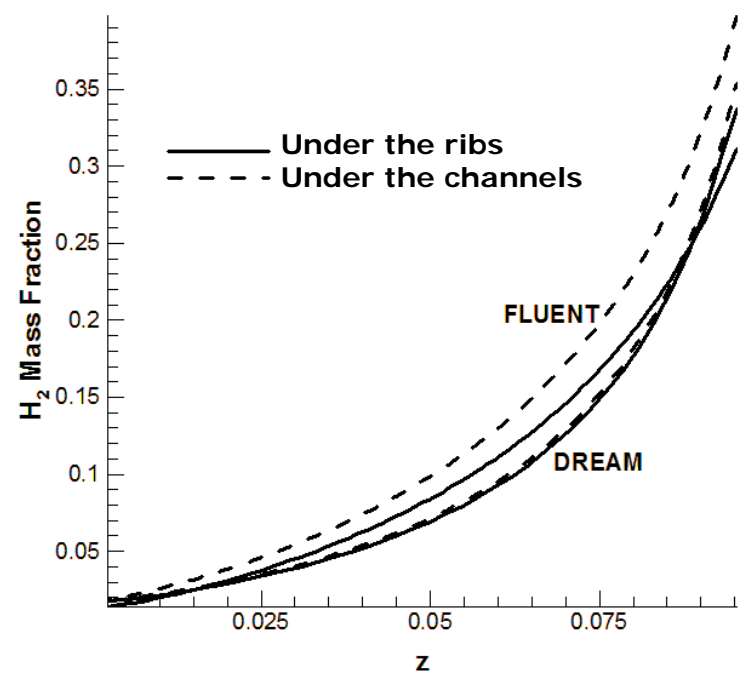

(c)

Figure 6.14: Hydrogen mass fraction at the anode/ electrolyte interface for counter-flow case; (a) DREAM (b) FLUENT, and (c) Profiles along the channel direction near the middle of the cell 
Table 6.7: Predictions for key parameters for co-flow configuration

\begin{tabular}{|c|c|c|c|c|c|c|c|}
\hline Model & $\begin{array}{c}\text { Voltage } \\
(\mathrm{V})\end{array}$ & $\begin{array}{c}\mathrm{i}_{\max } \\
\left(\mathrm{A} / \mathrm{m}^{2}\right)\end{array}$ & $\begin{array}{c}\mathrm{i}_{\min } \\
\left(\mathrm{A} / \mathrm{m}^{2}\right)\end{array}$ & $\begin{array}{c}\text { Max. solid } \\
\mathrm{T}(\mathrm{K})\end{array}$ & $\begin{array}{c}\text { Min. solid } \\
\mathrm{T}(\mathrm{K})\end{array}$ & $\begin{array}{c}\text { Air Exit } \mathrm{T} \\
(\mathrm{K})\end{array}$ & $\begin{array}{c}\text { Fuel Exit } \\
\mathrm{T}(\mathrm{K})\end{array}$ \\
\hline $\mathrm{D}$ & 0.726 & 8774 & 458 & 1336 & 1217 & 1335 & 1335 \\
\hline $\mathrm{F}$ & 0.728 & 4549 & 819 & 1342 & 1196 & 1335 & 1343 \\
\hline
\end{tabular}

Table 6.8: Predictions of key parameters for counter flow configuration

\begin{tabular}{|c|c|c|c|c|c|c|c|}
\hline Model & $\begin{array}{c}\text { Voltage } \\
(\mathrm{V})\end{array}$ & $\begin{array}{c}\mathrm{i}_{\max } \\
\left(\mathrm{A} / \mathrm{m}^{2}\right)\end{array}$ & $\begin{array}{c}\mathrm{i}_{\min } \\
\left(\mathrm{A} / \mathrm{m}^{2}\right)\end{array}$ & $\begin{array}{c}\text { Max. solid } \\
\mathrm{T}(\mathrm{K})\end{array}$ & $\begin{array}{c}\text { Min. solid } \\
\mathrm{T}(\mathrm{K})\end{array}$ & $\begin{array}{c}\text { Air Exit } \mathrm{T} \\
(\mathrm{K})\end{array}$ & $\begin{array}{c}\text { Fuel Exit } \\
\mathrm{T}(\mathrm{K})\end{array}$ \\
\hline $\mathrm{D}$ & 0.757 & 6659 & 1168 & 1342 & 1191 & 1335 & 1207 \\
\hline $\mathrm{F}$ & 0.732 & 4413 & 1028 & 1345 & 1202 & 1335 & 1203 \\
\hline
\end{tabular}




\section{CHAPTER 7: PARAMETRI C STUDY}

\subsection{Introduction}

Following the successful verification of DREAM SOFC, several parametric studies were performed. This chapter presents the results of numerical investigations done using DREAM SOFC to study the effect of grid, temperature dependence of conductivities, electrolyte-thickness and the heat transfer coefficient on the performance of the SOFC. Geometry of the SOFC, grid, material properties and the operating conditions for all the cases are same as the benchmark case presented in Chapter 6 unless specified otherwise.

\subsection{Grid Sensitivity}

Though the results of the verification study presented in Chapter 6 show that the DREAM SOFC is consistent with the other models from literature, it was not established that the results are not sensitive to further grid refinement. To confirm that the grid density used in the study was detailed enough the co-flow case with constant conductivities (altered benchmark case used for comparison with FLUENT SOFC) was repeated with a coarser grid. The fine grid has $111 \times 21 \times 20$ nodes as opposed to $148 \times$ $35 \times 40$ in the original grid. 


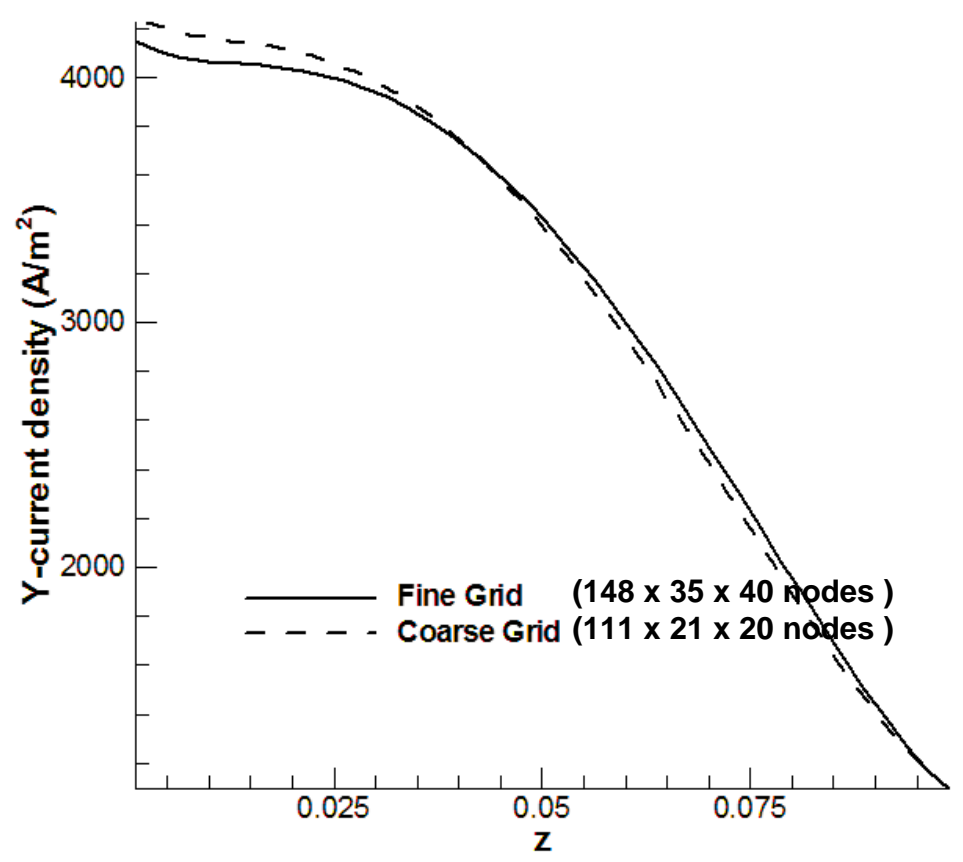

Figure 7.1: Effect of grid density on the current distribution

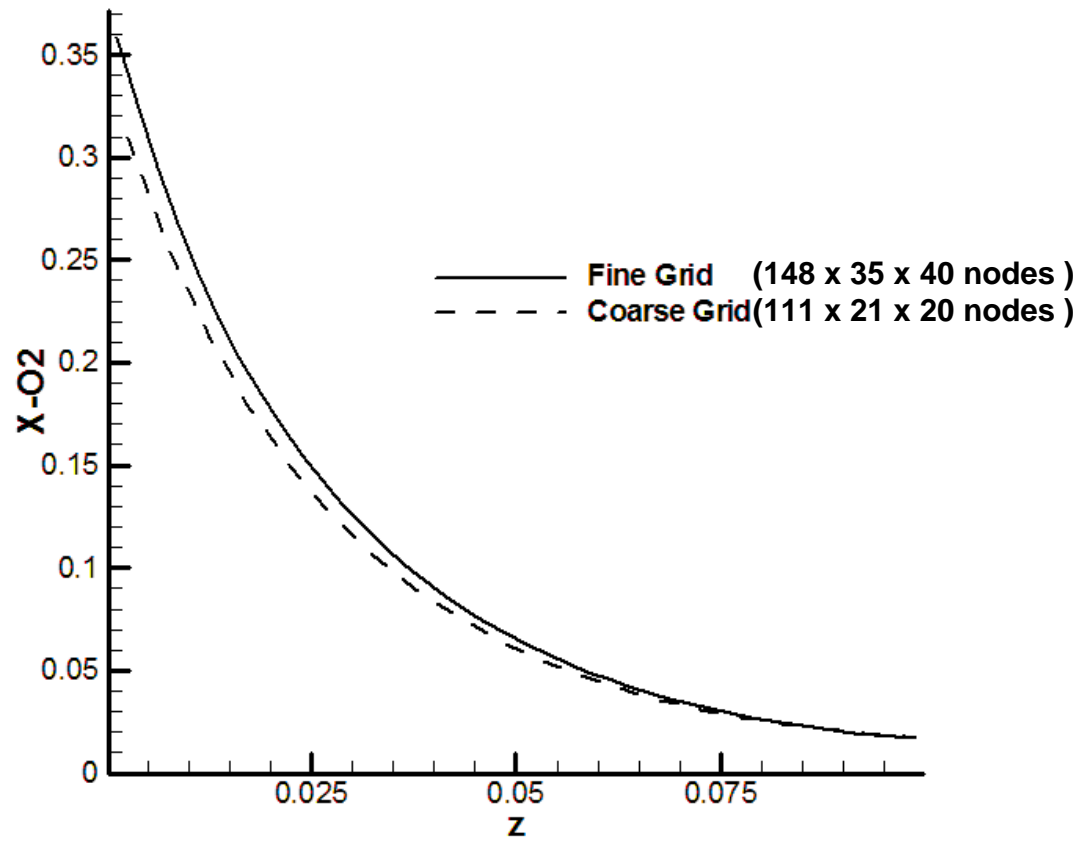

Figure 7.2: Effect of grid density on the hydrogen mass fraction distribution 


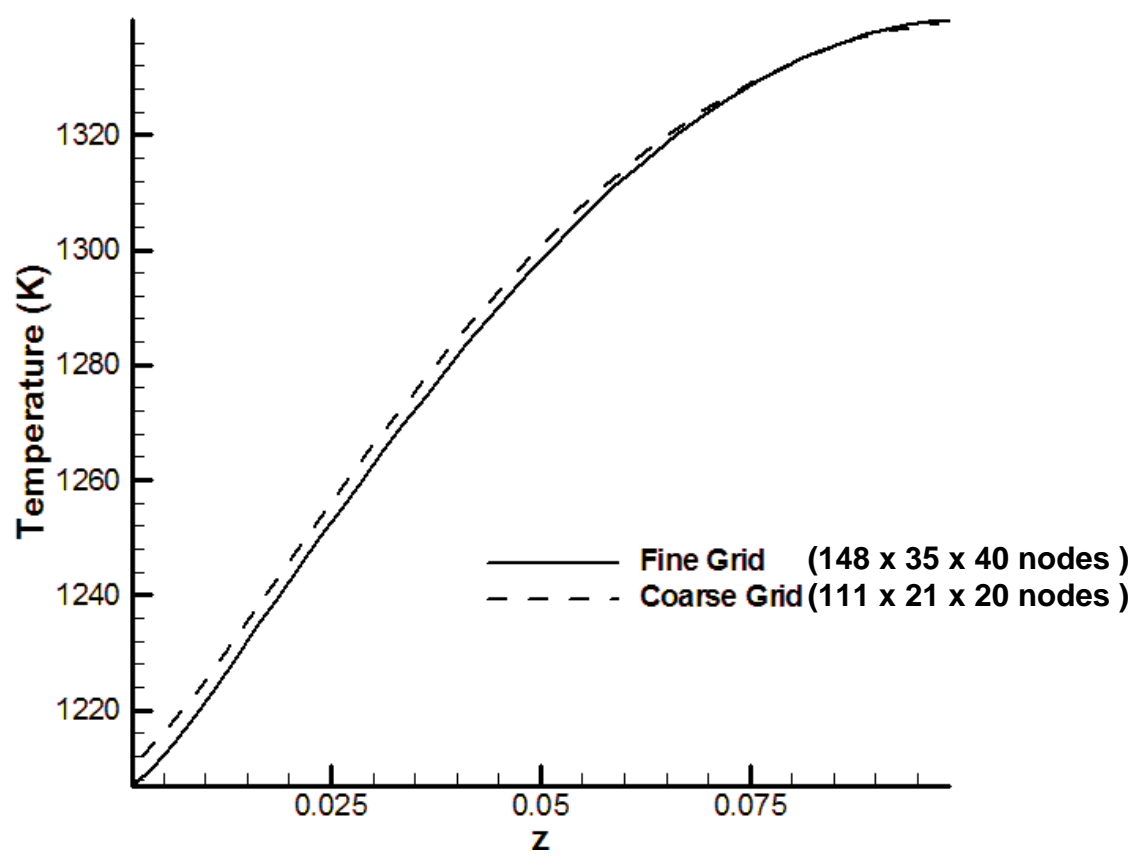

Figure 7.3: Effect of grid density on the temperature distribution

The results of the fine and the coarse grid cases are compared in Figs. 7.1 through 7.3 using profiles along the flow direction at the center of the cell in the electrolyte/anode interface plane. It can be seen from Fig. 7.1 that the current density is not significantly affected by the grid refinement. Similarly, the profiles of temperature and hydrogen concentration shown in Figs 7.2 and 7.3 reveal that the solution is only slightly affected by the grid and that too only near the inlet.

To obtain a more formal assessment of numerical uncertainty in the calculations, Richardson's extrapolation was used to extrapolate the solution to the zero grid size using the following relation.

$$
\varphi_{e x t}=\frac{r^{p} \varphi_{h_{1}}-\varphi_{h_{2}}}{r^{p}-1}
$$


Where $\varphi_{h_{1}}$ and $\varphi_{h_{2}}$ are solutions on two different grids, $\varphi_{\text {ext }}$ is the extrapolated solution, $p$ is the order of the numerical method and $r$ is the ratio of average grid sizes $\left(\frac{h_{2}}{h_{1}}\right)=\left(\frac{N_{1}^{\text {tot }}}{N_{2}^{\text {tot }}}\right)^{\frac{1}{3}}$ ( $N^{\text {tot }}$ denotes total number of nodes in each grid). The extrapolated can then be used to calculate the following parameters which quantify the uncertainty in the computations [64].

Grid Convergence Index

$$
G C I=1.25\left|\frac{\varphi_{e x t}-\varphi_{f}}{\varphi_{f}}\right|
$$

Extrapolated Relative Error

$$
E R E=\left|\frac{\varphi_{e x t}-\varphi_{f}}{\varphi_{e x t}}\right|
$$

Here $\varphi_{h}$ is the solution on the fine grid. Predicted minimum solid temperature was chosen for error analysis since it is one of the global parameters that varied most between the fine grid $(1202.24 \mathrm{~K})$ and coarse grid $(1209.067 \mathrm{~K})$ solutions. Since the three-dimensional solution was of second order and the one-dimensional gas channel model was first order, the order of the overall solution was chosen as 1.5. The grid ratio between the fine and coarse grids was 1.644. With these values the extrapolated value of the minimum solid temperature was $1196.079 \mathrm{~K}$. The Grid Convergence Index was $0.64 \%$ and Extrapolated Relative Error was $0.52 \%$ (i.e. approximately $\pm 6 \mathrm{~K}$. Thus it can be concluded that the solution obtained from the coarse grid is practically grid independent. 
An important observation from Figs 7.2 and 7.3 is that the gradient of concentration and temperature is not zero near the inlet though no-flux condition is prescribed at this boundary. This was thought to be a result of the fact that there are sources of species and heat due to the high current densities near the boundary (Fig. 7.1). To see if this is indeed the case, a new case is simulated where there is a small region near the entrance of gasses where there is no electrochemical activity and thus there are no species and heat sources. The inactive area is first $12.5 \mathrm{~mm}$ along the flow direction which is one eighth of the total length. Figures 7.4 through 7.6 show the profiles of $y$-current density, specie concentration and temperature along the flow direction near the center of the cell at the anode/electrolyte interface. It can be seen from Fig. 7.4 that there is no current for first oneeighth of the cell length as mentioned already.

Figure 7.5 shows that the concentration in the inactive region is not constant though there is no current in this region. This is due to the fact that there will be diffusion through the porous electrode even in the absence of the current. The gradient of concentration near the inlet, however, seems to be approaching zero in Fig 7.5. Thus it can be concluded that the non-zero gradient at this boundary observed in the original simulation is due to the source of species due to the current. Also it can be seen from Fig. 7.5 that there is a change in the slope of the profile at the boundary of inactive and active regions which is a result of different conditions on either side of this boundary. Similarly, the profile of temperature shown in Figure 7.6 shows a change in slope at the boundary of active and inactive regions. Also, the gradient of temperature near the inlet is approaching zero as prescribed. Thus it is confirmed that if there are sources near the boundary the gradient may not be zero even if there is no flux across the boundary. 


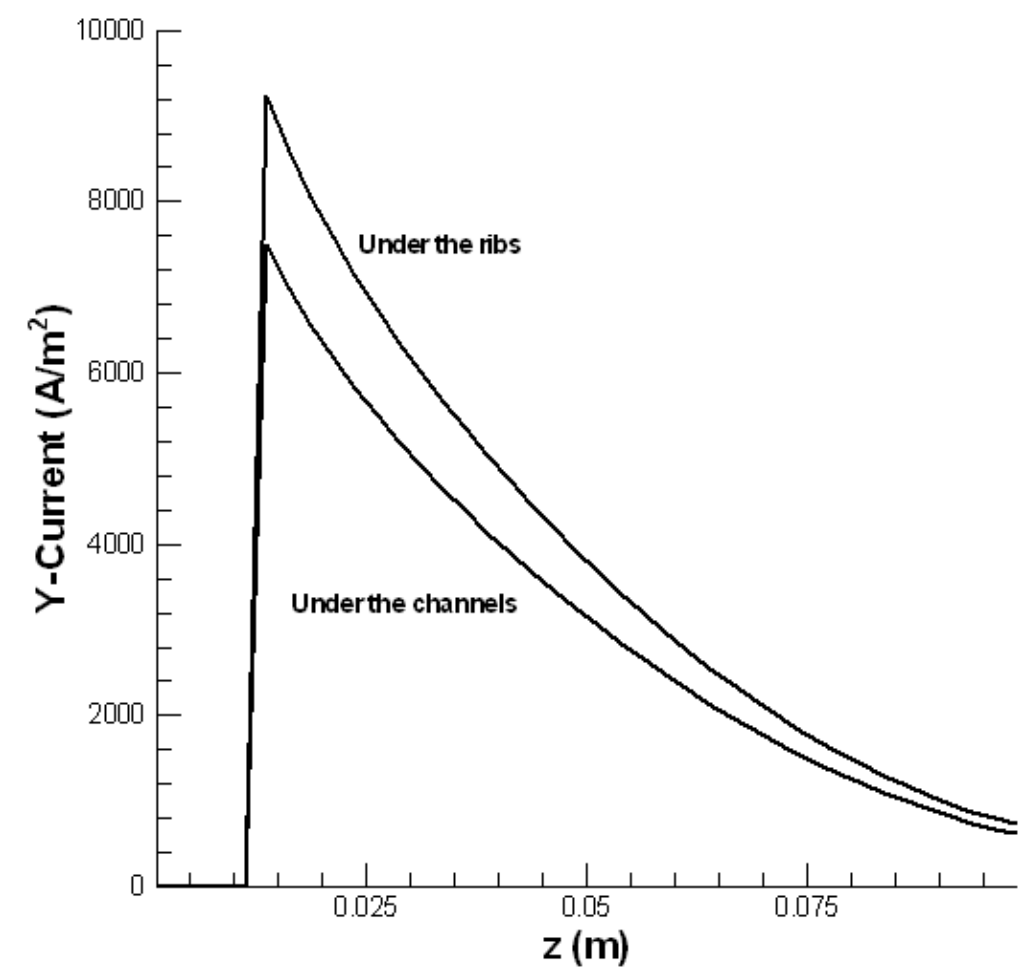

Figure 7.4: Effect of inactive entrance region on the current distribution

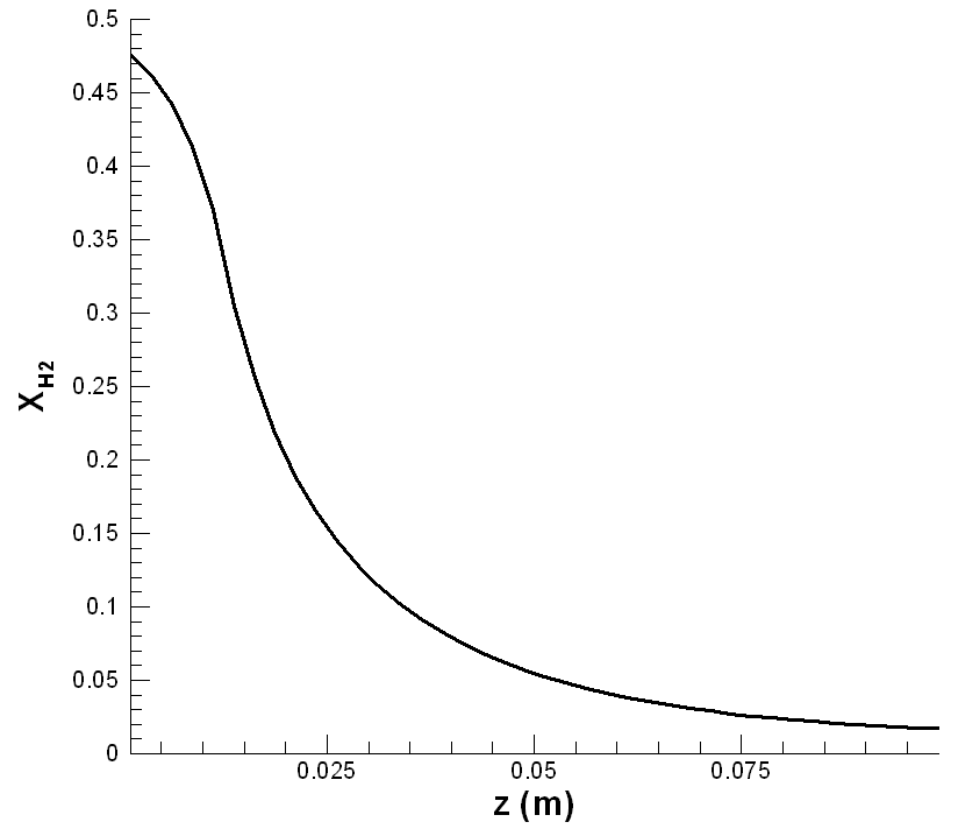

Figure 7.5: Effect of inactive entrance region on the hydrogen mass fraction distribution 


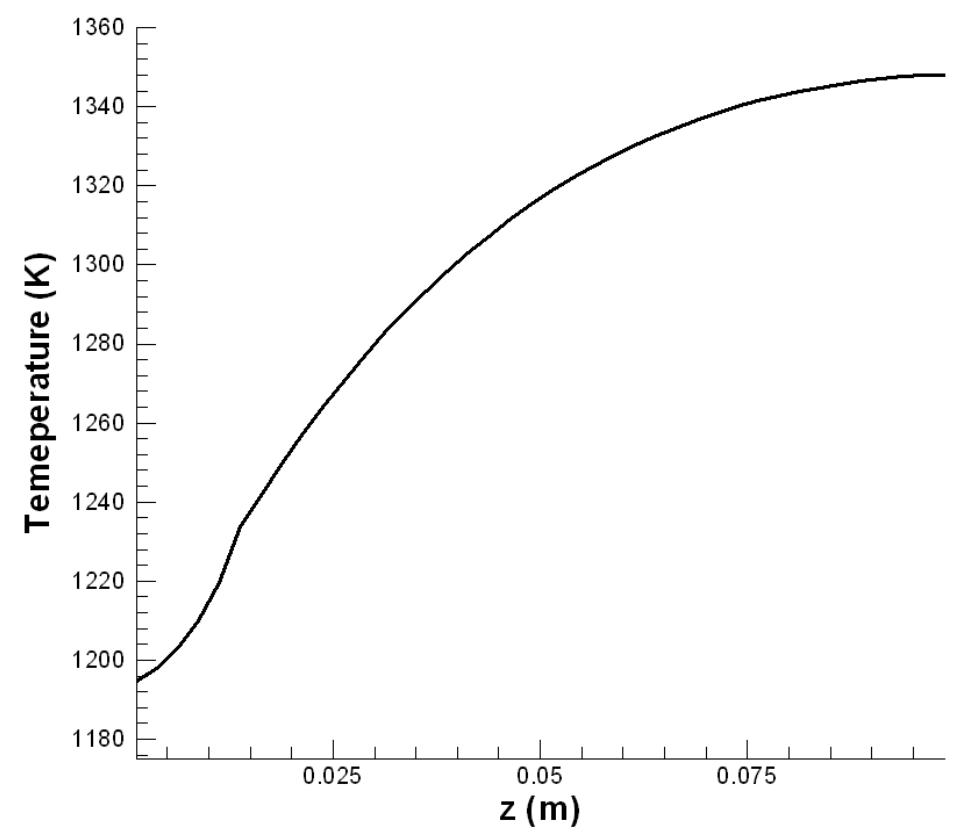

Figure 7.6: Effect of inactive entrance region on the temperature distribution

\subsection{Effect of variable electrical conductivity}

In Chapter 6, co-flow and counter-flow benchmark cases are slightly altered by making the electrical conductivity of the materials independent of temperature in order to compare DREAM SOFC with FLUENT SOFC. Here, results of DREAM SOFC for the original benchmark and constant conductivity cases are compared to assess the implications of constant conductivity assumption. Two cases were run with constant conductivities, with conductivities evaluated at temperatures $1300 \mathrm{~K}$ and $1200 \mathrm{~K}$ respectively using the formulas given in Table 6.2. Figure 7.7 shows the current density profiles along the direction of gas flow near the center of the cell at the anode/electrolyte interface for the three cases. It can be seen from the figure that there is a larger variation in current density along the direction of gas flow for the constant conductivity $(1300 \mathrm{~K})$ case than for the variable conductivity case. For variable conductivity case, the conductivity increases 
along the flow direction as the temperature increases which will in turn reduce the ohmic over-potential. As result, though the local Nernst potential decreases along the direction of gas flow, the favorable conductivity variation is conducive for relatively higher currents even near the exit where the temperatures are highest (see Fig. 7.9). For constant conductivity (1300 K) case, however, since the conductivity does not vary with temperature, the current tends to concentrate in the region close to the inlet due high activity of the reactants in this region. Also the constant values used for the conductivities are for a temperature of $1300 \mathrm{~K}$ which is towards the higher end of the range of temperatures predicted inside the cell which means that the conductivities through out the cell are relative high. The current density distribution for the second constant conductivity $(1200 \mathrm{~K})$ case has qualitatively similar behavior as the constant conductivity $(1300 \mathrm{~K})$ case but the overall range of variation is smaller. Thus qualitatively different behavior of the variable conductivity case could be attributed to the temperature dependence of electrical conductivity

The profiles of hydrogen mass fraction along the flow direction inside the fuel channel near the center of the cell shown in Fig. 7.8 are a direct result of the current distributions shown in Fig. 7.7 Since the current densities are higher near the inlet for constant conductivity cases, consumption of hydrogen is more in this region which is evident from a more rapid drop in the hydrogen concentration near the inlet for these cases compared to the variable conductivity case. The exit concentration however is same for all three cases since the total current and utilization are same for all of them. 


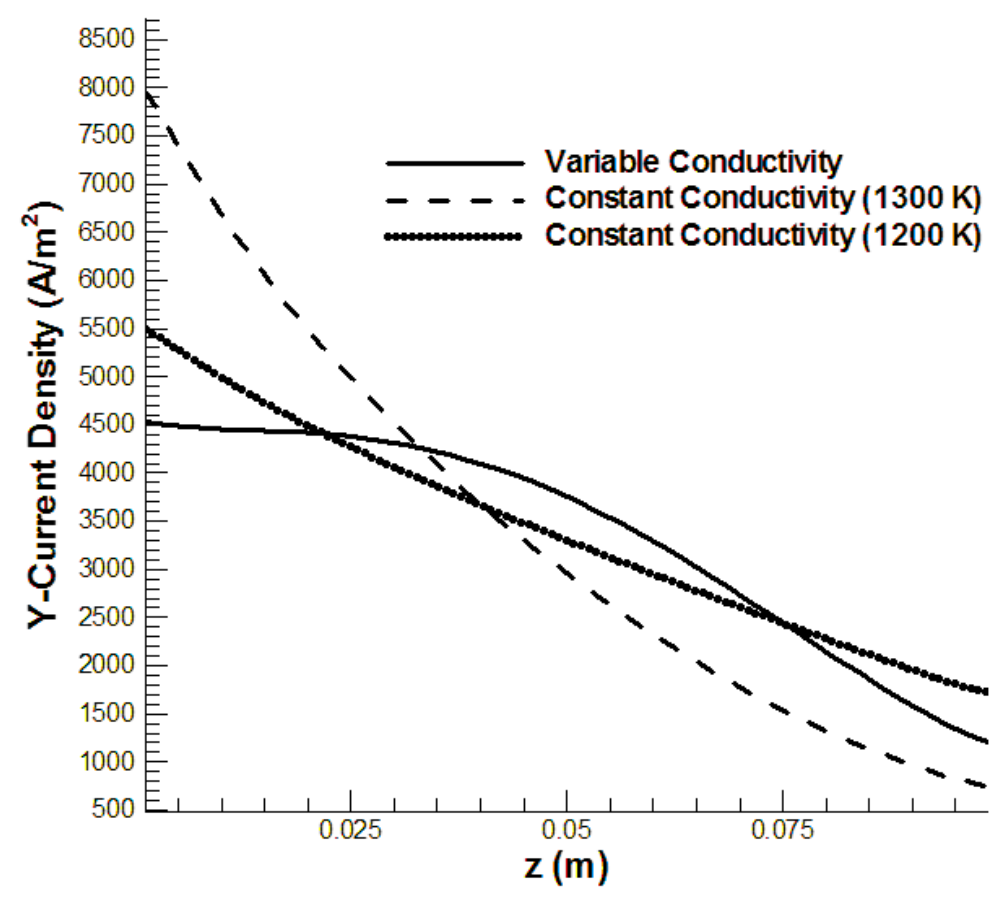

Figure 7.7: Effect of temperature dependence of conductivity on the current density distribution at the anode/ electrolyte interface for the co-flow configuration

Figure 7.9 shows temperature profiles along the flow direction inside the air channel near the center of the cell. Once again, the higher temperatures near the inlet for constant conductivity cases are due to higher current densities which cause higher ohmic and electrochemical heating in that region. The temperature at the exit is highest for the constant conductivity $(1200 \mathrm{~K})$ case. This is due to the fact that the overall heat produced is higher for this case compared to the variable conductivity and the constant conductivity $(1300 \mathrm{~K})$ cases. As it was already mentioned, the conductivities for constant conductivity cases are evaluated at $1300 \mathrm{~K}$ and $1200 \mathrm{~K}$ whereas the temperature inside the cell varies between $1173 \mathrm{~K}$ and $1340 \mathrm{~K}$ with most of the regions above $1200 \mathrm{~K}$. Thus the overall electrical conductivity is highest for constant conductivity $(1300 \mathrm{~K})$ case followed by variable conductivity and constant conductivity $(1200 \mathrm{~K})$ cases. Thus ohmic over-potential and ohmic heating are more for constant conductivity (1200 
K) and variable conductivity cases compared to the constant conductivity $(1300 \mathrm{~K})$ case. This can also be seen from overall cell voltage which is 0.726 $\mathrm{V}$ for constant conductivity $(1300 \mathrm{~K})$ case, $0.711 \mathrm{~V}$ for variable conductivity case and $0.626 \mathrm{~V}$ for constant conductivity $(1200 \mathrm{~K})$ case.

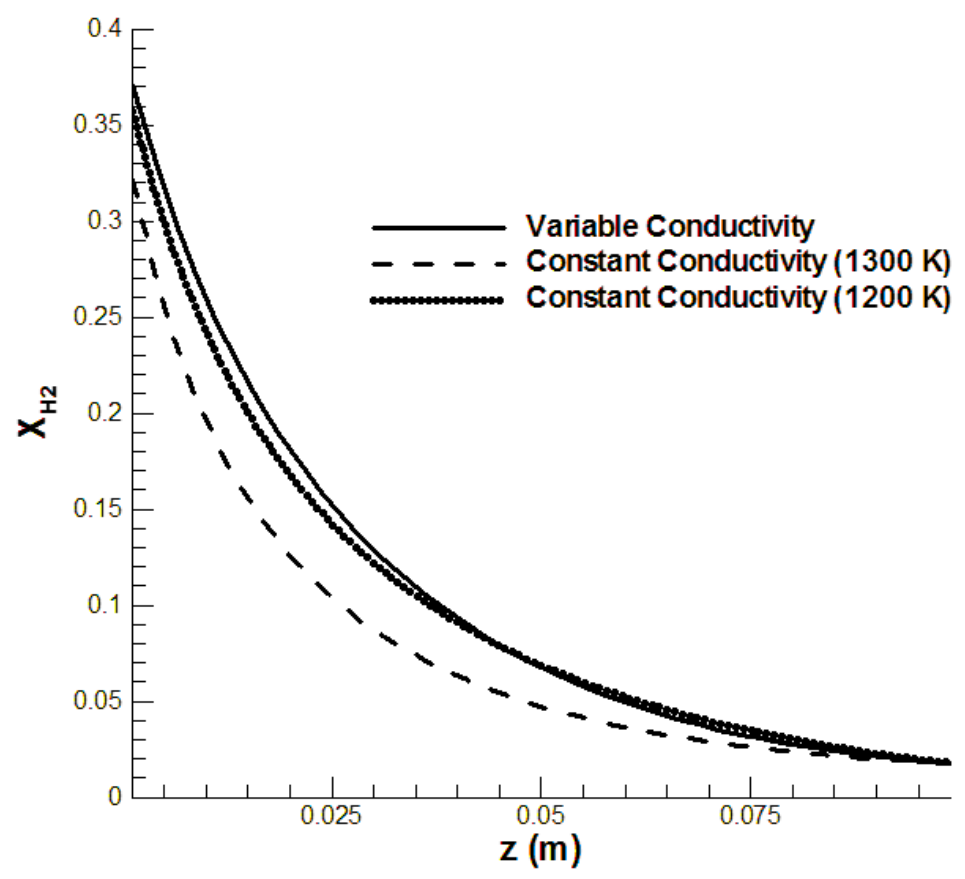

Figure 7.8: Effect of temperature dependence of conductivity on the hydrogen mass fraction distribution inside the fuel channel for co flow configuration 


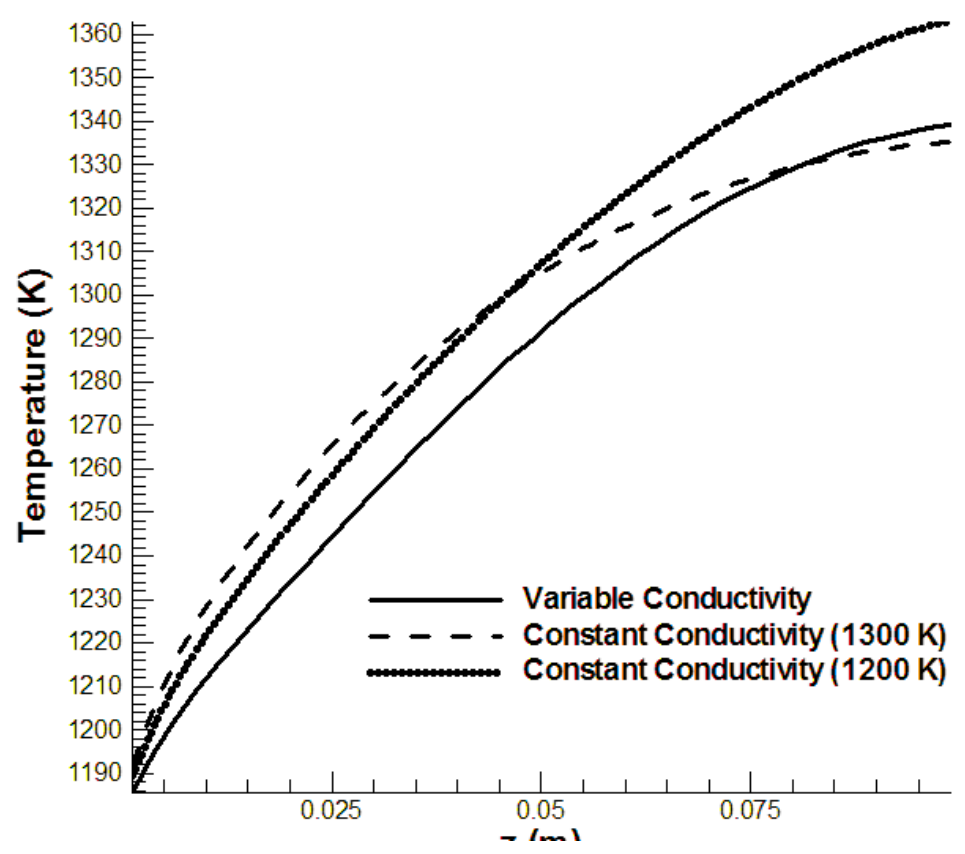

Figure 7.9: Effect of temperature dependence of conductivity on the temperature distribution inside the air channel for the co-flow configuration

Counter flow geometry results for the cases with and without variable conductivity are compared in Figs 7.10 through 7.12. It has to be noted that air inlet is a $z=0 \mathrm{~mm}$ and fuel inlet is at $z=100 \mathrm{~mm}$. Since air and fuel are flowing in opposite directions, the fuel activity increases as air activity decreases along the direction of air flow. However, since the variation in hydrogen concentration is more significant than the variation in oxygen concentration, the high currents are located near the fuel inlet (see Fig. 7.10) which is also the location of high temperature as shown in Fig. 7.12. Contrary to co-flow geometry (Fig. 7.7), in the current distribution for counter flow geometry (Fig. 7.10) the variation is more for variable conductivity case than the constant conductivity cases. This is a result of the two favorable conditions for current flow, high fuel activity and high temperatures (which increase the conductivity for the variable conductivity case), both existing near the fuel inlet. For the constant conductivity cases the current 
distribution is more uniform due to opposite variation of the fuel and oxygen activities.

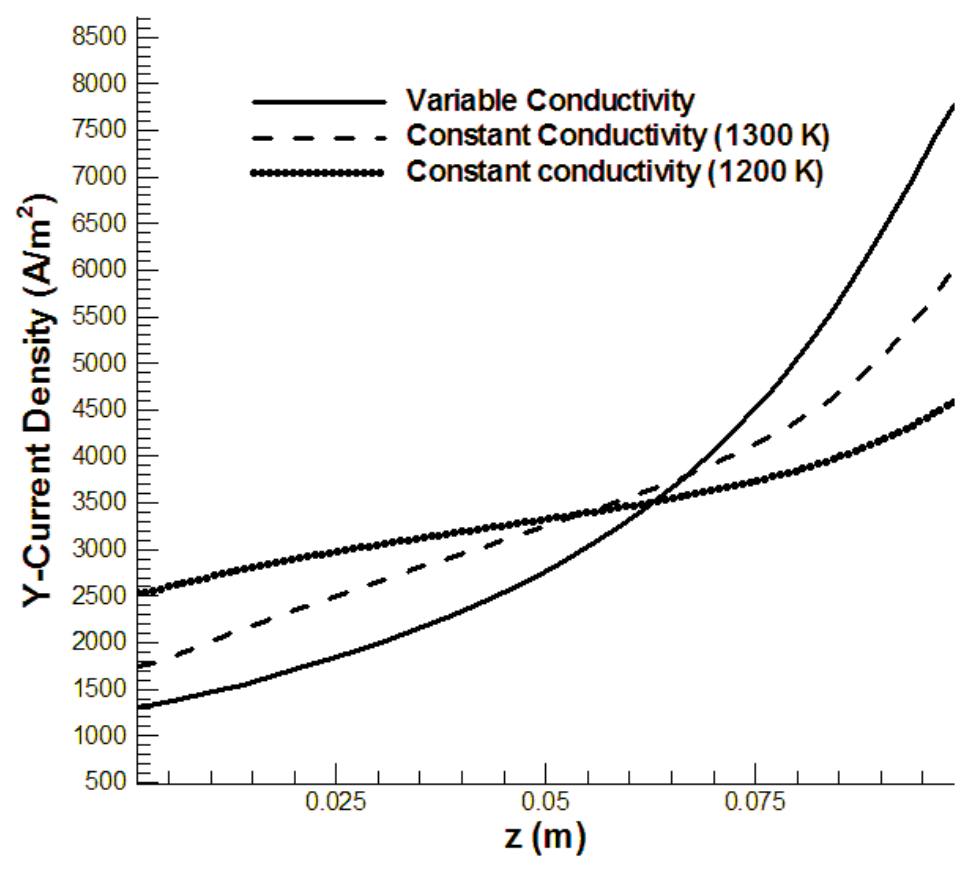

Figure 7.10: Effect of temperature dependence of conductivity on the current density distribution at anode/ electrolyte interface for the counter-flow configuration

The hydrogen concentration profiles along the fuel channel at the center of the cell are shown in Fig. 7.11 for the counter flow configuration. Near the fuel inlet the hydrogen concentration decreases more rapidly for the variable conductivity case due to the higher currents. The temperature profiles shown in Fig. 7.12 are along an air channel near the center of the cell. Starting at the inlet the temperature in the air channel is initially higher for the constant conductivity cases but farther downstream, the temperature increases more rapidly for the variable conductivity case. This once again is a result of the current distributions shown in Fig. 7.10. As in the case of coflow configuration, air exit temperature is highest for constant conductivity $(1200 \mathrm{~K})$ case followed by variable conductivity case due to lower overall electrical conductivity resulting in higher ohmic heating. The overall cell 
voltages of the counter-flow cell are $0.758 \mathrm{~V}$ for constant conductivity (1300 $\mathrm{K})$ case, $0.722 \mathrm{~V}$ for variable conductivity case and 0.644 for constant conductivity $(1300 \mathrm{~K})$ case.

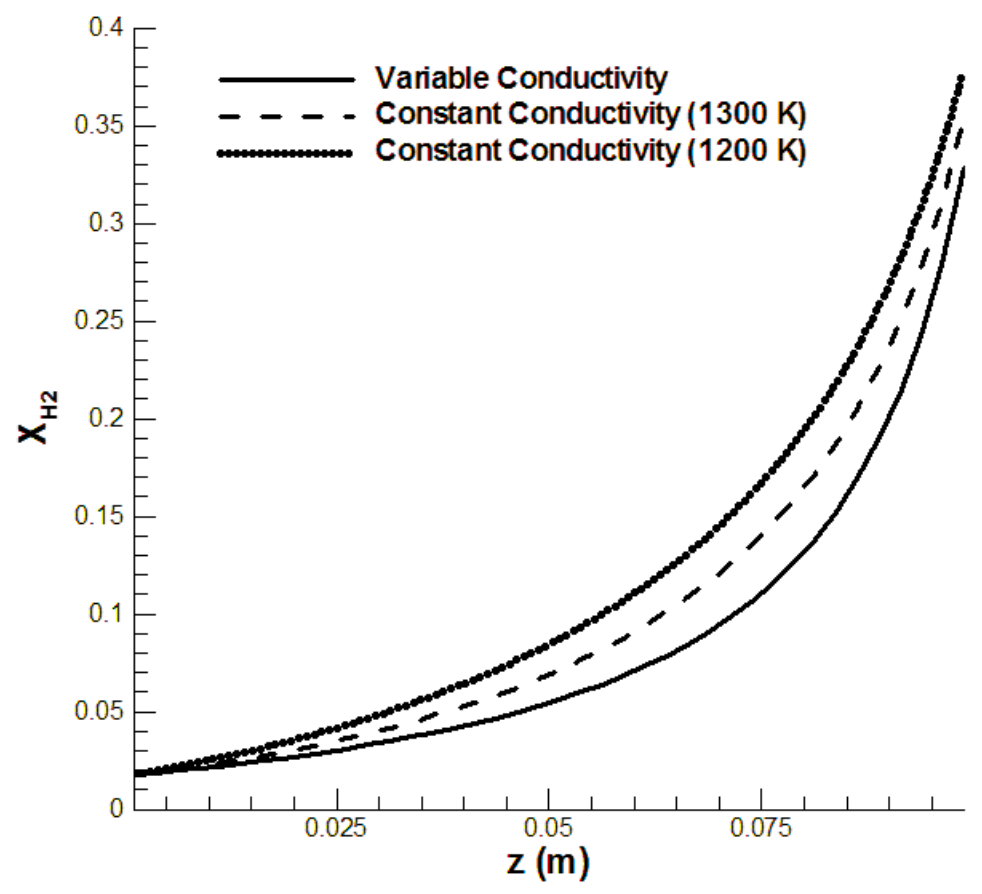

Figure 7.11: Effect of temperature dependence of conductivity on the hydrogen mass fraction distribution inside a fuel channel for the counter-flow configuration

Thus it is shown that variable electric conductivities have a profound effect on the predictions of three dimensional distributions of current and temperature. Assuming constant conductivities could lead to results that are not representative of the reality. In conclusion, it can be stated that the temperature dependence of electric conductivity in component materials is an important aspect that has to be taken into account in the multi-dimensional modeling of solid oxide fuel cells. 


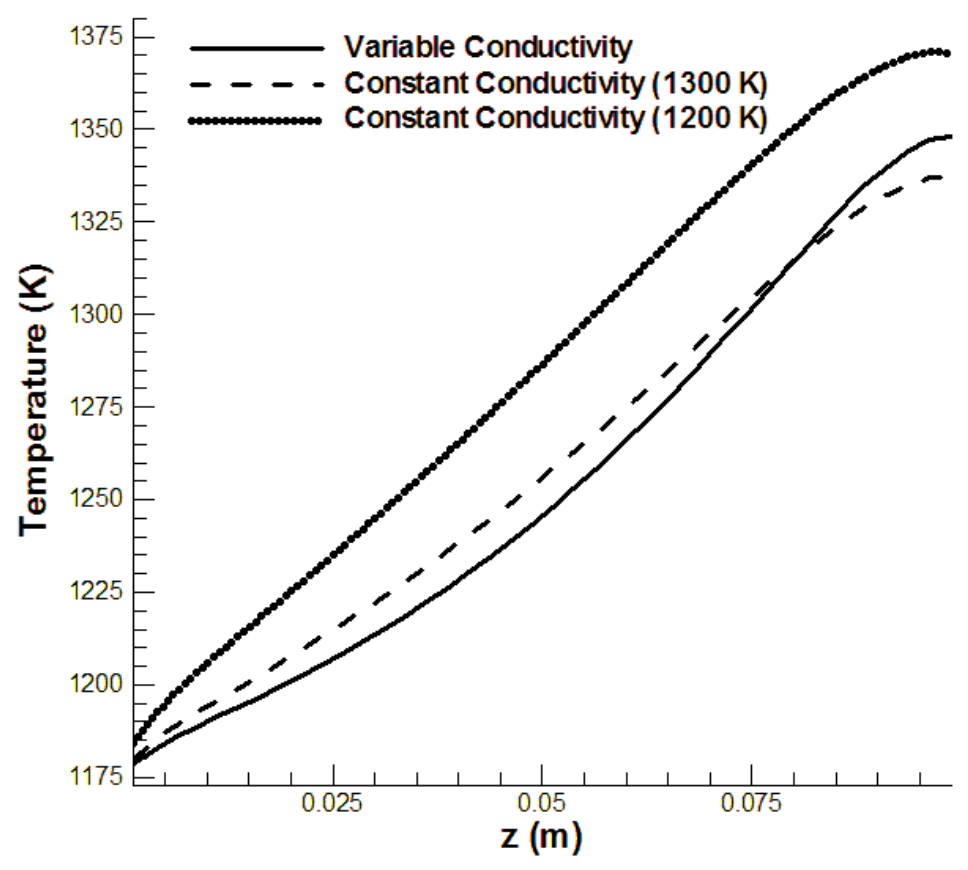

Figure 7.12: Effect of temperature dependence of conductivity on the temperature distribution inside an air channel for the counter-flow configuration

\subsection{Effect of Thickness of Electrolyte}

To study the effect of thickness of the electrolyte on the performance of the cell, a new co-flow case is run with a thinner electrolyte and the results are compared with the original benchmark case. The electrolyte of the altered case is 50 microns thick as opposed to 150 microns in the original case. Figure 7.13 shows the profiles of current density along the gas flow direction near the center of the cell at the anode/electrolyte interface. For the thin electrolyte case, the current densities are high near the gas inlets with almost negligible current densities near the outlets. This could be a result of less resistance to current in this case due to thinner electrolyte (electrolyte is the component with least electrical conductivity). 


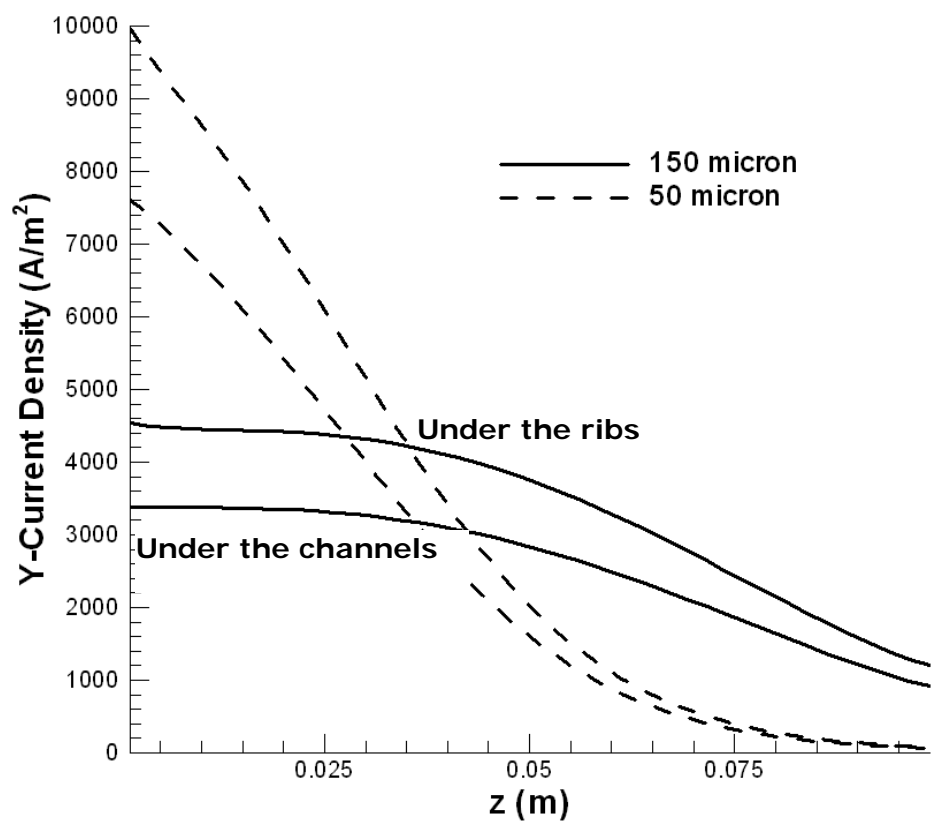

Figure 7.13: Effect of electrolyte thickness on the current density distribution at the anode/ electrolyte interface

Profiles of hydrogen concentration in fuel channel and temperature in air channel shown in Figs. 7.14 and 7.15 respectively are once again in line with the current density distribution. Due to higher current densities near the inlet for the thin electrolyte case, the hydrogen concentration drops drastically compared to the thick electrolyte case. The exit concentration, however, is same for both the cases as expected. Also the large gradients of temperatures near the inlet for the thin electrolyte can also be attributed to the high current densities. The exit temperature is lower for the cell with higher overall conductivity, as expected, which is the one with thin electrolyte. Accordingly the cell voltages are $0.748 \mathrm{~V}$ and $0.711 \mathrm{~V}$ for thin electrolyte and thick electrolyte cells respectively. In the light of this study, it may be noted that the convective heat transfer coefficient should be carefully chosen in order to produce reliable results. 


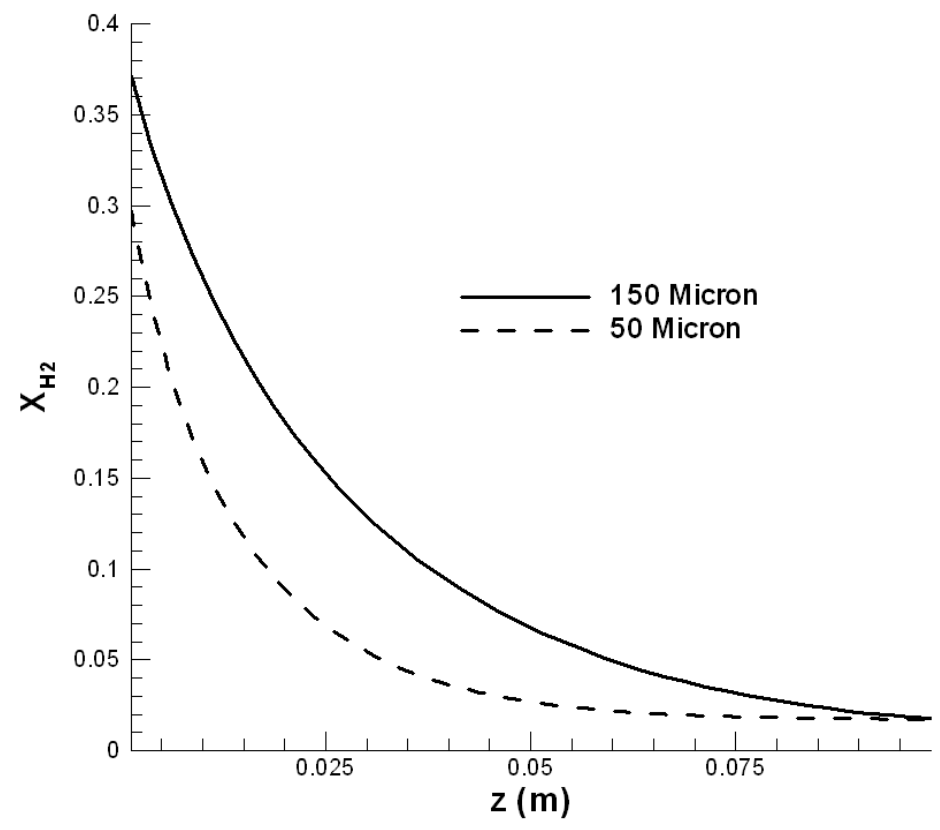

Figure 7.14: Effect of electrolyte thickness on the hydrogen mass fraction distribution inside a fuel channel

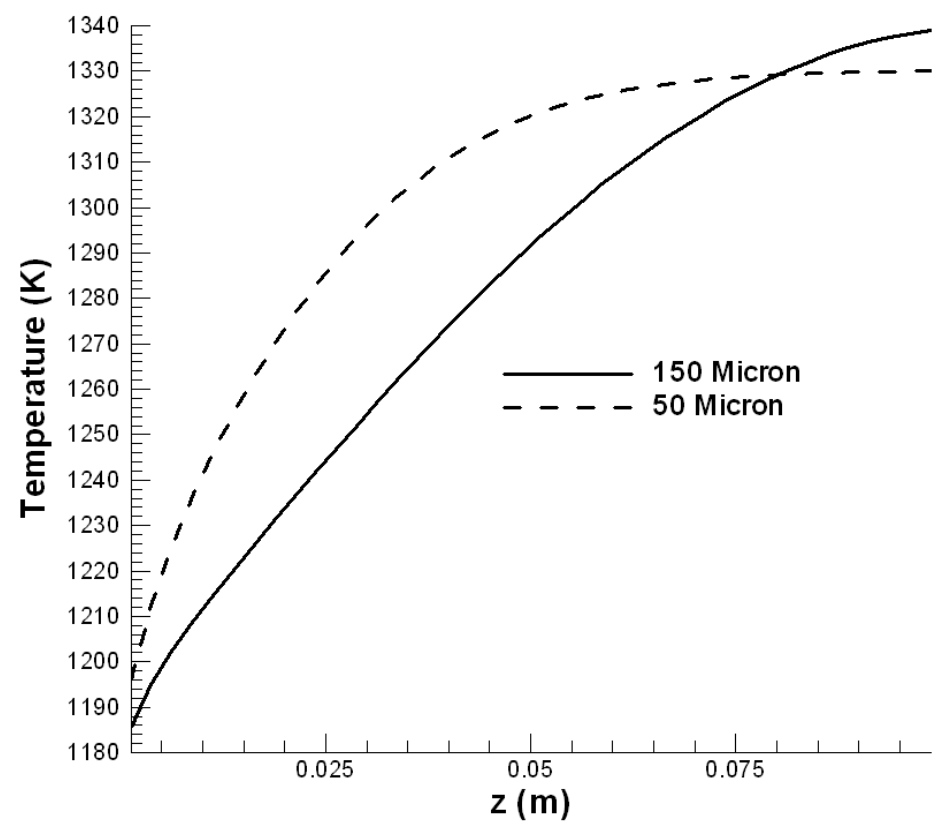

Figure 7.15: Effect of electrolyte thickness on the temperature distribution inside the air channel 


\subsection{Effect of convection heat transfer coefficient}

The convection heat transfer coefficient between the gases in the channel and the channel walls is an important input parameter that is needed for DREAM SOFC. In all the simulations until now a Nusselt number of 20 is assumed for both air and fuel channels. In order to assess the influence of this important parameter, the co-flow benchmark case was repeated with a Nusselt number of 4 for channels. The results for these two cases are compared in Figs. 7.16 through 7.18. The temperature profiles along the center rib and an adjacent air channel for the two cases are shown in Fig 7.16. It can be seen from Fig. 7.16 that the temperature profile along the air channel is almost similar for the two cases. This is expected since same current is produced in both the cases and thus similar amounts of heat should be transferred to the air. Temperature inside the solid, however, is much higher for the low heat transfer coefficient case. This is expected since a higher temperature gradient would be required between the walls and the gas if the same amount of heat should be convected with a lower convection coefficient. A more interesting consequence is the effect of these higher temperatures in the solid on the current distribution. As it can be seen from Fig. 7.17 the current densities near the gas inlets are higher for the low heat transfer coefficient case probably due to higher conductivities resulting from higher temperatures. The profile of concentration of hydrogen along the fuel channel shown in Fig. 7.18 is consistent with the current distribution in Fig. 7.16 


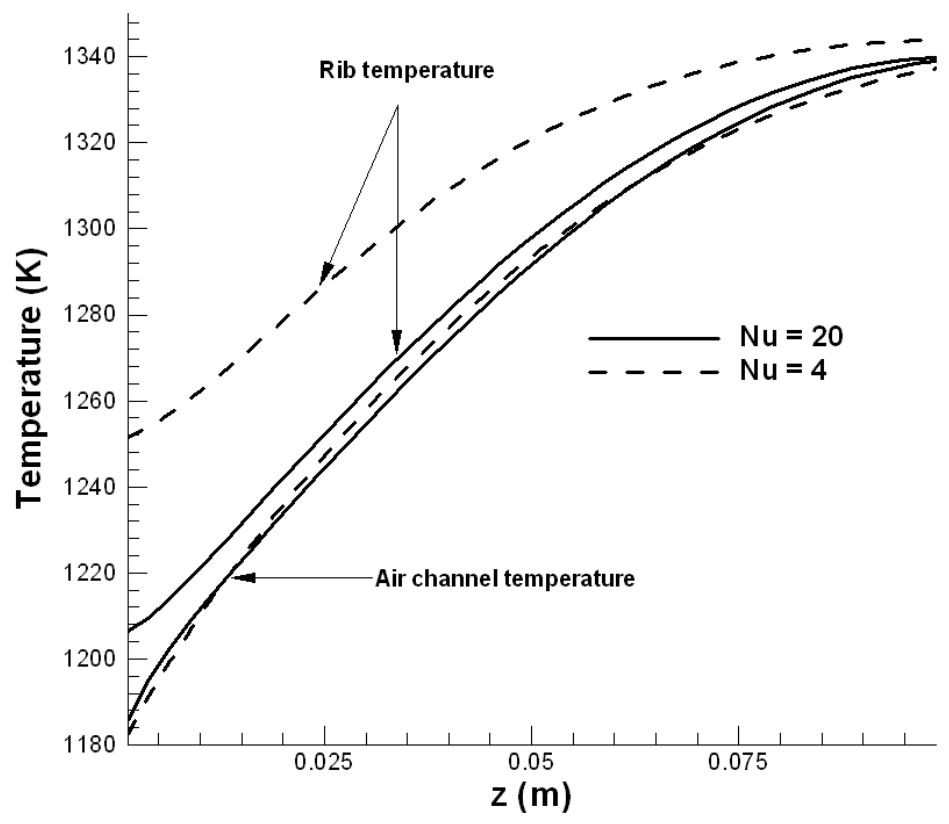

Figure 7.16: Effect of convective heat transfer coefficient on the temperature distribution inside an air channel

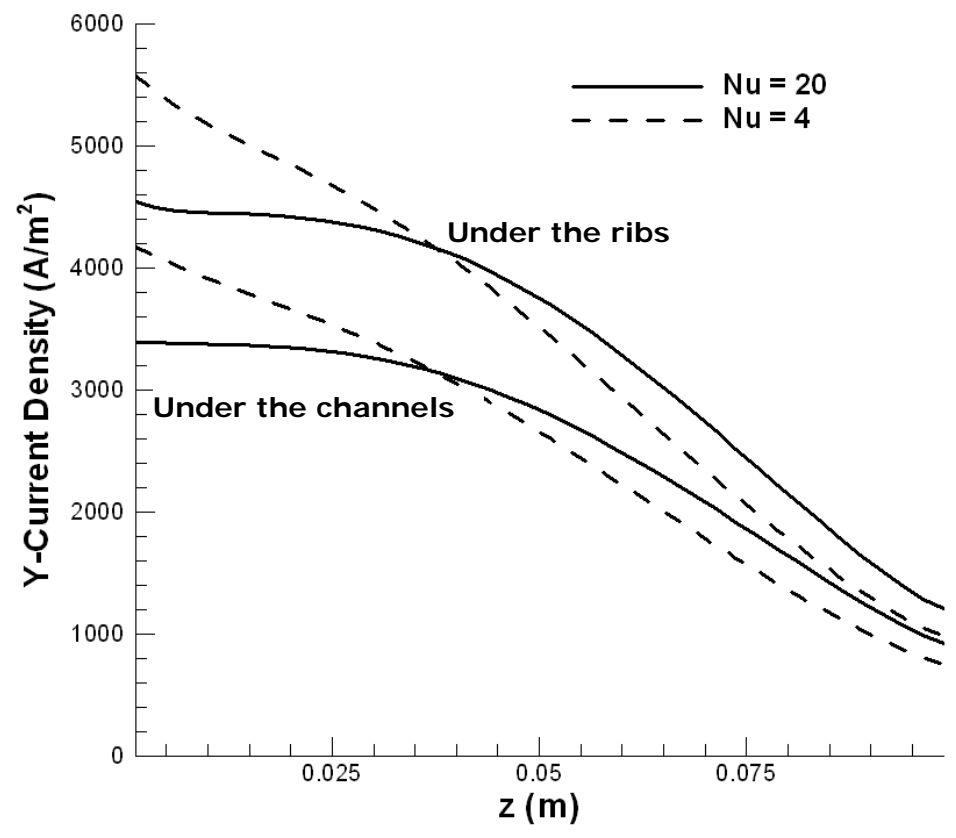

Figure 7.17: Effect of convective heat transfer coefficient on the current density distribution at the anode/ electrolyte interface 


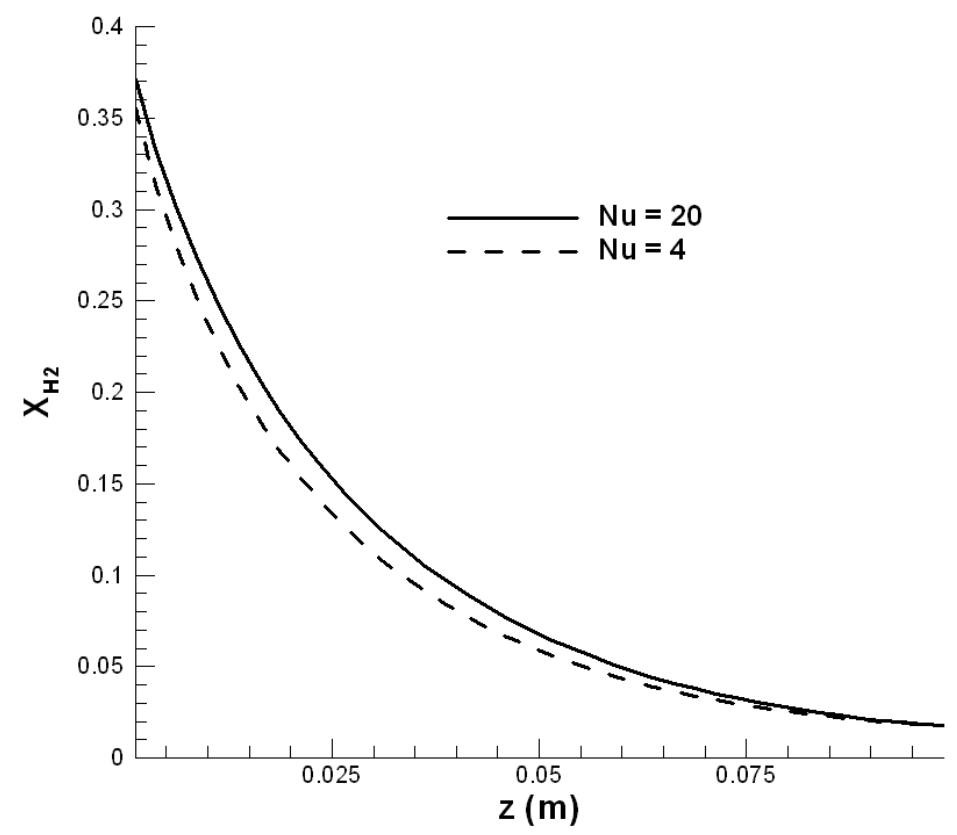

Figure 7.18: Effect convective heat transfer coefficient on the hdrogen mass fraction distribution inside a fuel channel

\subsection{Start-up Transients}

DREAM SOFC is a time accurate model which is capable of simulating transient operation of a SOFC. As a first step towards performing transient simulations, the start-up of the base case SOFC considered so far in the calculations is simulated. The cell was initially at a uniform temperature of $1173 \mathrm{~K}$ with air and fuel $\left(90 \% \mathrm{H}_{2} 10 \% \mathrm{H}_{2} \mathrm{O}\right.$ by volume) flowing at constant rates of $8.43 \times 10^{-5} \mathrm{~kg} / \mathrm{s}$ and $7.3 \times 10^{-7} \mathrm{~kg} / \mathrm{s}$ respectively. At time $\mathrm{t}=0$ the cell started producing a total current of $30 \mathrm{Amp}$ resulting in consumption of species and production of heat. Figure 7.19 shows the time variation of temperature at a point near the geometric center of the SOFC. It can be seen from Fig. 7.19 that it took about 30 minutes $(1762 \mathrm{sec})$ for the cell to reach a steady state. The changes in distributions of current density and temperature inside the cell during this transient period are shown in Figs. 7.20 \& 7.21. Figure 7.20 shows the instantaneous distributions of current density near the 
electrolyte/anode interface at various times. It was observed that most of the time variation in current density distribution occurred in the first few seconds and then there is only a slight variation with time (see Fig. 7.20) as the cell slowly heated up. This confirms the usual assumption of fast electrochemistry in SOFC. Figure 7.21 shows the instantaneous temperature distributions near the anode/electrolyte interface. During the initial period the instantaneous hot regions are towards the entrance of the gases where the reaction rates are high. But as the time proceeded and the gases are heated up, the hot region moved downstream eventually reaching the exit area of the gases.

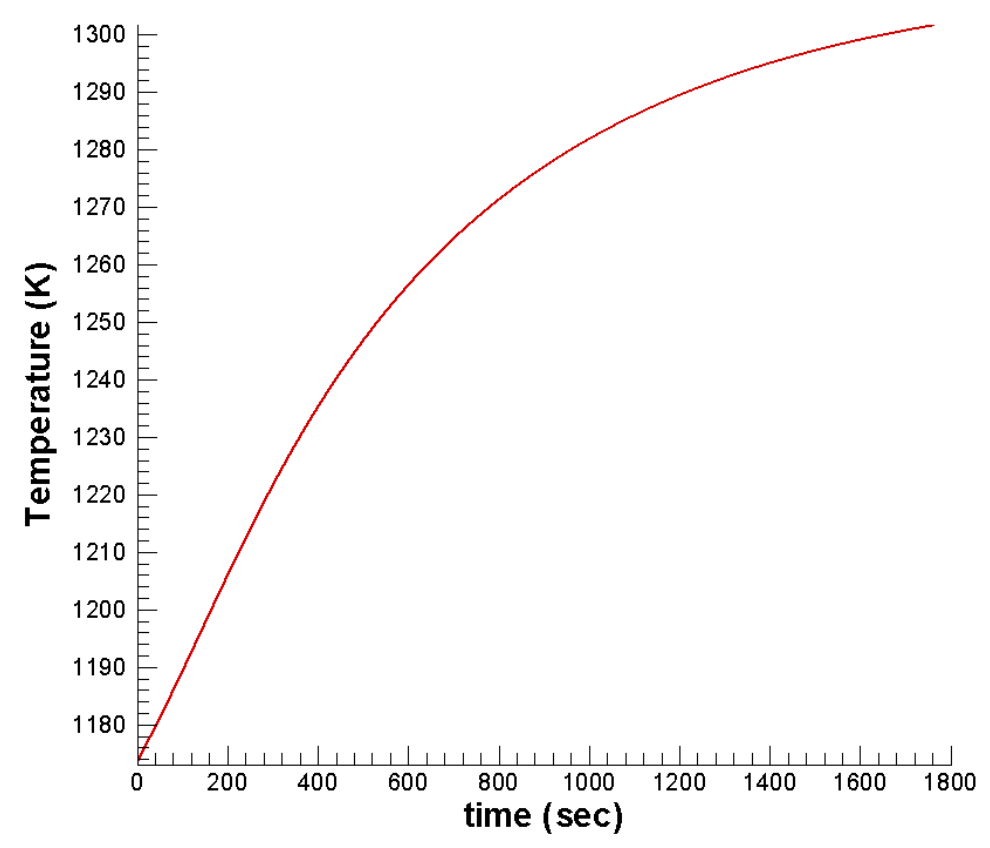

Figure 7.19: Time variation of temperature at a monitor point near the center of the SOFC 


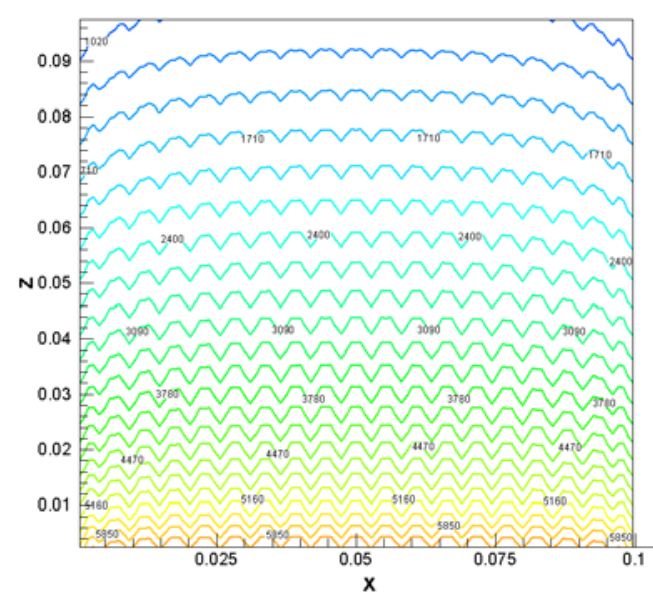

(a) $402 \mathrm{sec}$

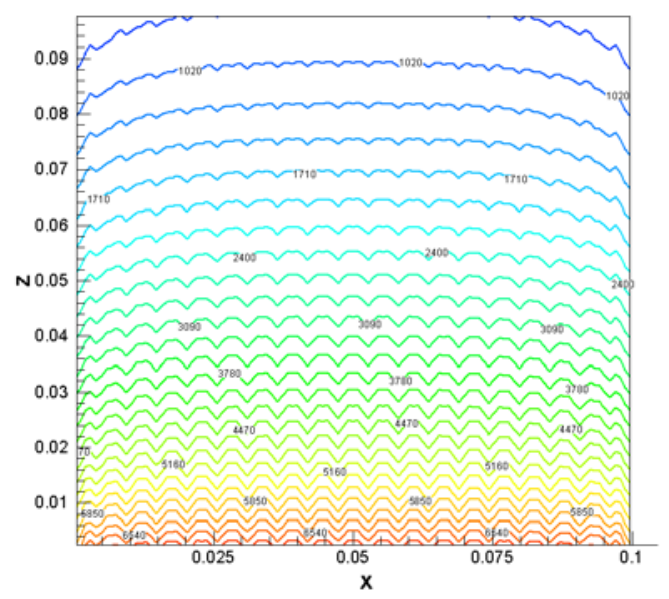

(a) $1202 \mathrm{sec}$

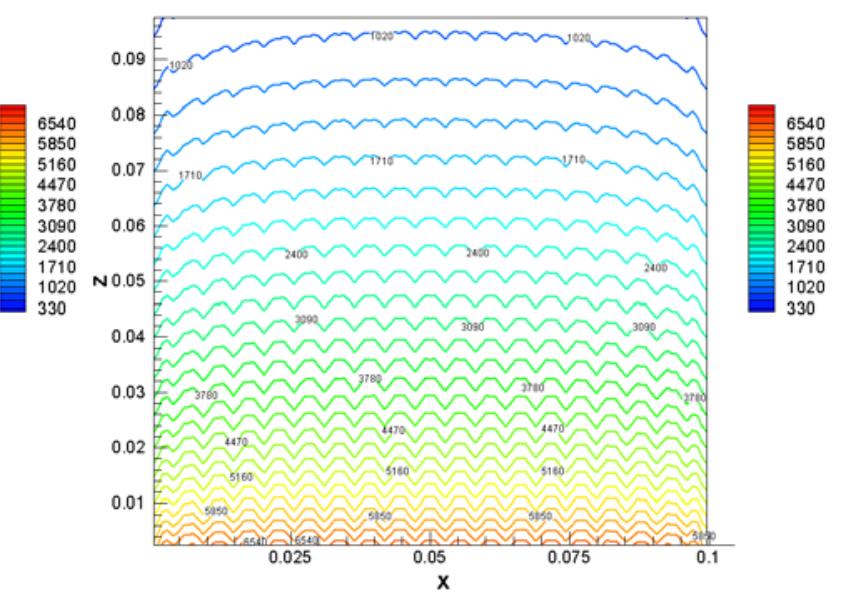

(b) $802 \mathrm{sec}$

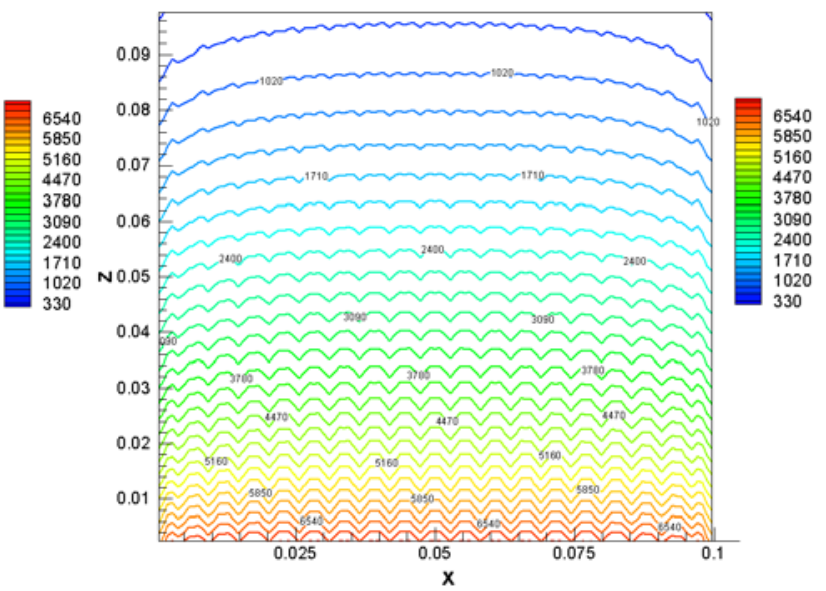

(b) $1602 \mathrm{sec}$

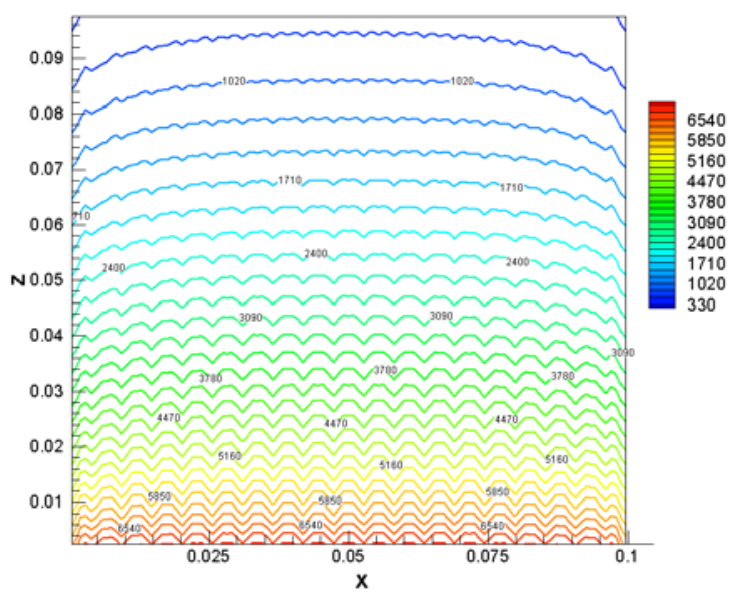

(b) $1762 \mathrm{sec}$

Figure 7.20: $\mathrm{Y}$-current density $\left(\mathrm{A} / \mathrm{m}^{2}\right)$ contours near anode/ electrolyte interface at various instances 


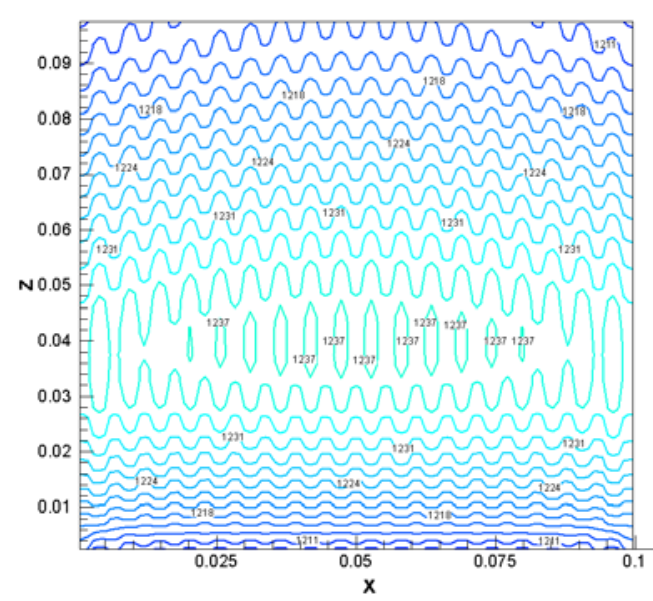

(a) $402 \mathrm{sec}$

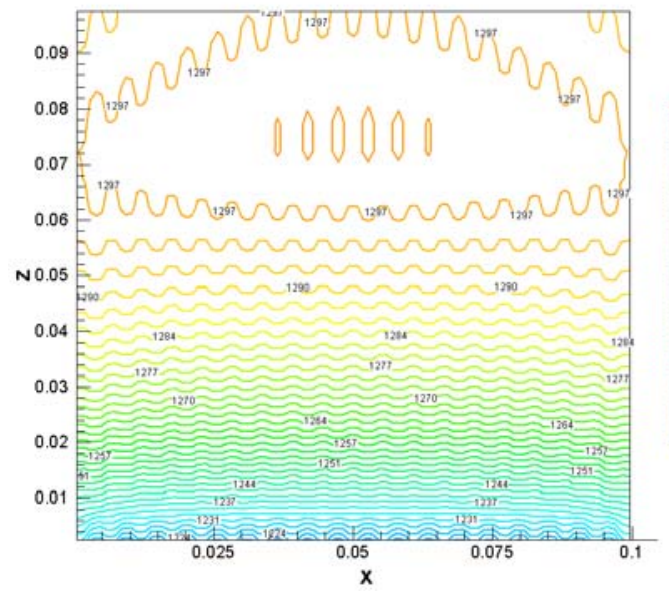

(a) $1202 \mathrm{sec}$

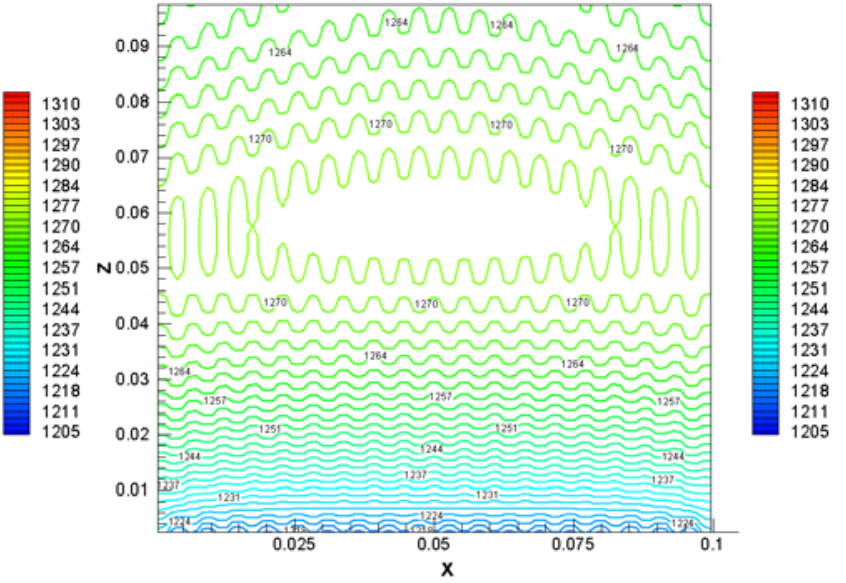

(b) $802 \mathrm{sec}$

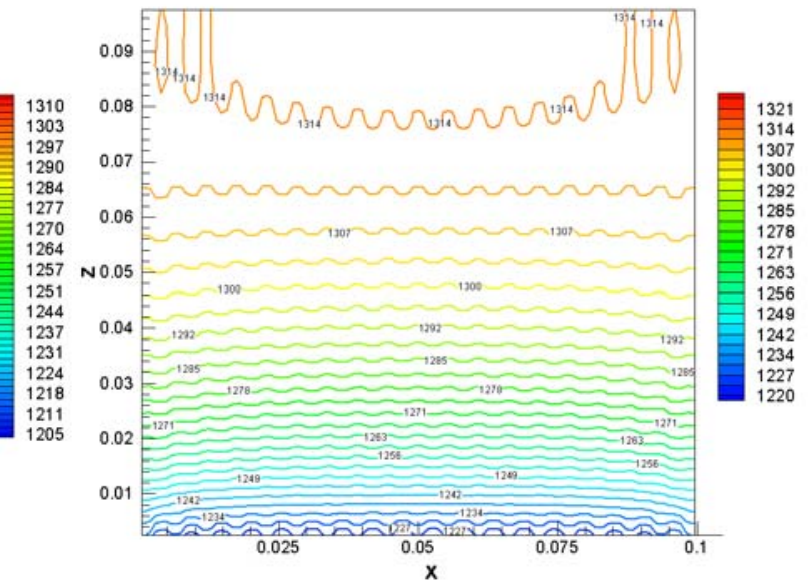

(b) $1602 \mathrm{sec}$

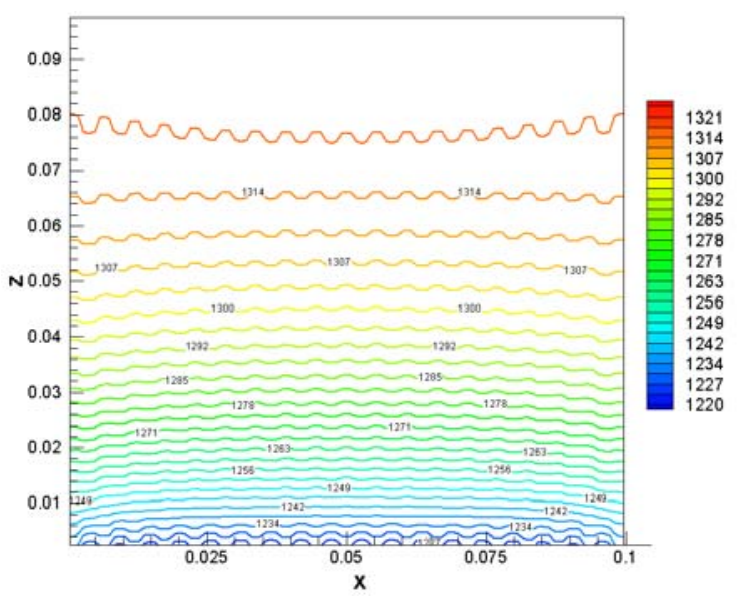

(b) $1762 \mathrm{sec}$

Figure 7.21: Temperature (K) contours near anode/ electrolyte interface at various instances 


\section{CHAPTER 8: CONCLUSI ONS AND FUTURE WORK}

\subsection{Conclusions}

- A new reduced order modeling strategy is proposed for fuel cell modeling which is less complex than a full three-dimensional model but still resolves important three dimensional distributions inside key components.

- The new pseudo-three dimensional model is a combination of three-dimensional model for solid and porous regions, and a one dimensional model for gas channels.

- A new electrochemistry model was developed for use in three dimensional modeling of Solid Oxide Fuel Cells which calculates the electric potential differences across the anode/electrolyte and cathode/electrolyte interfaces separately.

- The new electrochemistry model is separately validated using experimental results and then incorporated into the pseudo threedimensional model.

- A computer code, DREAM SOFC, was developed for the proposed pseudo three dimensional model based on an existing CFD code DREAM. 
- $\quad$ DREAM SOFC was successfully verified by simulating benchmark test cases available in the literature and comparing the results with those from other models in the literature.

- Comparison of DREAM SOFC with the three dimensional FLUENT SOFC model for slightly altered benchmark tests gave a decent agreement between the two codes.

- A parametric study was performed to study the effect of grid size, variable electrical conductivity, electrolyte thickness and convective heat transfer coefficient on the predictions for the benchmark test case.

- The grid study and a Numerical uncertainty analysis demonstrated that the numerical discretization error in the simulations is small.

- It was demonstrated that the temperature dependence of the electrical conductivity of the fuel cell materials is an important aspect which has to be taken into account in multi-dimensional modeling in order to avoid major errors in calculated distributions.

- The temperature dependence of the electrical conductivity causes a more uniform current distribution in co-flow configuration and a more non-uniform current distribution in counter-flow configuration

- The DREAM SOFC model showed that fuel cells with thinner electrolytes produce more non-uniform current distribution but yield higher overall voltages as it would be expected. 
- Convective heat transfer coefficient between the gases and the channel walls is a critical parameter that affects the solution and thus it has to be carefully chosen.

- Start up transients of a co-flow SOFC are simulated which showed that it took about $30 \mathrm{~min}$ for the cell to reach steady state. The thermal transients took much longer than electrodynamic transients as anticipated.

- The location of instantaneous hot regions during the start up of a co-flow SOFC changes from being near the gas inlets at the beginning towards the gas outlets at steady state.

- $\quad$ Current density distribution changes only slightly after the first few seconds as the temperatures inside the cell slowly increase

\subsection{Future Work}

- The model could be further advanced by incorporating the following aspects into it

o Oxide ion transport in the electrolyte

o Convection inside the porous regions

o Axial diffusion in the one-dimensional model used for the gas channels

o Manifold model to predict the flow distribution among the channels 
o Hydrocarbon fuel capabilities

o Internal reforming of hydrocarbon fuels

o Radiation heat transfer

o Thermal stress model coupling

- $\quad$ The model could also be used to simulate an SOFC stack by parallelizing DREAM SOFC to run on a cluster of computers. 


\section{REFERENCES}

[1] Celik, I. B. and Pakalapati S. R., 2003, "A Modular Approach to SOFC Modeling," final report submitted to Oak Ridge Associated Universities (ORAU), Oak Ridge, TN.

[2] Pakalapati, S. R., 2003, "Numerical Study of Current Distribution Inside the Cathode and Electrolyte on a Solid Oxide Fuel Cell," Thesis, Mechanical and Aerospace Engineering Department, West Virginia University, Morgantown.

[3] Crowe, B. J., 1973, FUEL CELLS: A Survey, National Aeronautics and Space Administration, Washington D.C.

[4] Singhal, S. C., and Kendall, K., 2003, High Temperature Solid Oxide Fuel Cells: Fundamentals, Design and Application, Elsevier Ltd., Oxford, UK

[5] Minh, N. Q., 1993, "Solid Oxide Fuel Cells: Materials, Fabrication Processes and Development Trends" in Badwal, S. P. S., Bannister, M. J., and Hannink R. H. J., 1993, Science and Technology of Zirconia, Technomic Publishing Co., Inc., Lancaster, PA.

[6] Burt, A. C., 2005, "Refinement of Numerical Models and Parametric Study of SOFC Stack Performance," Dissertation, West Virginia University, Morgantown. 
[7] EG\&G Technical Services Inc., 2004, "Fuel Cell Handbook," (Seventh Edition) Technical Report, US Department of Energy, Office of Fossil Energy, National Energy Technology Laboratory, Morgantown, WV.

[8] McIntosh, S., nd Gorte, R. J., 2004, "Direct hydrocarbon Solid Oxide Fuel Cells", Chemical Reviews, 104 (10), pp 4845-4865.

[9] Ormerod, R. M., 2003, "Solide Oxide Fuel Cells," Chemical Society Reviews, 32, pp. 17-28.

[10] Von Spakowsky, M. R., and Olsommer, B., 2002, "Fuel Cell Systems and System Modeling and Analysis Perspectives for Fuel Cell Development," Energy Cenversion and Management, 43, pp. 1249-1257.

[11] Mitterdorfer, A., and Gauckler, L. J., 1999, "Identification of Reaction Mechanism of the Pt, $\mathrm{O}_{2(\mathrm{~g})} \mid$ Yttria-Stabilized Zirconia System; Part 1: General Framework, Modelling, and Structural Investigation," Solid State Ionics, 117, pp. 187-202.

[12] Mitterdorfer, A., and Gauckler, L. J., 1999, "Identification of Reaction Mechanism of the Pt, $\mathrm{O}_{2(\mathrm{~g})} \mid$ Yttria-Stabilized Zirconia System; Part 2: Model Implementation, Parameter Estimation, and Validation," Solid State Ionics, 117, pp. 203-217.

[13] Mitterdorfer, A., and Gauckler, L. J., 1999, "Reaction Kinetics of the Pt, $\mathrm{O}_{2(\mathrm{~g})} \mid \mathrm{c}-\mathrm{ZrO}_{2}$ System: Precursor-Mediated Adsorption," Solid State Ionics, 120, pp. 211-225. 
[14] Bieberle, A., and Gauckler, L. J., 2000, "Reaction Mechanism of $\mathrm{Ni}$ Pattern Anodes for Solid Oxide Fuel Cells," Solid State Ionics, 135, pp. 337-345.

[15] Bieberle, A., and Gauckler, L. J., (2002) "State-Space Modeling of the Anodic SOFC system $\mathrm{Ni}_{1} \mathrm{H}_{2}-\mathrm{H}_{2} \mathrm{O}$ |YSZ," Solid State Ionics, 146, 23-41.

[16] Lehnert, W., Meusinger, J., and Thom, F., 2000, "Modeling of gas tranport phenomena in SOFC anodes," Journal of Power Sources, 87, pp. 57-63.

[17] Yakabe, H., Hishinuma, M., Uratani, M., Matsuzaki, Y., and Yasuda, I., 2000, "Evaluation and modelling of performance of anode-supported solid oxide fuel cell," Journal of Power Sources, 86, pp. 423-431.

[18] Wu, Z., and Liu, M., 1997, "Modeling of Ambipolar Transport Propoerties of Composite Mixed Ionic-Electronic Conductors," Solid State Ionics, 93, pp. 65-84.

[19] Virkar, A. V., Chen, J., Tanner, C. W., and Kim, J. W., 2000, "The role of electrode microstructure on activation and concentration polarization in solid oxide fuel cells," Solid State Ionics, 131, pp. 189-198.

[20] Hall, D. J. and Colclaser, R. G., 1999, "Transient Modeling of and Simulation of a Tubular Solid Oxide Fuel Cell," IEEE Transactions on Energy Conversion, 14(3), pp. 749-753.

[21] Gemmen, R. S., Liese, E., Rivera, J. G., Jabbari, F., and Brouwer, J., 2000, "Development of Dynamic modeling tools for Solid Oxide and 
Molten Carbonate Fuel Cell Hybrid Gas Turbine Systems," Proceedings of ASME Turbo Expo, May 8-11, Munich, Germany.

[22] Standaert, F., Hammes K., and Woudstra, N., 1998, "Analytical Fuel Cell Modeling; Non-Isothermal Fuel Cells," Journal Power Sources, 70, pp 181-199.

[23] Yuan, J., Rokni, M., and Sunden, B., 2001, "Simulation of Fully Developed Laminar Heat and Mass Transfer in Fuel Cell Ducts with Different Cross-Sections," International Journal of Heat and Mass Transfer, 44, pp. 4047-4058.

[24] Schichlein,H., Feuerstein, M., Muller, A., Weber, A., Krugel, A., and Ivers-Tiffee, E., 1999, "System Identification: A New Modeling Approach For SOFC Single Cells," Proceedings of SOFC VI, Eds. Singhal, S.C. and Dokiya, M, The Electrochemical Society, Pennington, NJ.

[25] Huang, X., and Reifsnider, K. L., 2001, "Modeling Long Term Performance Of Solid Oxide Fuel Cells: A Phenomenological Approach," Proceedings of The $15^{\text {th }}$ Annual Conference on Fossil Energy Materials, Apr 30 - May 2, Knoxville, TN.

[26] Vayenas, C. G. and Debenedetti P. G., 1985, "Cross Flow, Steady-State Electrochemical Reactors: A Steady-State Analysis," Industrial \& Engineering Chemistry Fundamentals, 24, pp 316-324.

[27] Ferguson, J. R., Fiard, J. M., and Herbin, R., 1996, "Three-dimensional numerical simulation for various geometries of solid oxide fuel cells," Journal of Power Sources, 58, pp. 109-122. 
[28] Yakabe, H., Ogiwara, T., Hishinuma, and M., Yasuda, I., 2001, "3-D model calculation for planar SOFC," Journal of Power Sources, 102, pp. 144-154.

[29] Aguiar, P., Chadwick, D., and Kreshenbaum, L., 2002, "Modeling of an Indirect Internal Reforming Solid Oxide Fuel Cell," Chemical Engineering Science, 57, pp 1665-1677.

[30] Achenbach, E., 1994, "Three-dimensional and time dependent simulation of a planner solid oxide fuel cell stack," Journal of Power Sources, 49, pp. 333-348.

[31] He, W. and Chen Q., 1995, "Three-dimensional simulation of a molten carbonate fuel cell stack using computational fluid dynamics technique," Journal of Power Sources, 55, pp. 25-32.

[32] He, W. and Chen Q., 1998, "Three-dimensional simulation of a molten carbonate fuel cell stack under transient conditions," Journal of Power Sources, 73, pp. 182-192.

[33] Hirata, H., and Hori, M., 1996, "Gas-Flow Uniformity and Cell Performance in a Molten Carbonate Fuel Cell Stack," Journal of Power Sources, 63, pp 115-120.

[34] Burt, A., Celik, I., Gemmen, R. and Smirnov, A., 2004, "A Numerical Study of Cell-to-Cell Variations in a SOFC Stack" Journal of Power Sources, 126, pp.76-87.

[35] Burt, A., Celik, I., Gemmen, R. and Smirnov, A., 2003, "Influence of Radiative Heat Transfer on Variation of Cell Voltage within a Stack," 
Proceedings of First International Conference on Fuel Cell Science, Engineering and Technology, April 21-23, Rochester, NY

[36] Selimovic, A., and Palsson, J., 2002, "Networked Solid Oxide Fuel Cell Stacks Combined with Gas Turbine Cycles," Journal Of Power Sources, $106,76-82$.

[37] Stiller, C., Mathisen, O., Seljebo, S., Bolland, O., Karolieussen, H., Thorub, B., 2003, "Simulation-Based Comparison of Combined SOFC/GT Cycles with Flat-Plate and Tubular Fuel Cell Models," Proceedings of Fuel Cell Seminar 2003, Miami.

[38] Freeh, J. E., Pratt, J. W., and Brouwer, J., 2004, "Development of a Solid-Oxide Fuel Cell / Gas Turbine Hybrid System model for Aerospace Applications," Proceedings of ASME Turbo Expo 2004, June 14-17, Vienna, Austria.

[39] Bedringas, A. W., Ertesvag, I. S., Byggstoyl, S., and Magnussen, B. F., 1996, "Exergy Analysis Of Solid-Oxide Fuel-Cell (SOFC) Systems," Energy, 22(4), 403-412.

[40] Koyama, S., Kraines, S., Tanaka, K., Wallace, D., Yamada, K., Komiyama, H., 2004, "Integrated model frame work for the evaluation of SOFC/GT system as a central power source," International Journal of Energy Research, 28, pp. 13-30.

[41] Grens, E. A. and Tobias, C. W., 1964, "Analysis of Dynamic Behavior of Flooded Porous Electrodes," Z. Elektrochem., 68(3), pp. 236-249. 
[42] Patankar, S. V., 1980, Numerical Heat Transfer and fluid flow, Hemisphere Publications.

[43] Celik, I. B., Pakalapati, S. R., Gemmen, R. S., 2003, "Modeling of the Potential Jump at Electrode-Electrolyte Interface Using Singularity Distribution," SOFC VIII proceedings of the international symposium, The Electrochemical Society, Inc., New Jersey, pp 1317-1329.

[44] Badeau Jr., A. E., "Analysis of a Curved Buoyant Jet in an Enclosure using LES," Ph. D Thesis, West Virginia University, Morgantown, WV

[45] Li, J., "Critical Issues for Predicting Worker Exposure to Gaseous Contaminants in a Wind Tunnel," Ph. D Thesis, West Virginia University, Morgantown, wV

[46] Hu, G., 2005, "Towards Large Eddy Simulation of Dispersed Gas-Liquid Two Phase Turbulent Flow," Ph. D Thesis, West Virginia University, Morgantown, WV.

[47] Celik, I. B., Ersahin, C., and Tatli, E., 2004, "One-Dimensional Transient Solver for Transport Phenomena," Report, Mechanical and Aerospace Engineering Department, Morgantown, WV.

[48] Barrendrecht, E., 1993, "Electrochemistry of Fuel Cells," in Fuel Cell Systems, editors: L.J.M.J. Blomen and M.N. Mugerwa, Plenum Press, New York, pp. 73-119.

[49] Zha, S. W., Xia, C. R., Meng, G. Y., 2001, "Calculation of the E.M.F of Solid Oxide Fuel Cells," Journal of applied Electrochemistry, 31, pp. 9398. 
[50] Moran, M. J., Shapiro, H. N., 2000, Fundamentals of Engineering Thermodynamics, John Wiley \& sons, Inc., New York.

[51] Fogler, H., 1991, Elements of Chemical Reaction Engineering, Prentice Hall, New Jersey.

[52] Bard., A. J., Faulkner L. R., 1980, Electrochemical Methods: Fundamentals and Applications, John Wiley \& sons, Inc., New York.

[53] Rubinstein, I., 1995, Physical Electrochemistry, Marcel Dekker, Inc., New York.

[54] Godickemeier, M., Gauckler, L. J., 1998, "Engineering of Solid Oxide Fuel Cells With Ceria-Based Electrolytes," Journal of electrochemical society, 145, pp. 414-421.

[55] Costamagna, P. and Honegger, K., 1998, "Modeling of solid oxide heat exchanger integrated stacks and simulation at high fuel utilization," Journal of Electrochemical Society., 145(11), pp. 3995-4007.

[56] Co, A. C., Xia, S. J., Birss, V. I., 2003, "Oxygen Reactions at Lasrmno $_{3}$ /Yittria-Stabilized Zirconia (LSM/YSZ) Interfaces," SOFC VIII, Proceedings of International symposium, The Electrochemical Society, Inc., New Jersey, pp 478-487.

[57] Esquirol A., Bonanos N., Brandon N., Kilner J., Mogensen M., 2003, "Electrochemical Characterization of a $\mathrm{La}_{0.6} \mathrm{Sr}_{0.4} \mathrm{Co}_{0.2} \mathrm{Fe}_{0.803-\delta}$ Cathode for IT-SOFCs," SOFC VIII proceedings of the international symposium, The Electrochemical Society, Inc., New Jersey, pp.580-590 
[58] Bird, R. B., Stewart, W. E., and Lightfoot, E. N., 2002, Transport Phenomenon, second edition, John Wiley \& sons Inc., New York.

[59] Cussler, E. L., 1997 Diffusion mass transfer in fluid systems, Cambridge University press, Cambridge, UK

[60] Zhao, F., Armstrong, T.J., Virkar, A.V., 2003, " Measurement of $\mathrm{O}_{2}-\mathrm{N}_{2}$ Effective Diffusivity in Porous Media at High Temperatures Using an Electrochemical Cell", Journal of electrochemical society, 150(3), pp. A249-A256.

[61] Jiang, Y., Virkar, A. V., 2003, "Fuel Composition and Diluent Effect on Gas Transport and Performance of Anode-Supported SOFCs", Journal of electrochemical society, 150(7), pp. A942-A951

[62] Godickemeier, M., Sasaki, K., Gauckler, L.J., 1997, "Electrochemical Characteristics of Cathodes in Solid Oxide Fuel Cells Based on Ceria Electrolytes," Journal of electrochemical society, 144, pp. 1635-1646.

[63] Achenbach, E., 1995, "Status of the IEA Benchmark Test I on Stack Modeling," IEA-Workshop, Rome, Italy.

[64] Celik, I. B., and Li, J., 2005, "Assessment of Numerical Uncertainty for the Calculations of Turbulent Flow Over a Backward-Facing Step," International Journal for Numerical Methods in Fluids, 49, pp. 10151031.

[65] Gemmen, R. S., 2004, Lecture notes for MAE 593G - An Introduction to Fuel Cell Technology, Dr. Ismail Celik, Instructor, West Virginia University, Morgantown, WV. 


\section{APPENDIX A}

\section{Additional Plots}

Some additional plots from the results of co-flow benchmark case are presented in this appendix in order to demonstrate the details resolved by DREAM SOFC. Figure a.1 shows the variation of electric potential along the thickness (y-direction) of the cell. The profile is taken at the geometrical center of the cell and it passes through the ribs. The profile in Fig. a.1 exhibits the expected behavior is a fuel cell (see Fig. 5.1) It can be seen that the ohmic drop in the electrolyte is considerably larger than that in other components. The current traces in $x-y$ plane at the mid-section $(z=0.05)$ of the SOFC are shown in Fig. a.2. It can be see that the current tends to pass through the regions under the channels inside the PEN due to higher activity of the reactants in these locations. The variation of Hydrogen and Oxygen mass fractions along the $y$-direction are shown in Figs. a.3 and a.4. The profile are taken close to the center of the cell and they pass through the channels. Since one dimensional model was used for the channels the mass fraction inside the channel does not vary with thickness. Also, there is not much variation in the mass fractions inside the porous electrodes since the thickness is very small. 


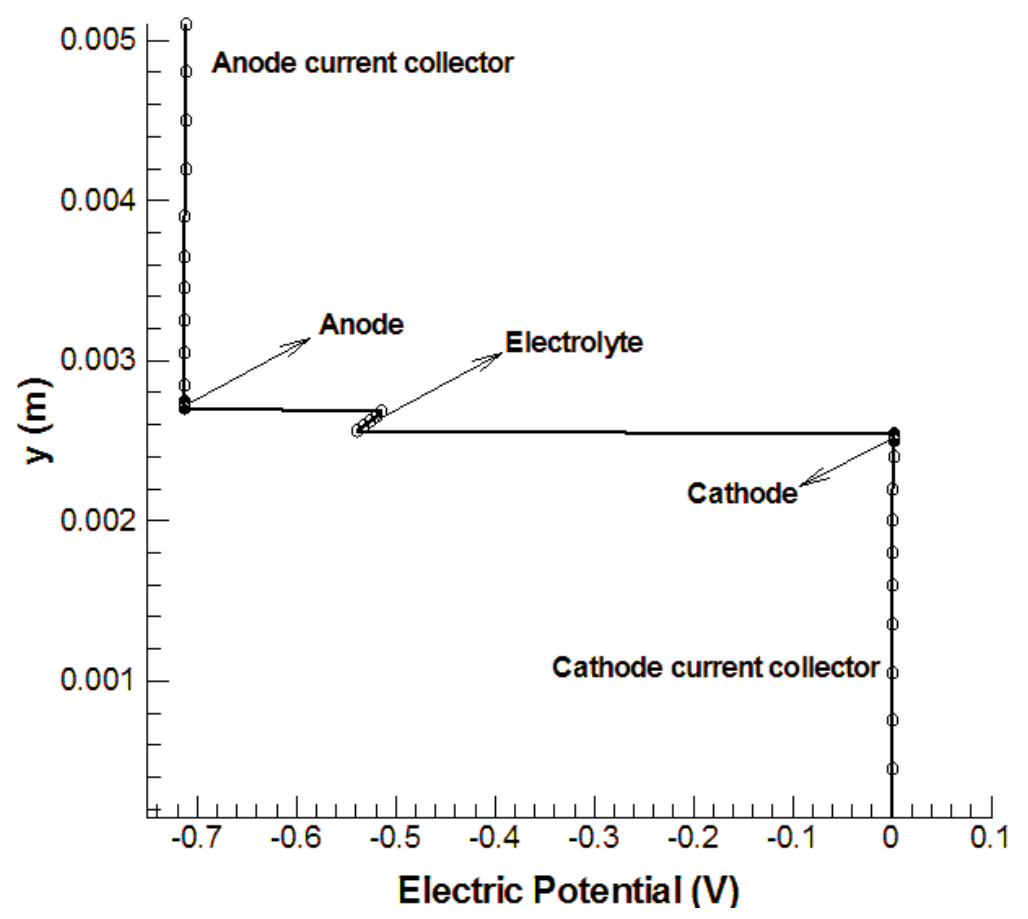

Figure a.1: Variation of electric potential along the thickness of the SOFC

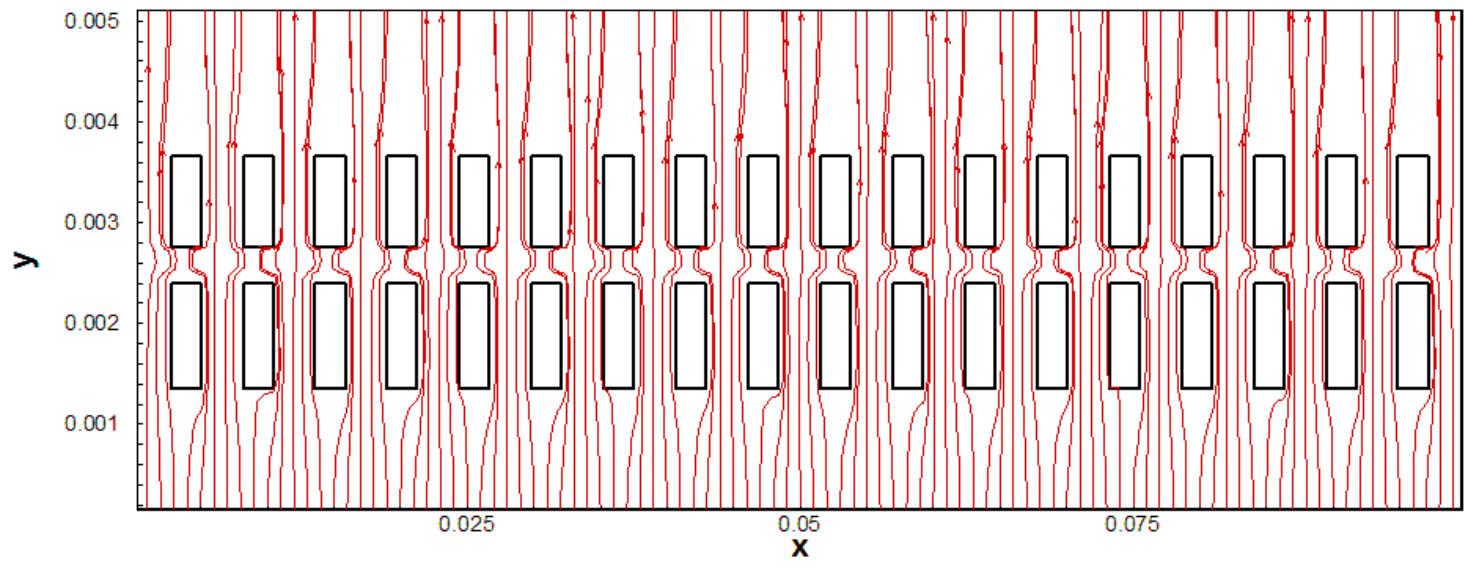

Figure a.2: Current lines inside the SOFC at the mid-section 


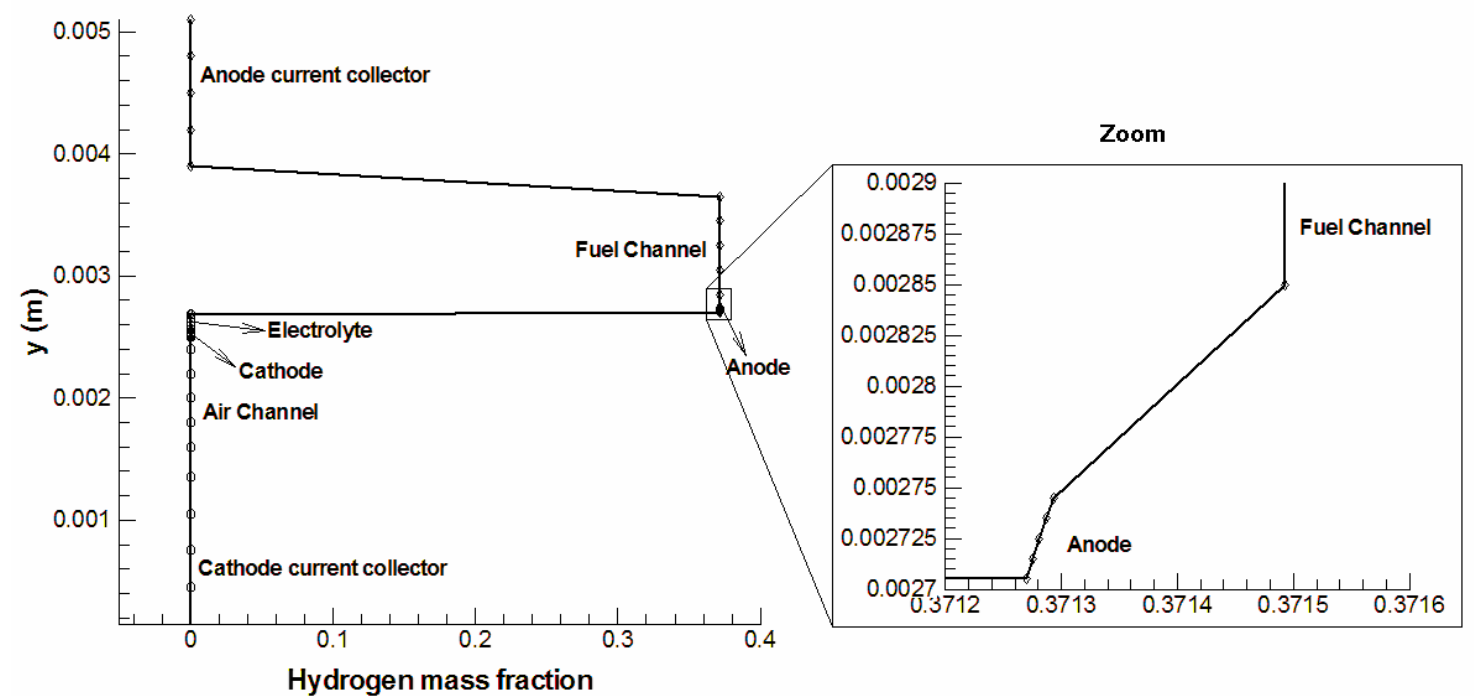

Figure a.3: Variation of $\mathrm{H}_{2}$ mass fraction along the thickness of the SOFC

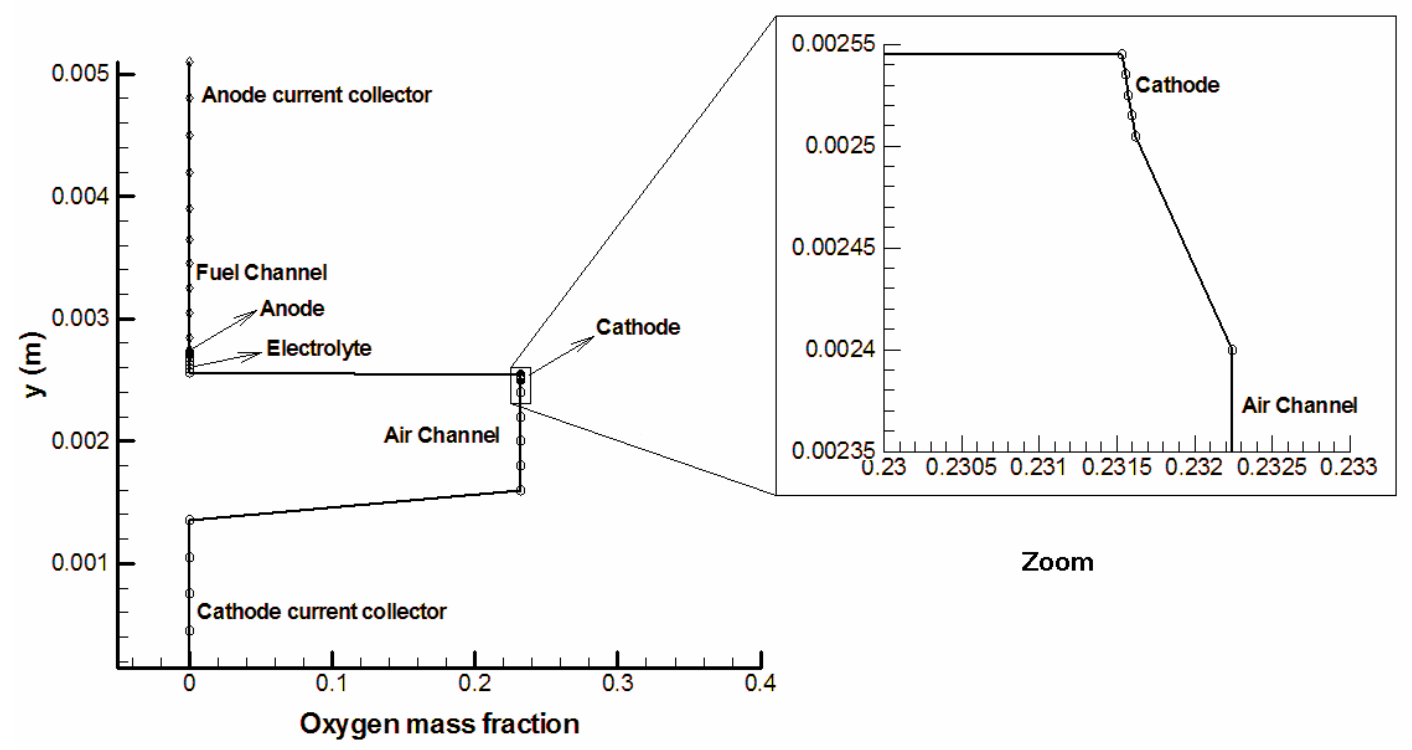

Figure a.4: Variation of $\mathrm{O}_{2}$ mass fraction along the thickness of the SOFC 


\section{APPENDIX B}

\section{Chapman-Enskog Model For Calculating Binary Diffusivities}

Chapman-Enskog model is most commonly method used to calculate the diffusion coefficients and is accurate to about 8\% [59]. According to this theory, the binary diffusivity of two gases $a$ and $b$ is given by

$$
D_{a-b}=\frac{1.86 \times 10^{-3} T^{\frac{3}{2}}\left(\frac{1}{M_{a}}+\frac{1}{M_{b}}\right)^{\frac{1}{2}}}{P \sigma_{a b}^{2} \Omega}
$$

Here $D_{a-b}$ is in $\mathrm{cm}^{2} / \mathrm{s}, T$ is absolute temperature, $P$ is pressure in atmospheres and $M_{a}$ and $M_{b}$ are molecular weights of $a$ and $b$ respectively, $\sigma_{a b}$ is the collison diameter in angstroms and is given by

$$
\sigma_{a b}=\frac{\sigma_{a}+\sigma_{b}}{2}
$$

The dimensionless molecular parameter $\Omega$, called collision integral, is a function of dimensionless temperature ${ }^{k T} / \varepsilon_{a b}$. Here $k$ is the Boltzmann's constant and the characteristic energy $\varepsilon_{a b}$ is given by

$$
\varepsilon_{a b}=\sqrt{\varepsilon_{a} \varepsilon_{b}}
$$


Tables with values of $\sigma$ and $\varepsilon / k$ for various gasses can be found in Bird et. al. [58] and Cussler [59] among others. Also $\Omega$ is tabulated against $k T / \varepsilon$ in the aforementioned references. 


\section{APPENDIX C}

\section{Steady state zero dimensional model to check mass and energy balances of a three dimensional solution}

A simple steady state zero dimensional model that was used to check the mass and energy balances for the solutions obtained from multidimensional model is presented here. The model assumes that there is not heat transfer across the boundaries except at the gas inlets and exits. Given the average exit temperatures of the fuel and air the model checks if the energy balance is satisfied and also it can predict an overall average exit temperature for both fuel and air. The model equations are simple steady state balances of mass, species and energy.

The inputs to the model to estimate an overall average exit gas temperature are: Current, I, Cell voltage, V, Fuel utilization, $\phi_{\mathrm{H}_{2}}$, Fuel composition, $X_{\mathrm{H}_{2}}^{\text {inlet }}, X_{\mathrm{H}_{2} \mathrm{O}}^{\text {inlet }}$, Fuel inlet temperature, $T_{\text {fuel }}^{\text {inlet }}$, Air utilization $\phi_{\mathrm{O}_{2}}$, Air Composition $\mathrm{X}_{\mathrm{O}_{2}}^{\text {inlet }}, X_{\mathrm{N}_{2}}^{\text {inlet }}$, and Air inlet temperature, $T_{\text {air }}^{\text {inlet }}$.

Additional input to check the energy balance are: Air exit temperature, $T_{\text {air }}^{\text {exit }}$, and Fuel exit temperature, $T_{\text {fuel }}^{\text {exit }}$. 


\section{Model Equations}

The amount of fuel supplied is given by

$$
\dot{m}_{\text {fuel }}^{\text {inlet }}=\frac{2 I}{2 F} \frac{1 \times 10^{-3}}{\phi_{\mathrm{H}_{2}} X_{\mathrm{H}_{2}}^{\text {inlet }}}
$$

In Eq. (c.1), the 2 in the numerator is the molecular weight of the hydrogen and the 2 in the denominator is the number of moles of electrons per mole of hydrogen. Corresponding numbers for oxygen are 32 and 4 respectively. The amount of air supplied is given by

$$
\dot{m}_{\text {air }}^{\text {inlet }}=\frac{32 I}{4 F} \frac{1 \times 10^{-3}}{\phi_{\mathrm{O}_{2}} X_{\mathrm{O}_{2}}^{\text {inlet }}}
$$

It should be noted that the mass flow rates in Eqs. (c.1) and (c.2) are expressed in $\mathrm{kg} / \mathrm{s}$. Due to electrochemical reactions and the resulting ionic current, oxygen from air side is transferred to the fuel side where it reacts with hydrogen and forms water. At steady state the amount of fuel mixture exiting the system is given by

$$
\dot{m}_{\text {fuel }}^{\text {exit }}=\dot{m}_{\text {fuel }}^{\text {inlet }}+\phi_{\mathrm{O}_{2}} X_{\mathrm{O}_{2}}^{\text {inlet }} \dot{m}_{\text {air }}^{\text {inlet }}
$$

Similarly the steady state flow rate at air stream exit is given by

$$
\dot{m}_{\text {air }}^{\text {exit }}=\dot{m}_{\text {air }}^{\text {inlet }}-\phi_{\mathrm{O}_{2}} X_{\mathrm{O}_{2}}^{\text {inlet }} \dot{m}_{\text {air }}^{\text {inlet }}
$$

The exit composition of the hydrogen is given by 


$$
X_{H_{2}}^{\text {exit }}=\frac{X_{H_{2}}^{\text {inlet }} \dot{m}_{\text {fuel }}^{\text {inlet }}\left(1-\phi_{\mathrm{H}_{2}}\right)}{\dot{m}_{\text {fuel }}^{\text {exit }}}
$$

and

$$
X_{\mathrm{H} 2 \mathrm{O}}^{\text {exit }}=1-X_{\mathrm{H} 2}^{\text {exit }}
$$

and the exit composition of the air is given by

$$
X_{\mathrm{O}_{2}}^{\text {exit }}=\frac{X_{\mathrm{O}_{2}}^{\text {inlet }} \dot{m}_{\text {air }}^{\text {inlet }}\left(1-\phi_{\mathrm{O}_{2}}\right)}{\dot{m}_{\text {air }}^{\text {exit }}}
$$

and

$$
X_{N_{2}}^{e x i t}=1-X_{O_{2}}^{e x i t}
$$

The average values of exit fuel and air concentrations from the three dimensional solution can be compared to the concentrations calculated above to see it the three dimensional solution satisfies mass balance.

If the average values of air and fuel exit temperature are known from the three dimensional solution, the steady state energy balance can be checked using the simple equation

$$
\dot{m}_{\text {air }}^{\text {inlet }} h_{\text {air }}^{\text {inlet }}+\dot{m}_{\text {fuel }}^{\text {inlet }} h_{\text {fuel }}^{\text {inlet }}-V I-\dot{m}_{\text {air }}^{\text {exit }} h_{\text {air }}^{\text {exit }}-\dot{m}_{\text {fuel }}^{\text {exit }} h_{\text {fuel }}^{\text {exit }}=r e s
$$


The enthalpies are functions of both temperature and composition. For a balanced solution the residue, res, should be a small value. A more reasonable indicator would be a normalized value of the residue

$$
\operatorname{res}^{*}=\frac{r e s}{\dot{m}_{\text {air }}^{\text {inlet }} h_{\text {air }}^{\text {inlet }}+\dot{m}_{\text {fuel }}^{\text {inlet }} h_{\text {fuel }}^{\text {inlet }}}
$$

Alternately an overall average exit temperature for both air and fuel can be calculated following the derivation of Gemmen [65].

$$
T_{\text {avg }}^{\text {exit }}=T^{\text {inlet }}+\left(\frac{-\Delta H}{2 F}-V\right) \frac{I}{\dot{m}_{\text {air }}^{\text {exit }} C P_{\text {air }}^{\text {exit }}+\dot{m}_{\text {fuel }}^{\text {exit }} C p_{\text {fuel }}^{\text {exit }}}
$$

Where $\Delta H$ is the enthalpy change for the fuel reaction evaluated at the inlet temperature and $C p$ is the specific heat. It may be noted that hear constant specific heat assumption is used. 